MARIA RITA PEREZ DE OLIVEIRA

\title{
ESTUDO DAS CONDIÇÕES DE HIDRÓLISE DE ÁLCOOIS
} PRIMÁRIOS SULFATADOS 
MARIA RITA PEREZ DE OLIVEIRA

\section{ESTUDO DAS CONDIÇÕES DE HIDRÓLISE DE ÁLCOOIS PRIMÁRIOS SULFATADOS}

Dissertação apresentada à Escola Politécnica da Universidade de São Paulo para obtenção do Título de Mestre em Engenharia

Área de Concentração:

Engenharia Química

Orientador:

Prof. Dr. Roberto Guardani

São Paulo 
Este exemplar foi revisado e alterado em relação à versão original, sob responsabilidade única do autor e com a anuência de seu orientador.

São Paulo, de maio de 2011

Assinatura do autor

Assinatura do orientador

FICHA CATALOGRÁFICA

Oliveira, Maria Rita Perez de

Estudo das condições de hidrólise de álcoois primários sulfatados / M.R.P. de Oliveira. -- ed.rev. -- São Paulo, 2011.

$139 \mathrm{p}$.

Dissertação (Mestrado) - Escola Politécnica da Universidade de São Paulo. Departamento de Engenharia Química.

1.Cinética 2.Modelagem de dados 3.Processos químicos I.Universidade de São Paulo. Escola Politécnica. Departamento de Engenharia Química II.t. 
Dedico este trabalho à minha família, em especial aos meus pais, Hélvio e Elisabete, aos meus irmãos, Mariana e José Ricardo, e ao meu marido, Rodrigo, com muito amor e carinho. 


\section{AGRADECIMENTOS}

Ao meu orientador, Prof. Dr. Roberto Guardani, pela confiança e dedicação dispensada na construção deste trabalho.

Ao Prof. Dr. Reinaldo Giudici, à Prof ${ }^{a}$. Dr ${ }^{a}$. Maria Elena Santos Taqueda e ao Prof. Dr. Antonio Carlos Silva Costa Teixeira da Escola Politécnica da Universidade de São Paulo pelas excelentes contribuições.

Ao Prof. Dr. Frank Quina do Departamento de Química Fundamental do Instituto de Química da Universidade de São Paulo pelo apoio na etapa final deste trabalho.

À Oxiteno S.A Indústria e Comércio pela oportunidade.

Aos profissionais do Laboratório da Planta Piloto da Oxiteno pelo envolvimento e participação durante a execução dos experimentos.

À minha família que compreendeu a minha ausência e me apoiou em inúmeros momentos.

Aos prezados colegas Márcio Andrade Dias e Emerson Barros Venceslau pelo incentivo e pelo companheirismo durante essa jornada.

E a todos os demais que também contribuíram para a execução deste trabalho. 


\section{RESUMO}

Álcoois primários sulfatados de cadeia longa, usualmente na forma de sais de sódio, são tensoativos de grande interesse comercial utilizados em diversas formulações de higiene pessoal e limpeza doméstica. Eles são produzidos comercialmente através da reação de álcoois etoxilados com trióxido de enxofre seguida de imediata neutralização com hidróxido de sódio. O produto formado é uma solução neutra de álcool primário etoxilado sulfatado em água. Sabe-se que a armazenagem desse produto por longos períodos de tempo em temperaturas elevadas pode levar à hidrólise completa, mas, em condições normais de uso e temperatura ambiente é esperado que o produto seja resistente à hidrólise. No entanto observou-se que algumas amostras comerciais de lauril éter sulfato de sódio que foram estocadas por diferentes períodos de tempo em frascos fechados à temperatura ambiente sofreram hidrólise em intervalos de tempo relativamente curtos. Isso leva à hipótese de que o comportamento de hidrólise seria influenciado por outras variáveis além da temperatura e do tempo de estocagem. O presente trabalho consistiu em identificar as variáveis de maior impacto na reação de hidrólise por meio de experimentos planejados. O teor de ativos foi acompanhado ao longo da reação para avaliar o efeito da presença de eletrólitos, de material insulfatado, em diferentes temperaturas, variando-se o $\mathrm{pH}$ inicial por meio da adição de ácido clorídrico. O comportamento da reação de hidrólise observado foi compatível com aquele descrito na literatura para o dodecil sulfato de sódio. A hidrólise apresentou-se como sendo autocatalítica, com a aceleração da taxa de reação provavelmente causada pela presença de íons hidrogênio liberados na reação. Foi possível identificar que as variáveis de maior efeito na reação foram: $\mathrm{pH}$ inicial, o teor de cloreto de sódio e a temperatura. $\mathrm{O}$ modelo de troca iônica em pseudo-fase foi utilizado para o tratamento dos resultados experimentais e mostrou-se adequado tendo sido, portanto, utilizado para prever o comportamento de estabilidade do produto à temperatura ambiente e nas condições em que o produto é normalmente comercializado. Um modelo empírico de redes neurais foi desenvolvido com sucesso para prever o comportamento do $\mathrm{pH}$ ao longo do tempo para as condições estudadas.

Palavras-chave: hidrólise ácida de álcoois primários sulfatados de cadeia longa, catálise micelar, hidrólise de álcoois etoxilados sulfatados, reação micelar, modelo de redes neurais, modelo de troca iônica em pseudo-fase 


\begin{abstract}
Long-chain primary alkyl sulfuric acids, usually as their sodium salts, are important commercial surfactants used in a large number of household and personal care formulations. They are commercially produced by treatment of mixtures of ethoxylated fatty alcohols with sulfur trioxide followed by immediate neutralization with sodium hydroxide, a neutral aqueous mixture of sodium primary alkyl ether sulfate is obtained. It is known that prolonged storage of the material at elevated temperature can lead to complete hydrolysis but under normal use and typical environmental conditions the product is expected to be resistant to hydrolysis. In spite of that it has been observed that some commercial samples of sodium lauryl ether sulfate stored for different periods of time in sealed containers at room temperature have undergone hydrolysis in a relatively short period of time which leads to the hypothesis that the hydrolysis behavior would be strongly influenced by variables other than temperature and storage time. The present work consisted of identifying the process variables with the most significant effect on the acid hydrolysis by using experimental design. The rate of hydrolysis has been followed acidimetrically to evaluate the effect of electrolytes as well as the concentration of unsulfated matter at different temperatures, over a wide initial $\mathrm{pH}$ range, under the presence of added hydrochloric acid. The pattern of kinetic behaviour observed was broadly the same as previously described for the sodium dodecyl sulfate. The hydrolysis presented the characteristic autocatalytic form, the catalysis presumably arising from the production of hydrogen sulfate ions. It was possible to observe that the most significant effects on the rate of hydrolysis were the initial $\mathrm{pH}$, the total amount of sodium chloride and the temperature. The results were also discussed in terms of the ion-exchange pseudophase model of the micelle reaction. Accordingly to the fitting of parameters that was carried out it is possible to conclude that the pseudo-phase ion-exchange theory is found to account satisfactorily for the results reported and it was used to predict the stability behavior of the product at room temperature and under normal commercial conditions. A neural network based model was also successfully developed in order to predict the $\mathrm{pH}$ behavior in the conditions studied.
\end{abstract}

Keywords: acid-hydrolysys of long alkyl chain sulfated alcohol, micellar catalysis, hydrolysis of alkyl ether sulfates, micelle reaction, neural network model, ion-exchange pseudo-phase model 


\section{LISTA DE FIGURAS}

Figura 1- Dados de análise de pH das amostras 22

Figura 2- Variação na concentração de DSS no tempo para a reação de hidrólise a $100^{\circ} \mathrm{C}$ em solução inicialmente neutra; (ㅁ) 1\% DSS; ( $\mathbf{\Delta}$ )10\% DSS (BETHELL et al., 2001) ......................................... 26 Figura 3- Medidas de tensão superficial de uma solução de DSS em diferentes estágios de purificação $\left(25^{\circ} \mathrm{C}\right)$ e o impacto em um menor tempo para estabilização da medida (MYSELS, 1986) .................. 29 Figura 4- Efeito do envelhecimento das amostras na leitura de tensão superficial (MYSELS, 1986).. 30 Figura 5- Esquema de arquitetura de rede neural artificial com três camadas ..................................... 52

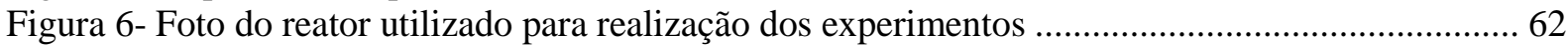

Figura 7- Ilustração da separação de fases observada em alguns experimentos ................................... 70 Figura 8- Acompanhamento ao longo da reação de hidrólise a $100^{\circ} \mathrm{C}$ e $\mathrm{pH}$ inicialmente neutro (a) variação no teor de ativos (b) variação no valor de $\mathrm{pH}, 25^{\circ} \mathrm{C}$

Figura 9- Resultados para a resposta de fração convertida de ativos no tempo $Y 1$ por diferentes métodos (em \% de ativos/h); (a) método de titulação com solução catiônica, (b) análise do teor de sulfato de sódio e (c) análise do teor de ativos residual pelo método de titulação com solução básica 76 Figura 10- Avaliação da correlação entre as repostas de variação de pH e de fração convertida de ativos

Figura 11- Ilustração de como foi determinado o tempo de estabilidade por meio da intersecção de retas ajustadas aos dados por regressão linear..

Figura 12- Correlação observada entre as respostas de fração convertida de ativos e o tempo de estabilidade.

Figura 13- Ilustração dos efeitos para $Y 1$

Figura 14- Ilustração dos efeitos para $Y 2$

Figura 15- Ilustração dos efeitos para $Y 3$

Figura 16- Acompanhamento da reação de hidrólise a nas seguintes condições:

$T=80^{\circ} \mathrm{C} ; \mathrm{pH}=4,0 ; \mathrm{AE2EO}=0,80 \% ; \mathrm{NaCl}=0,20 \% ; \mathrm{Na}_{2} \mathrm{SO}_{4}=0,80 \%$ (EXPERIMENTO 1) (a)

variação no teor de ativos (b) variação no valor de $\mathrm{pH}, 25^{\circ} \mathrm{C}$.

Figura 17- Acompanhamento da reação de hidrólise a nas seguintes condições:

$T=80^{\circ} \mathrm{C} ; \mathrm{pH}=7,0 ; \mathrm{AE2EO}=0,80 \% ; \mathrm{NaCl}=0,04 \% ; \mathrm{Na}_{2} \mathrm{SO}_{4}=0,80 \%$ (EXPERIMENTO 3) (a)

variação no teor de ativos (b) variação no valor de $\mathrm{pH}, 25^{\circ} \mathrm{C}$

Figura 18- Acompanhamento da reação de hidrólise a nas seguintes condições:

$T=100^{\circ} \mathrm{C} ; \mathrm{pH}=4,0 ; \mathrm{AE2EO}=0,80 \% ; \mathrm{NaCl}=0,04 \% ; \mathrm{Na}_{2} \mathrm{SO}_{4}=0,40 \%$ (EXPERIMENTO 4) (a)

variação no teor de ativos (b) variação no valor de $\mathrm{pH}, 25^{\circ} \mathrm{C}$.

Figura 19- Acompanhamento da reação de hidrólise a nas seguintes condições:

$\mathrm{T}=100^{\circ} \mathrm{C} ; \mathrm{pH}=4,0 ; \mathrm{AE} 2 \mathrm{EO}=1,20 \% ; \mathrm{NaCl}=0,04 \% ; \mathrm{Na}_{2} \mathrm{SO}_{4}=0,80 \%$ (EXPERIMENTO 5) (a)

variação no teor de ativos (b) variação no valor de $\mathrm{pH}, 25^{\circ} \mathrm{C}$

Figura 20- Acompanhamento da reação de hidrólise a nas seguintes condições:

$\mathrm{T}=80^{\circ} \mathrm{C} ; \mathrm{pH}=7,0 ; \mathrm{AE2EO}=1,20 \% ; \mathrm{NaCl}=0,04 \% ; \mathrm{Na}_{2} \mathrm{SO}_{4}=0,40 \%$ (EXPERIMENTO 6) (a)

variação no teor de ativos (b) variação no valor de $\mathrm{pH}, 25^{\circ} \mathrm{C}$

Figura 21- Acompanhamento da reação de hidrólise a nas seguintes condições:

$T=100^{\circ} \mathrm{C} ; \mathrm{pH}=7,0 ; \mathrm{AE2EO}=0,80 \% ; \mathrm{NaCl}=0,20 \% ; \mathrm{Na}_{2} \mathrm{SO}_{4}=0,40 \%$ (EXPERIMENTO 7) (a)

variação no teor de ativos (b) variação no valor de $\mathrm{pH}, 25^{\circ} \mathrm{C}$

Figura 22- Acompanhamento da reação de hidrólise a nas seguintes condições:

$\mathrm{T}=80^{\circ} \mathrm{C} ; \mathrm{pH}=4,0 ; \mathrm{AE} 2 \mathrm{EO}=1,20 \% ; \mathrm{NaCl}=0,20 \% ; \mathrm{Na}_{2} \mathrm{SO}_{4}=0,40 \%$ (EXPERIMENTO 8) (a)

variação no teor de ativos (b) variação no valor de $\mathrm{pH}, 25^{\circ} \mathrm{C}$

Figura 23- Acompanhamento da reação de hidrólise a nas seguintes condições:

$T=100^{\circ} \mathrm{C} ; \mathrm{pH}=7,0 ; \mathrm{AE2EO}=1,20 \% ; \mathrm{NaCl}=0,20 \% ; \mathrm{Na}_{2} \mathrm{SO}_{4}=0,80 \%$ (EXPERIMENTO 10) (a)

variação no teor de ativos (b) variação no valor de $\mathrm{pH}, 25^{\circ} \mathrm{C}$

Figura 24- Acompanhamento da reação de hidrólise a nas seguintes condições:

$T=90^{\circ} \mathrm{C} ; \mathrm{pH}=5,5 ; \mathrm{AE2EO}=1,00 \% ; \mathrm{NaCl}=0,12 \% ; \mathrm{Na}_{2} \mathrm{SO}_{4}=0,60 \%$ (EXPERIMENTOS 2,9 e 11) (a)

variação no teor de ativos (b) variação no valor de $\mathrm{pH}, 25^{\circ} \mathrm{C}$ 
Figura 25- Variação do erro experimental ao longo do tempo para a medida do teor de ativos (a) teor de ativos e desvio padrão (b) desvio padrão em função do tempo para o teor de ativos

Figura 26- Variação do erro experimental ao longo do tempo para a medida de $\mathrm{pH}$ (a) $\mathrm{pH}$ e desvio padrão (b) desvio padrão em função do tempo para o pH.

Figura 27- Comparação dos dados experimentais com os ajustes realizados utilizando-se o modelo 109 Figura 28- Análise de sensibilidade para os parâmetros do modelo simplificado .............................. 111

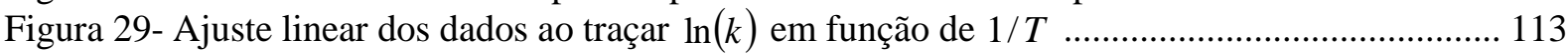

Figura 30- Comportamento estimado para o teor de ativos do produto em suas condições normais de produção segundo modelo.

Figura 31- Comportamento estimado para o pH do produto em suas condições normais de produção segundo modelo

Figura 32- Variação do erro para o conjunto de treinamento ( $R M S T$ ) e para o conjunto de teste

( $R M S T T$ ) variando-se o número de apresentações ao longo do ajuste da RN considerando-se o melhor ajuste obtido para a resposta de teor de ativos

Figura 33- Comparação do resultado de teor de ativo calculado pelo modelo com os dados experimentais para o melhor ajuste obtido (a) considerando-se o conjunto de dados de treinamento (b) considerando-se o conjunto de dados de teste.

Figura 34- Variação do erro para o conjunto de treinamento ( $R M S T$ ) e para o conjunto de teste

( $R M S T T$ ) variando-se o número de apresentações ao longo do ajuste da RN considerando-se o melhor ajuste obtido para a resposta de $\mathrm{pH}$.

Figura 35- Comparação do resultado de $\mathrm{pH}$ calculado pelo modelo com os dados experimentais para o melhor ajuste obtido (a) considerando-se o conjunto de dados de treinamento (b) considerando-se o conjunto de dados de teste.

Figura 36- Comparação dos dados de pH obtidos através de uma simulação para as condições do ponto central com os dados obtidos experimentalmente.....

Figura 37: Correlação observada entre os dados de teor de ativos e de variação do $\mathrm{pH}$...................... 128

Figura 38- Ajuste realizado para determinação da resposta de tempo de estabilidade para

EXPERIMENTO 1

Figura 39- Ajuste realizado para determinação da resposta de tempo de estabilidade para

EXPERIMENTO 2

Figura 40- Ajuste realizado para determinação da resposta de tempo de estabilidade para

EXPERIMENTO 5

Figura 41- Ajuste realizado para determinação da resposta de tempo de estabilidade para

EXPERIMENTO 8

Figura 42- Ajuste realizado para determinação da resposta de tempo de estabilidade para

EXPERIMENTO 9.

Figura 43- Ajuste realizado para determinação da resposta de tempo de estabilidade para

EXPERIMENTO 11 


\section{LISTA DE TABELAS}

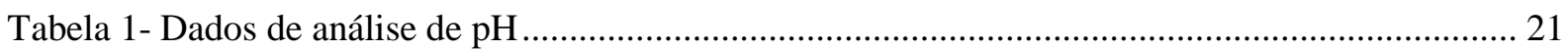

Tabela 2- Variáveis avaliadas e níveis adotados no planejamento experimental ................................. 55

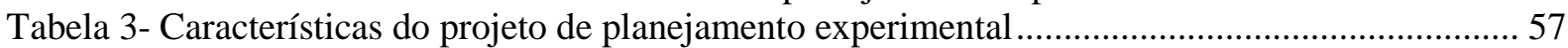

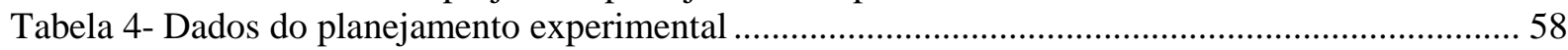

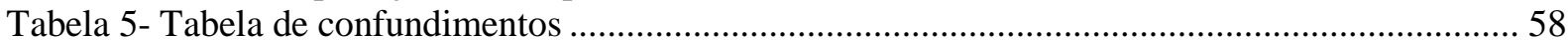

Tabela 6- Respostas utilizadas na análise dos resultados ........................................................................ 59

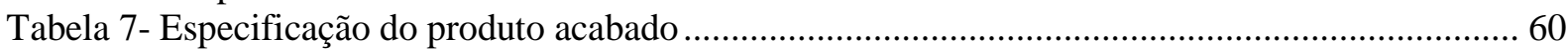

Tabela 8- Resultados obtidos para a resposta de taxa de conversão de ativos ........................................ 78

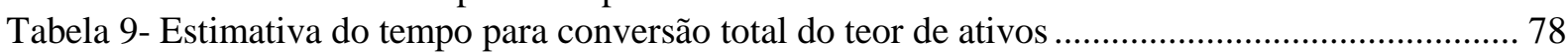

Tabela 10- Resultados obtidos para a resposta de variação de $\mathrm{pH}$ no tempo........................................ 79

Tabela 11- Resultados obtidos para a resposta de tempo de estabilidade ............................................ 82

Tabela 12- Resultados para as respostas avaliadas no planejamento experimental ............................ 83

Tabela 13- Variáveis não codificadas e as respostas obtidas para cada experimento para análise no

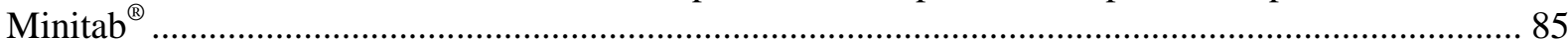

Tabela 14- Estimativa dos efeitos e coeficientes para cada resposta estudada ................................... 87

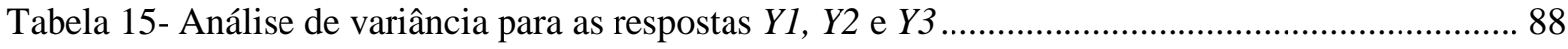

Tabela 16- Comentários e análise dos resultados e de quais seriam as variáveis significativas para cada

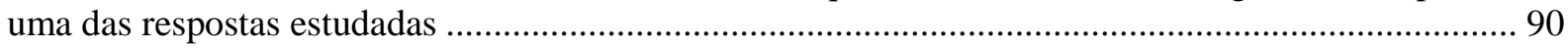

Tabela 17- Resultados de cálculo de média e desvio padrão para as medidas realizadas na repetição

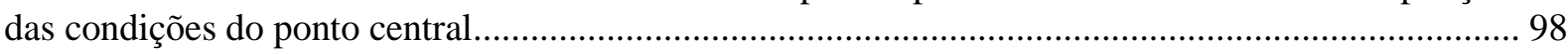

Tabela 18- Resultados do ajuste dos parâmetros para cada condição experimental ............................. 107

Tabela 19- Resultados da análise de correlação do parâmetro ajustado $Q$ com as variáveis estudadas

Tabela 20- Resultado do incremento no valor da função objetivo ao variar os parâmetros............... 108

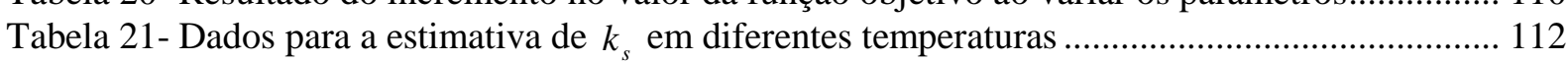

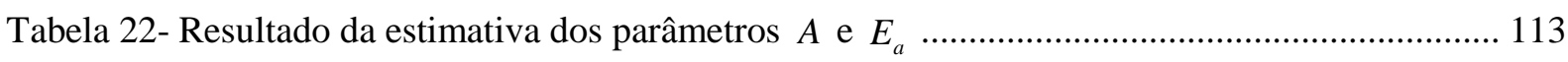

Tabela 23- Estimativa para $k_{s}$ e $Q$ à temperatura ambiente ............................................................ 115

Tabela 24- Apresentação das variáveis de entrada e suas respectivas faixas de variação na ordem

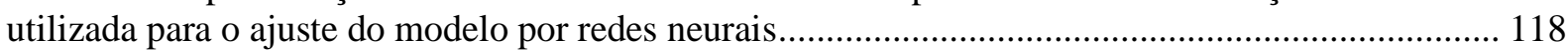

Tabela 25- Resultados dos ajustes para a RN com teor de ativos como variável de saída.................. 121

Tabela 26- Resultados dos ajustes para a RN com pH como variável de saída .................................. 125 


\section{LISTA DE ABREVIATURAS E SIGLAS}

AE2EO

ALKOPON N

$\mathrm{CMC}$

DESS 2EO

DSS

$\mathrm{F}$

FFNN

GL

GRG

LASH

LESS 2EO

LSCP

LSS

MS

PM

PPIEM

$\mathrm{RN}$

SDS

SLES EO

SLS

SS

TIPF
Teor de álcool etoxilado 2EO não sulfatado (teor de insulfatados)

Marca comercial da Oxiteno para o LESS 2EO

Concentração micelar crítica

Dodecil éter sulfato de sódio 2EO

Dodecil sulfato de sódio

Razão F

Feedforward network

Graus de liberdade

Generalized reduced gradient

Linear alquil benzeno sulfonato

Lauril éter sulfato de sódio 2EO

Laboratório de Simulação e Controle de Processos

Lauril sulfato de sódio

Média quadrática

Peso molecular

Pseudo-phase íon exchange model

Rede neural

Sodium dodecyl sulfate

Sodium lauryl ether sulfate $2 E O$

Sodium lauryl sulfate

Soma dos quadrados

Modelo de troca iônica em pseudo-fase 


\section{LISTA DE SÍMBOLOS}

\begin{tabular}{|c|c|}
\hline$p K a$ & Constante de dissociação de um ácido \\
\hline$\left[\mathrm{ROSO}_{3} \mathrm{H}\right]$ & Concentração total de $\mathrm{ROSO}_{3} \mathrm{H}$ \\
\hline$\left[\mathrm{H}_{2} \mathrm{O}\right]$ & Concentração total de $\mathrm{H}_{2} \mathrm{O}$ \\
\hline rate & Taxa de reação \\
\hline$k_{2}$ & Constante cinética de reação \\
\hline$K$ & Constante de equilíbrio de reação \\
\hline$\left[H^{+}\right]$ & Concentração de íons hidrogênio \\
\hline$k_{2, o b s}$ & Constante cinética de reação \\
\hline$k_{w}$ & Constante cinética da reação de hidrólise em meio aquoso \\
\hline$k_{s}$ & Constante cinética da reação de hidrólise na presença de micelas \\
\hline$C_{T}$ & Concentração total de ativos \\
\hline$H_{T}$ & Concentração total de íons hidrogênio \\
\hline$\left[\mathrm{ROSO}_{3}^{-}\right]$ & Concentração total de $\mathrm{ROSO}_{3}^{-}$ \\
\hline$\left[H^{+}\right]_{w}$ & Concentração de íons hidrogênio na pesudo-fase aquosa \\
\hline$\left[\mathrm{ROSO}_{3}^{-}\right]_{w}$ & Concentração de $\mathrm{ROSO}_{3}^{-}$na pesudo-fase aquosa \\
\hline$\left[\mathrm{H}_{2} \mathrm{O}\right]_{w}$ & Concentração de $\mathrm{H}_{2} \mathrm{O}$ na pesudo-fase aquosa \\
\hline$\left[H^{+}\right]_{s}$ & Concentração de íons hidrogênio na região da camada de Stern \\
\hline$\left[\mathrm{ROSO}_{3}^{-}\right]_{s}$ & Concentração de $\mathrm{ROSO}_{3}^{-}$na região da camada de Stern \\
\hline$\left[\mathrm{H}_{2} \mathrm{O}\right]_{s}$ & Concentração de $\mathrm{H}_{2} \mathrm{O}$ na região da camada de Stern \\
\hline$C$ & Concentração de tensoativo na micela \\
\hline$V_{s}$ & Volume molar das cabeças polares dos tensoativos na camada de Stern \\
\hline$V$ & Volume molar do tensoativo \\
\hline $\bar{H}_{w}$ & Concentração local de íons hidrogênio na pesudo-fase aquosa \\
\hline $\bar{C}_{w}$ & Concentração local de monômeros de tensoativo na pseudo-fase aquosa \\
\hline $\bar{H}_{s}$ & Concentração local de íons hidrogênio na região da camada de Stern \\
\hline $\bar{C}_{s}$ & Concentração local de monômeros de tensoativo na região da camada de Stern \\
\hline$C M C$ & Concentração micelar crítica \\
\hline$H_{w}$ & Concentração analítica de íons hidrogênio na pseudo-fase aquosa \\
\hline$H_{s}$ & Concentração analítica de íons hidrogênio na região da camada de Stern \\
\hline $\begin{array}{l}K_{H / X}, K_{H / N a} \mathrm{e} \\
K_{O H / B r}\end{array}$ & Constantes de troca iônica \\
\hline$X_{w}$ & Concentração de contra-íons na pseudo-fase aquosa \\
\hline$X_{s}$ & Concentração de contra-íons na região da camada de Stern \\
\hline$\beta$ & Grau de associação do contra-íon à micela \\
\hline
\end{tabular}




\begin{tabular}{|c|c|}
\hline$p$ e $q$ & Índices estequiométricos \\
\hline $\bar{X}_{s}$ & Concentração local de contra-íons na região da camada de Stern \\
\hline$X_{T}$ & Concentração total de contra-íons \\
\hline $\bar{X}_{w}$ & Concentração local de contra-íons na pesudo-fase aquosa \\
\hline$\alpha$ & Grau de associação do contra-íon à micela \\
\hline$W_{i, j}$ & $\begin{array}{l}\text { Peso de conexão entre o neurônio } i \text { da camada de entrada ao neurônio } j \text { da } \\
\text { camada interna }\end{array}$ \\
\hline$W$ & Conjunto de pesos da rede neural \\
\hline$X_{i}$ & Variáveis de entrada da rede neural \\
\hline$W_{n+1, j}$ & $\begin{array}{l}\text { Peso de conexão entre o bias da camada de entrada e o neurônio } j \text { da camada } \\
\text { interna }\end{array}$ \\
\hline$O_{j}$ & $\begin{array}{l}\text { Valor de saída calculado pela função de transferência aplicada ao j-ésimo } \\
\text { neurônio da camada interna }\end{array}$ \\
\hline$E$ & Erro quadrático para otimização da rede neural \\
\hline$r$ & Total de dados experimentais do conjunto de treinamento da rede neural \\
\hline$Y_{k \text {,exp }}^{(m)}$ & Resultado experimental proveniente do conjunto de dados \\
\hline$Y_{k, c a l c}^{(m)}$ & Resultado calculado pela rede para uma variável de saída \\
\hline$\eta$ & Fator de aceleração ou fator de amortecimento ou taxa de aprendizado \\
\hline$f^{\prime}$ & Derivada da função de transferência sigmoidal \\
\hline$X 1$ & Variável temperatura do planejamento experimental \\
\hline$X 2$ & Variável pH inicial do planejamento experimental \\
\hline$X 3$ & Variável teor de insulfatados do planejamento experimental \\
\hline$X 4$ & Variável teor de cloreto de sódio do planejamento experimental \\
\hline$X 5$ & Variável teor de sulfato de sódio do planejamento experimental \\
\hline $2_{I I I}^{5-2}$ & Planejamento fatorial fracionado com cinco variáveis de resolução III \\
\hline$Y 1$ & Fração convertida de ativos no tempo \\
\hline$Y 2$ & Variação de pH no tempo \\
\hline$Y 3$ & Tempo de estabilidade \\
\hline$M M_{S O_{4}^{2-}}$ & Massa molar do íon $\mathrm{SO}_{4}^{2-}$ \\
\hline $\mathrm{MM}_{\mathrm{Na}_{2} \mathrm{SO}_{4}}$ & Massa molar do sulfato de sódio \\
\hline $\mathrm{MM}_{\mathrm{ROSO}_{3}^{-}}$ & Massa molar do $\mathrm{ROSO}_{3}^{-}$ \\
\hline$\Delta\left[\mathrm{ROSO}_{3}^{-}\right]$ & Concentração de ativos, em mol/kg, consumido pela reação de hidrólise \\
\hline$\Delta\left[\mathrm{H}_{3} \mathrm{O}^{+}\right]$ & $\begin{array}{l}\text { Concentração de íons } \mathrm{H}_{3} \mathrm{O}^{+} \text {, em mol } / \mathrm{kg} \text {, liberados no meio pela reação de } \\
\text { hidrólise }\end{array}$ \\
\hline$\left[\mathrm{H}_{3} \mathrm{O}^{+}\right]$ & Concentração, em mol $/ \mathrm{kg}$, de íons $\mathrm{H}_{3} \mathrm{O}^{+}$ \\
\hline$[\mathrm{NaOH}]$ & $\begin{array}{l}\text { Concentração, em mol } / \mathrm{kg} \text {, de } \mathrm{NaOH} \text { consumida na titulação da amostra para } \\
\text { determinação do teor de ativos residual }\end{array}$ \\
\hline$V_{t}$ & $\begin{array}{l}\text { Volume da solução básica utilizado na titulação para determinação do teor de } \\
\text { ativos residual }\end{array}$ \\
\hline
\end{tabular}




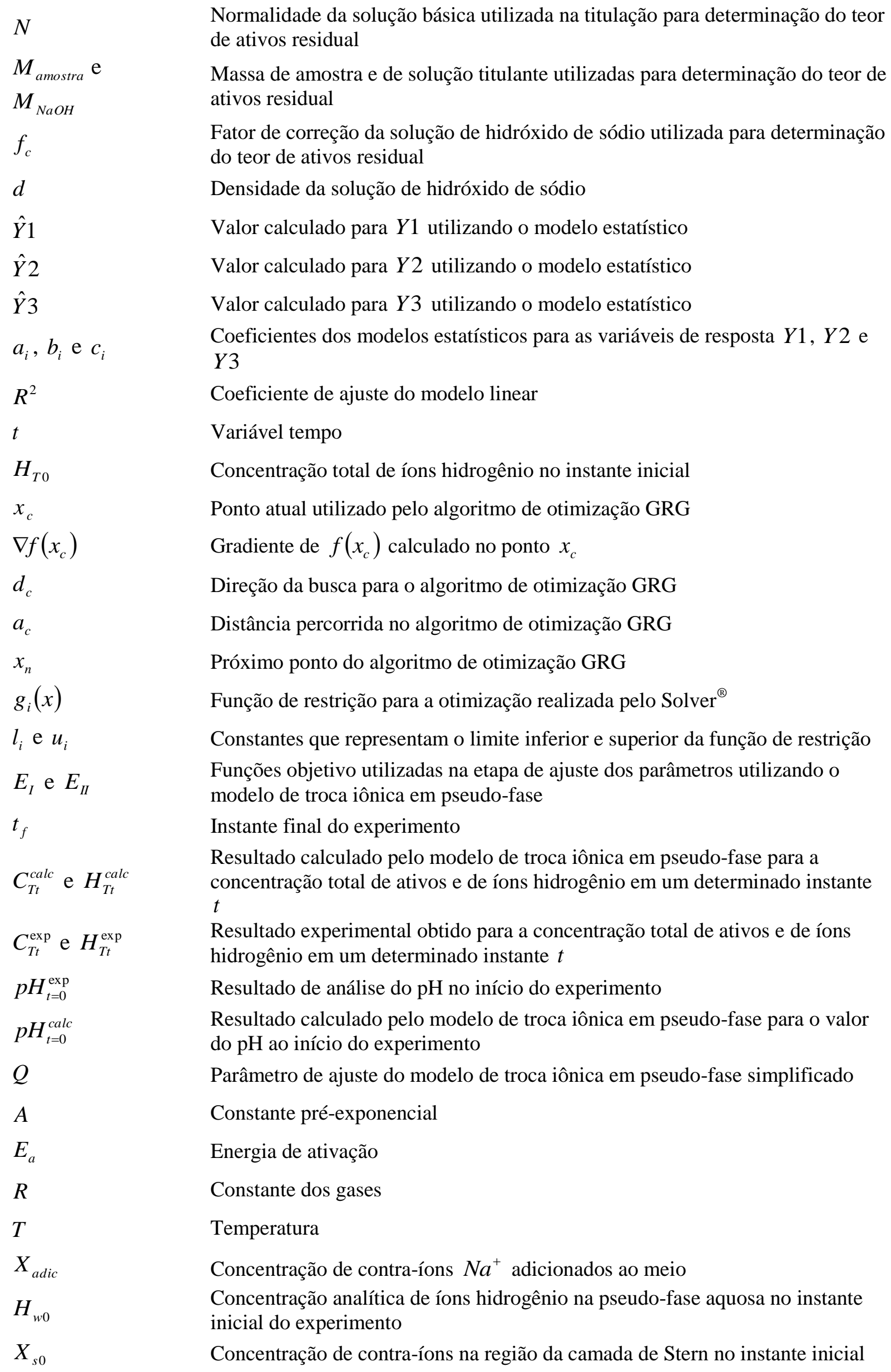

Normalidade da solução básica utilizada na titulação para determinação do teor de ativos residual

Massa de amostra e de solução titulante utilizadas para determinação do teor de ativos residual

Fator de correção da solução de hidróxido de sódio utilizada para determinação do teor de ativos residual

Densidade da solução de hidróxido de sódio

Valor calculado para $Y 1$ utilizando o modelo estatístico

Valor calculado para $Y 2$ utilizando o modelo estatístico

Valor calculado para $Y 3$ utilizando o modelo estatístico

Coeficientes dos modelos estatísticos para as variáveis de resposta $Y 1, Y 2 \mathrm{e}$ $Y 3$

Coeficiente de ajuste do modelo linear

Variável tempo

Concentração total de íons hidrogênio no instante inicial

Ponto atual utilizado pelo algoritmo de otimização GRG

Gradiente de $f\left(x_{c}\right)$ calculado no ponto $x_{c}$

Direção da busca para o algoritmo de otimização GRG

Distância percorrida no algoritmo de otimização GRG

Próximo ponto do algoritmo de otimização GRG

Função de restrição para a otimização realizada pelo Solver ${ }^{\circledR}$

Constantes que representam o limite inferior e superior da função de restrição

Funções objetivo utilizadas na etapa de ajuste dos parâmetros utilizando o modelo de troca iônica em pseudo-fase

Instante final do experimento

Resultado calculado pelo modelo de troca iônica em pseudo-fase para a concentração total de ativos e de íons hidrogênio em um determinado instante $t$

Resultado experimental obtido para a concentração total de ativos e de íons hidrogênio em um determinado instante $t$

Resultado de análise do $\mathrm{pH}$ no início do experimento

Resultado calculado pelo modelo de troca iônica em pseudo-fase para o valor do $\mathrm{pH}$ ao início do experimento

Parâmetro de ajuste do modelo de troca iônica em pseudo-fase simplificado

Constante pré-exponencial

Energia de ativação

Constante dos gases

Temperatura

Concentração de contra-íons $\mathrm{Na}^{+}$adicionados ao meio

Concentração analítica de íons hidrogênio na pseudo-fase aquosa no instante inicial do experimento

Concentração de contra-íons na região da camada de Stern no instante inicial 
do experimento

$X_{w 0}$

$R M S T$

RMSTT

$r^{\prime}$

$Y_{\text {calc }}^{(m)}$

$Y_{\exp }^{(m)}$

$a$ e $b$
Concentração de contra-íons na pseudo-fase aquosa no instante inicial do experimento

Erro quadrático médio para o conjunto de dados de treinamento da rede neural

Erro quadrático médio para o conjunto de dados de teste da rede neural

Total de dados experimentais do conjunto de teste da rede neural

Resultado calculado pela rede neural para uma determinada variável de saída

Resultado experimental para uma determinada variável de saída

Coeficientes angular e linear para o ajuste de $Y_{\text {calc }}^{(m)}$ em função de $Y_{\exp }^{(m)}$ 


\section{SUMÁRIO}

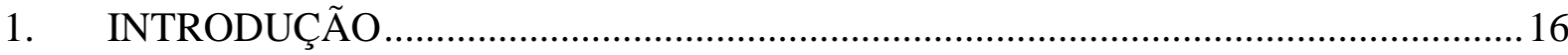

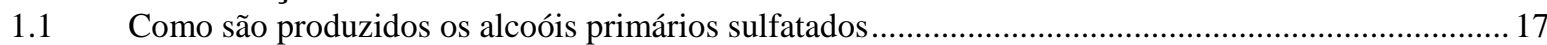

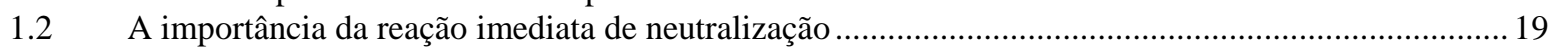

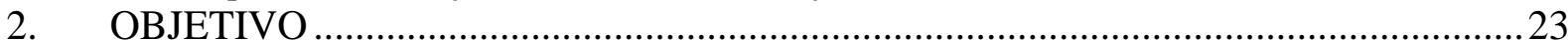

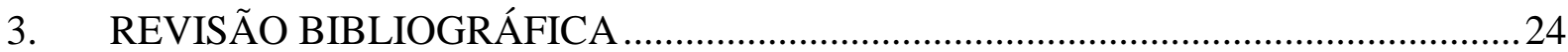

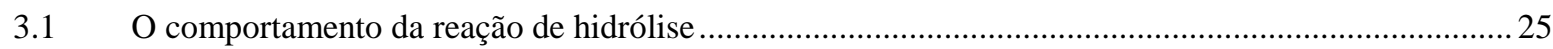

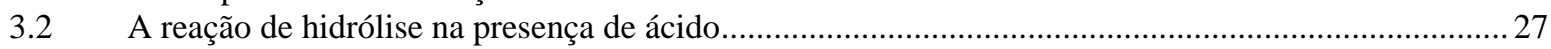

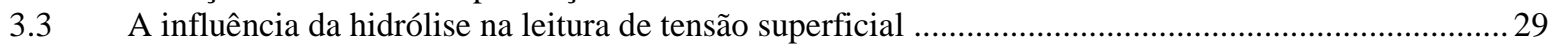

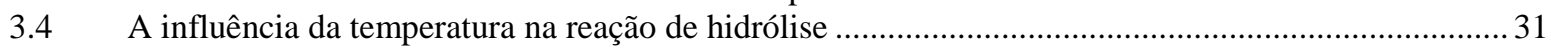

3.5 O efeito da concentração e da micelização na taxa de reação de hidrólise ………………………….....31

3.6 A influência da adição de eletrólitos na reação de hidrólise .................................................................34

3.7 A influência da adição de materiais não iônicos na hidrólise do DSS …………................................ 35

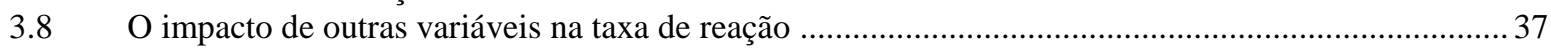

3.9 Modelo teórico para estimar o comportamento da reação …………................................................... 38

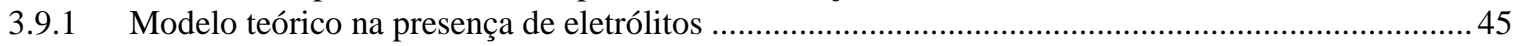

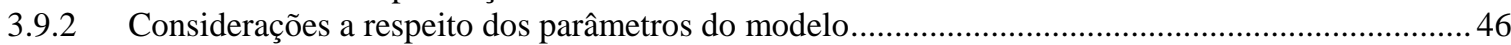

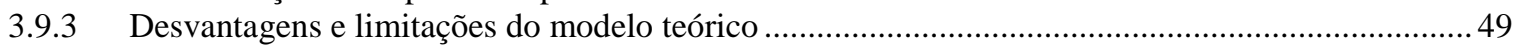

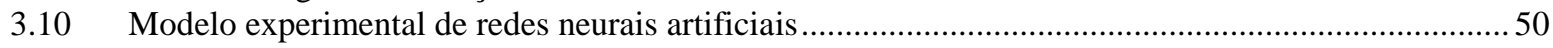

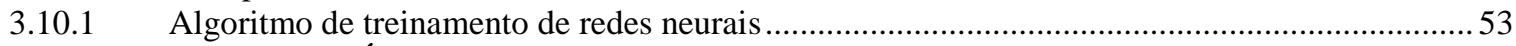

4. MATERIAIS E MÉTODOS

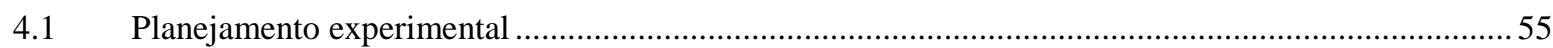

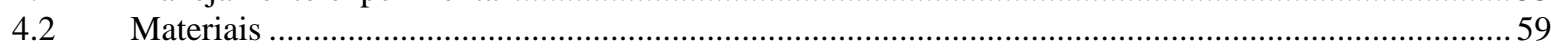

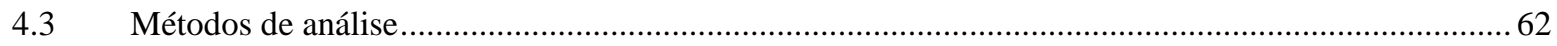

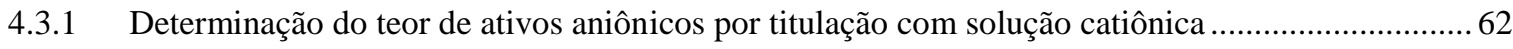

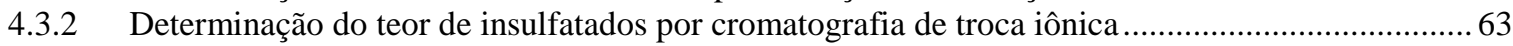

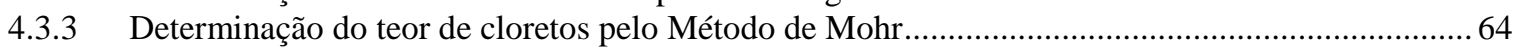

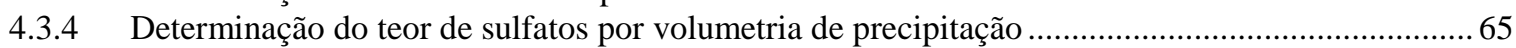

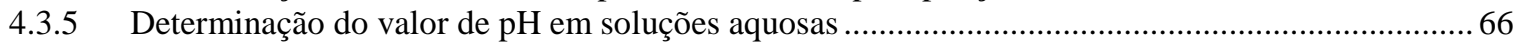

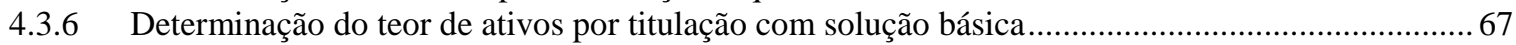

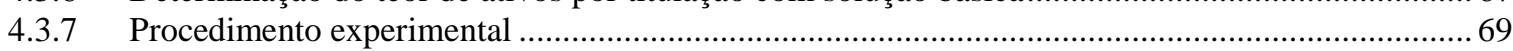

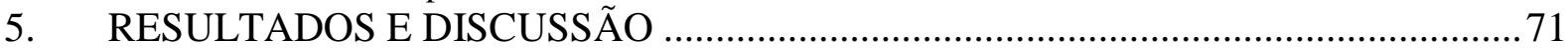

5.1 Testes preliminares para avaliação do comportamento de hidrólise ......................................................71

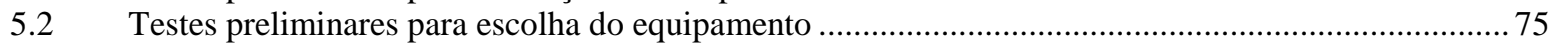

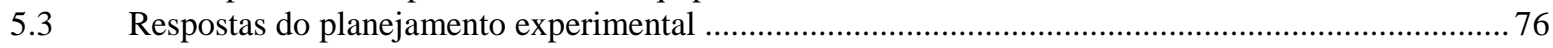

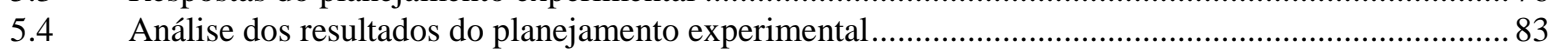

5.5 Comportamento da reação de hidrólise em cada experimento .............................................................. 92

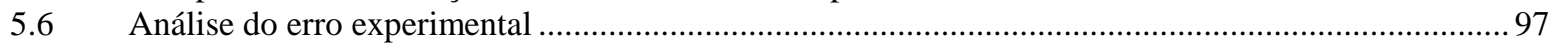

5.7 Ajuste dos dados experimentais utilizando um modelo teórico ...........................................................99

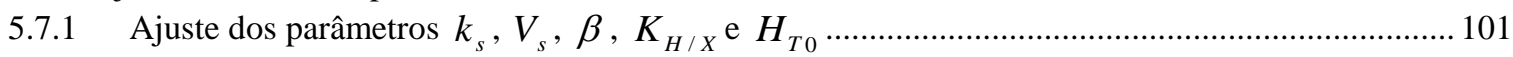

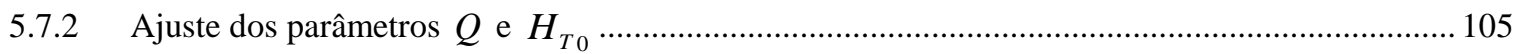

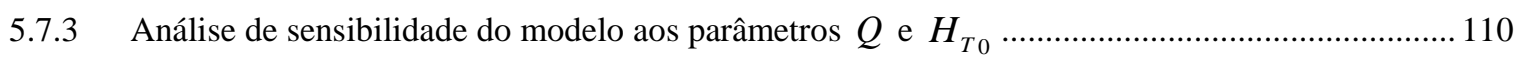

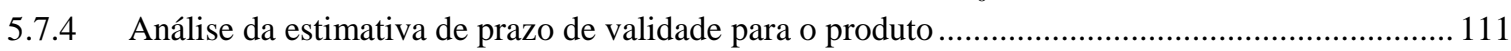

5.8 Análise dos dados experimentais utilizando um modelo de redes neurais .........................................117

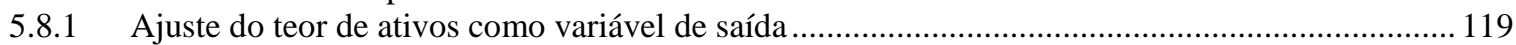

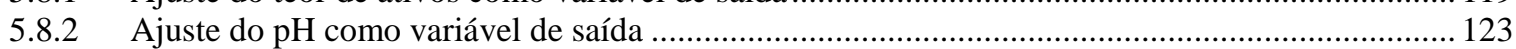

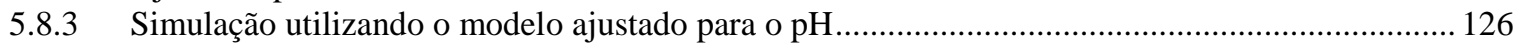

5.8.4 Estimativa da variação do teor de ativos a partir de dados de variação de $\mathrm{pH}$............................... 127

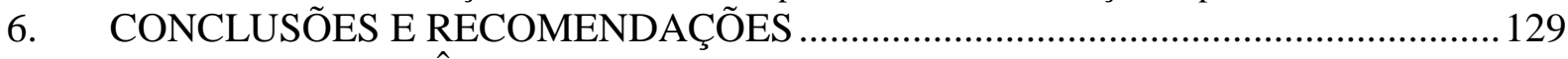

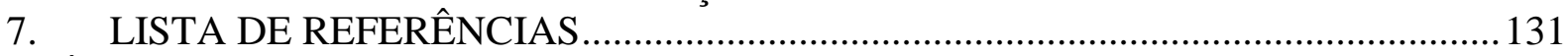

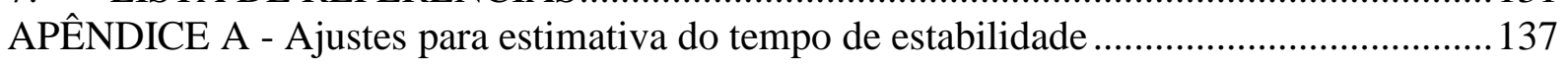




\section{INTRODUÇÃO}

O principal constituinte de uma formulação de um produto de higiene pessoal ou de limpeza doméstica é o tensoativo, uma substância contendo, em uma molécula simples, uma cauda lipofílica solúvel em óleo e uma cabeça polar hidrofílica solúvel em água.

O processo de limpeza por ação de um tensoativo aniônico ocorre através dos seguintes fenômenos: umectação do substrato e sujidade devido à redução das tensões interfaciais água/substrato e água/sujidade, remoção da sujidade do substrato e manutenção da sujidade em solução ou em uma suspensão estável para que seja posteriormente removida no momento do enxágue.

O lauril éter (2EO) sulfato de sódio - LESS 2EO (ou SLES 2EO: sodium lauryl ether sulfate) - é o tensoativo aniônico mais utilizado em formulações de higiene pessoal, sendo que no mercado de limpeza doméstica seu maior concorrente é o linear alquilbenzeno sulfonato (LASH) que tem $90 \%$ de sua produção anual destinada ao segmento de formulações de lava-roupas em pó e em formulações líquidas de lava-louças de uso manual (MODLER; JANSHEKAR; INOGUCHI, 2007).

Uma grande variedade de moléculas orgânicas é empregada como matéria-prima para produção de tensoativos a partir do processo de sulfatação/sulfonação. Estas podem ser baseadas em fontes naturais, minerais ou sintéticas. Dentre as matérias-primas mais utilizadas estão: linear alquil benzeno, álcoois primários, álcoois éter primários e alfa olefinas.

$\mathrm{Na}$ reação de sulfonação do linear alquil benzeno forma-se uma ligação $C-S O_{3}$, cuja configuração faz com que os sulfonados ácidos sejam hidroliticamente estáveis sendo, por isso, comercializados na sua forma ácida e neutralizados in situ, ou seja, durante o preparo da formulação para uso final.

$\mathrm{Na}$ reação de sulfatação forma-se uma ligação do tipo $\mathrm{C}-\mathrm{O}-\mathrm{SO}_{3}$, que faz com que os sulfatos ácidos precisem ser prontamente neutralizados, não sendo estáveis na sua forma ácida. 


\subsection{Como são produzidos os alcoóis primários sulfatados}

Sulfonação e sulfatação consistem em reações de introdução de um grupo $\mathrm{SO}_{3}$ em moléculas orgânicas. São processos mundialmente utilizados para produção de diversas classes de produtos, incluindo tensoativos, polímeros, aditivos para concreto, pesticidas e medicamentos. Considerando-se somente a indústria de tensoativos aniônicos é estimada a existência de cerca de 140 plantas ao redor do mundo resultando em uma capacidade de sulfonação (em termos de linear alquil benzeno sulfonato - LASH) de aproximadamente 4,9 milhões de toneladas (2003).

O processo de introdução de um grupo $\mathrm{SO}_{3}$ em um componente orgânico para produzir a configuração característica de $\mathrm{C}-\mathrm{O}-\mathrm{SO}_{3}$ é definido como sulfatação; quando a configuração $\mathrm{C}-\mathrm{SO}_{3}$ é produzida o processo é definido como sulfonação.

Os processos de sulfatação e sulfonação são utilizados para obtenção de tensoativos aniônicos solúveis em água. Esses processos usualmente utilizam ácido clorosulfônico ou trióxido de enxofre. Os ácidos sulfônicos derivados de álcoois primários são instáveis podendo sofrer reações de hidrólise ácida e por isso necessitam ser imediatamente neutralizados após o término da reação de sulfonação para evitar a formação de subprodutos indesejáveis produzidos em reações consecutivas.

O processo de sulfatação atualmente adotado pelas Unidades de Sulfatação da Oxiteno é a rota com base no trióxido de enxofre obtido a partir da reação de oxidação do enxofre com ar, sendo que o sulfato ácido é imediatamente neutralizado com $\mathrm{NaOH}$ após o término da reação de sulfatação.

No processo de sulfatação/sulfonação através da rota trióxido de enxofre, a corrente de $\mathrm{SO}_{3}$ diluída em ar entra no reator juntamente com a corrente orgânica, o álcool primário etoxilado no caso do LESS 2EO.

O mecanismo de reação de sulfatação de um álcool graxo primário corresponde a uma reação rápida de formação de um composto metaestável que se decompõe através de uma reação menos rápida do que a primeira mas ainda suficientemente rápida para que apenas o 
produto final seja notado. Este produto final de decomposição é o hidrogenosulfato de alquila ou sulfato/sal na forma ácida:

Reação rápida

$\mathrm{ROH}+2 \mathrm{SO}_{3} \rightarrow \mathrm{ROSO}_{2} \mathrm{OSO}_{3} \mathrm{H}$

Reação menos rápida

$\mathrm{ROSO}_{2} \mathrm{OSO}_{3} \mathrm{H}+\mathrm{ROH} \rightarrow 2 \mathrm{ROSO}_{3} \mathrm{H}$

Para a reação de formação do hidrogenosulfato de alquila o tempo de reação recomendado é de 1 minuto a $30-50^{\circ} \mathrm{C}$. Na prática a temperatura de sulfatação é determinada pela temperatura mínima na qual o álcool graxo de partida e a mistura reacional apresentamse na forma de uma fase móvel no estado líquido.

A reação de sulfatação de um álcool etoxilado é bastante similar, envolvendo também a rápida formação de um produto metaestável:

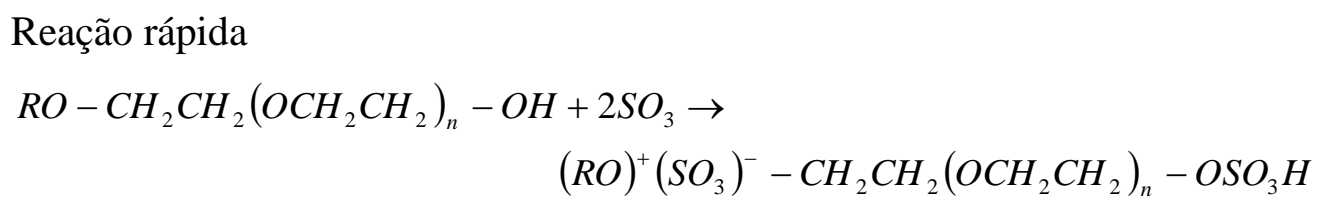

Reação menos rápida

$$
\begin{aligned}
&(\mathrm{RO})^{+}\left(\mathrm{SO}_{3}\right)^{-}-\mathrm{CH}_{2} \mathrm{CH}_{2}\left(\mathrm{OCH}_{2} \mathrm{CH}_{2}\right)_{n}-\mathrm{OSO}_{3} \mathrm{H}+\mathrm{R}\left(\mathrm{OCH}_{2} \mathrm{CH}_{2}\right)_{n+1} \mathrm{OH} \rightarrow \\
& 2 \mathrm{R}\left(\mathrm{OCH}_{2} \mathrm{CH}_{2}\right)_{n+1} \mathrm{OSO}_{3} \mathrm{H}
\end{aligned}
$$

O produto sulfatado ácido neste caso é considerado menos propenso à reação de decomposição térmica do que o produto ácido resultante da sulfatação do álcool primário não etoxilado. Atribui-se essa maior estabilidade ao efeito indutivo exercido pela cadeia etoxilada que atenua a reatividade do grupo $\mathrm{SO}_{3}$ (GROOT, 1991), mas ainda assim o produto ácido requer rápida e eficiente neutralização para obtenção de um produto final de alta qualidade. 


\subsection{A importância da reação imediata de neutralização}

A reação de neutralização entre o ácido orgânico e a base alcalina é instantânea e exotérmica e a homogeneização precisa ser suficientemente eficiente para que seja formada uma micro-dispersão do ácido orgânico no álcali diluído para evitar a ocorrência da indesejável reação de decomposição.

Como a reação de neutralização é altamente exotérmica e, considerando-se a instabilidade térmica do sulfato ácido quando submetido a altas temperaturas, faz-se necessário um bom controle da temperatura durante a reação de neutralização.

Outro fator essencial para a reação de neutralização é uma eficiente mistura do agente de neutralização com o ácido orgânico para que as reações indesejáveis de decomposição sejam minimizadas. A operação de mistura requer misturadores de alta taxa de cisalhamento uma vez que o produto formado tem um aspecto de pasta e sua viscosidade torna-se muito alta em baixas taxas de cisalhamento. Variações de temperatura, mesmo que pequenas $\left(+/-5^{\circ} \mathrm{C}\right)$ podem provocar profundas mudanças na estrutura de fase da pasta o que pode resultar em estruturas reologicamente indesejáveis tais como géis de difícil homogeneização.

Na etapa de neutralização a água de diluição é adicionada junto com o agente neutralizante.

É muito difícil manter o controle de $\mathrm{pH}$ na faixa de 7-9 durante a neutralização pois tratase de um sistema contendo ácido e base fortes, o pH é então controlado na faixa de 9-11, região na qual a curva de neutralização torna-se menos abrupta e sensível.

Na reação de neutralização tem-se que:

$$
\mathrm{ROSO}_{3} \mathrm{H}+\mathrm{NaOH} \rightarrow \mathrm{ROSO}_{3} \mathrm{Na}+\mathrm{H}_{2} \mathrm{O}
$$

Caso o processo de homogeneização não seja eficiente e resulte em pontos ácidos, ou seja, regiões de pH baixo devido à concentração de sulfato ácido não neutralizado, ou caso a massa completa de produto apresente pH menor que 6,0 a reação de hidrólise e decomposição em cadeia, que resulta na conversão do ácido orgânico ao material orgânico de partida, é favorecida (GROOT, 1991). 
A reação inicial de hidrólise irá criar as condições para que uma próxima reação de hidrólise ocorra e consequentemente essa situação conduzirá a uma queda do $\mathrm{pH}$ do produto nos tanques de estocagem. O produto resultante será de difícil recuperação e, por apresentar alta acidez, poderá causar corrosão em tanques, linhas e bombas.

Assim sendo o pH deve ser mantido alto $(9,0-11,0)$ durante a neutralização a fim de evitar que material ácido esteja presente na composição da massa de produto. Quando se deseja que a faixa de $\mathrm{pH}$ do produto final esteja especificada entre 6,0-7,0 a adição de buffers para o ajuste e controle do pH final é requerida sendo recomendado o uso de ácido fosfórico ou ácido cítrico após a etapa de neutralização.

\subsection{Dados históricos e motivação para o estudo de susceptibilidade à hidrólise}

O que se espera é que, em condições normais de uso, o que inclui temperatura média ao redor de $25^{\circ} \mathrm{C}$ e condição não-catalisada, o LESS 2EO, produto alvo deste estudo, seja resistente à hidrólise (STEPAN COMPANY, 2006) dentro de seu prazo de validade.

No entanto, um levantamento de algumas amostras comerciais do LESS 2EO a 27\% de concentração em massa de ativos aniônicos em água ainda dentro do prazo de validade estipulado para o produto (365 dias) mostrou que algumas amostras apresentavam o valor de $\mathrm{pH}$ abaixo do valor especificado.

Uma provável causa para a ocorrência dessa queda no valor de $\mathrm{pH}$ seria a ocorrência da reação de hidrólise ao longo do tempo, que, mesmo ocorrendo lentamente, poderia ter influenciado em uma queda no valor do $\mathrm{pH}$.

As amostras estavam sendo armazenadas em local seco e coberto, à temperatura ambiente. $\mathrm{O}$ pH dessas amostras comerciais que haviam sido produzidas em escala industrial em diferentes datas foi reanalisado em nov/07 e os resultados são apresentados na Tabela 1. 
Tabela 1- Dados de análise de $\mathrm{pH}$

\begin{tabular}{|c|c|c|c|}
\hline Data da produção do lote & Análise de pH nov/07 & Data da produção do lote & Análise de pH nov/07 \\
\hline $17 / 11 / 2005$ & 3,90 & $12 / 12 / 2006$ & 4,52 \\
\hline 08/11/2005 & 3,30 & $19 / 12 / 2006$ & 3,80 \\
\hline $24 / 11 / 2005$ & 4,10 & $22 / 12 / 2006$ & 6,68 \\
\hline $26 / 12 / 2005$ & 3,30 & 29/12/2006 & 8,53 \\
\hline $19 / 12 / 2005$ & 8,30 & $31 / 12 / 2006$ & 4,12 \\
\hline $02 / 12 / 2005$ & 3,90 & $31 / 12 / 2006$ & 6,10 \\
\hline $25 / 01 / 2006$ & 8,60 & $18 / 01 / 2007$ & 4,32 \\
\hline $23 / 01 / 2006$ & 6,90 & 20/01/2007 & 4,66 \\
\hline 05/01/2006 & 5,40 & $21 / 01 / 2007$ & 6,35 \\
\hline $19 / 02 / 2006$ & 4,30 & $27 / 01 / 2007$ & 3,80 \\
\hline 08/02/2006 & 3,80 & 28/01/2007 & 3,61 \\
\hline $15 / 02 / 2006$ & 7,40 & 03/02/2007 & 6,38 \\
\hline $14 / 03 / 2006$ & 7,40 & $04 / 02 / 2007$ & 4,15 \\
\hline 02/03/2006 & 7,90 & 08/02/2007 & 3,66 \\
\hline 26/03/2006 & 3,90 & $12 / 02 / 2007$ & 6,98 \\
\hline $28 / 04 / 2006$ & 3,30 & $19 / 02 / 2007$ & 6,60 \\
\hline $26 / 04 / 2006$ & 3,80 & $19 / 02 / 2007$ & 6,92 \\
\hline 26/04/2006 & 4,50 & 08/03/2007 & 6,42 \\
\hline 26/05/2006 & 3,30 & 09/03/2007 & 4,88 \\
\hline $13 / 05 / 2006$ & 3,80 & $18 / 03 / 2007$ & 6,94 \\
\hline $19 / 05 / 2006$ & 3,20 & $25 / 03 / 2007$ & 6,72 \\
\hline $23 / 06 / 2006$ & 4,25 & $28 / 03 / 2007$ & 6,80 \\
\hline $24 / 06 / 2006$ & 4,19 & $29 / 03 / 2007$ & 6,73 \\
\hline $24 / 06 / 2006$ & 4,09 & $02 / 04 / 2007$ & 8,15 \\
\hline $17 / 07 / 2006$ & 5,11 & $11 / 04 / 2007$ & 6,74 \\
\hline 04/08/2006 & 5,12 & $19 / 04 / 2007$ & 6,84 \\
\hline 09/08/2006 & 3,30 & $25 / 04 / 2007$ & 7,55 \\
\hline $10 / 08 / 2006$ & 3,82 & $25 / 04 / 2007$ & 7,12 \\
\hline $10 / 08 / 2006$ & 3,58 & $26 / 04 / 2007$ & 7,30 \\
\hline $23 / 08 / 2006$ & 4,52 & $13 / 05 / 2007$ & 7,91 \\
\hline 01/09/2006 & 4,62 & $14 / 05 / 2007$ & 7,72 \\
\hline 01/09/2006 & 5,16 & $14 / 05 / 2007$ & 6,81 \\
\hline $12 / 09 / 2006$ & 8,11 & 05/06/2007 & 6,50 \\
\hline $24 / 09 / 2006$ & 8,39 & 06/06/2007 & 5,24 \\
\hline 03/10/2006 & 5,08 & $07 / 06 / 2007$ & 6,66 \\
\hline $15 / 10 / 2006$ & 5,06 & 09/07/2007 & 8,10 \\
\hline $15 / 10 / 2006$ & 3,69 & $18 / 07 / 2007$ & 6,61 \\
\hline $15 / 10 / 2006$ & 8,28 & $16 / 08 / 2007$ & 8,50 \\
\hline $24 / 11 / 2006$ & 8,42 & $18 / 08 / 2007$ & 7,96 \\
\hline $25 / 11 / 2006$ & 6,33 & 01/09/2007 & 7,51 \\
\hline $26 / 11 / 2006$ & 6,05 & $13 / 09 / 2007$ & 7,78 \\
\hline $12 / 12 / 2006$ & 6,52 & $30 / 09 / 2007$ & 7,83 \\
\hline $12 / 12 / 2006$ & 6,70 & $13 / 10 / 2007$ & 8,15 \\
\hline
\end{tabular}

Considerando-se que a especificação para o valor de $\mathrm{pH}$ para esse produto é de 7,0- 9,0 percebe-se que grande parte dessas amostras teria sofrido uma modificação ao longo do tempo e encontravam-se abaixo do limite mínimo de $\mathrm{pH}$. 
Além disso, observa-se uma queda de $\mathrm{pH}$ bastante acentuada para algumas das amostras e os valores mais baixos de $\mathrm{pH}$ foram observados nas amostras mais envelhecidas.

No entanto observa-se que essa correlação de queda de $\mathrm{pH}$ com o tempo não é muito clara. Algumas amostras mais antigas - 2005/2006 - encontravam-se com valor de pH ainda dentro da especificação enquanto algumas amostras de 2007, e portanto mais recentes na ocasião do levantamento, apresentaram valores de $\mathrm{pH}$ abaixo de 5,0 como observa-se na Figura 1.

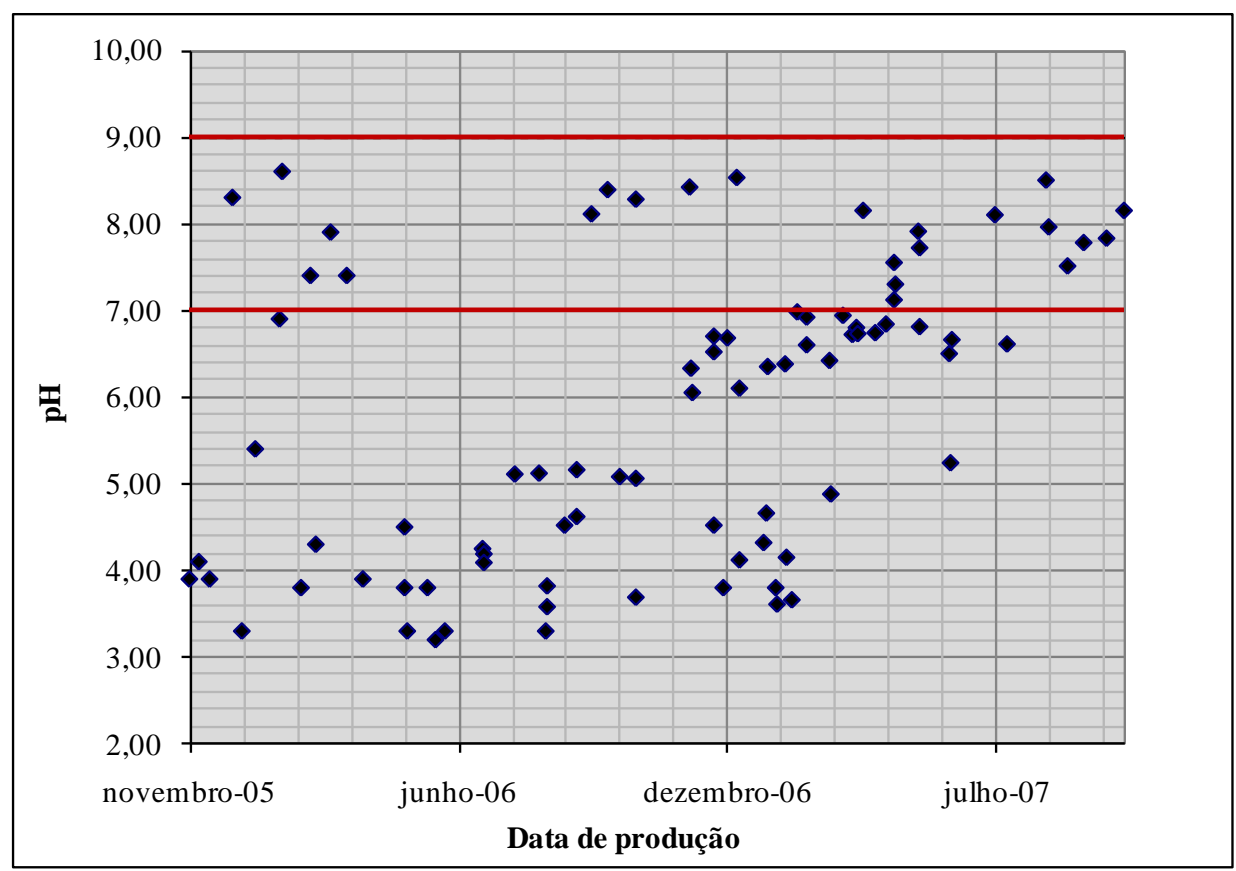

Figura 1- Dados de análise de pH das amostras

Uma possível hipótese é de que haja outros fatores não claramente identificados influenciando a taxa de reação de hidrólise além do tempo e temperatura como, por exemplo, variações na composição do produto de amostra para amostra ou variações nas condições de processo. 


\section{OBJETIVO}

O trabalho proposto nesta dissertação objetiva a avaliação da interferência das diversas variáveis envolvidas na taxa de reação de hidrólise de modo a se ter um maior grau de conhecimento sobre o comportamento do sistema.

O estudo será realizado com dados coletados a partir de experimentos planejados. $\mathrm{O}$ resultado esperado é um modelo confiável e representativo que contemple o efeito e interferência das variáveis estudadas na taxa de reação de hidrólise, permitindo a previsão de respostas e uma melhor compreensão a respeito do comportamento do produto acabado.

A partir deste estudo espera-se contribuir para implementar melhorias na fabricação e na composição do produto, assim como nas condições de manuseio e estocagem com o objetivo de minimizar a ocorrência dessa indesejável reação de decomposição. 


\section{REVISÃO BIBLIOGRÁFICA}

A maior parte dos estudos publicados a respeito da cinética de reação de hidrólise de produtos sulfatados refere-se ao dodecil sulfato de sódio - DSS (ou SDS: sodium dodecyl sulfate) - de cadeia carbônica C12, e que é muito semelhante ao lauril sulfato de sódio - LSS (ou SLS: sodium lauryl sulfate) - de cadeia carbônica C12/C14. O LSS, ou mesmo o DSS, no entanto, tem reduzida importância comercial para os segmentos de higiene pessoal e limpeza doméstica quando comparados ao LESS 2EO.

As informações e os estudos encontrados em literatura para o LSS e para o DSS serviram para nortear o estudo conduzido nesta dissertação que tem como alvo a reação de hidrólise do LESS 2EO em água.

São poucos os estudos divulgados a respeito da estabilidade do DSS e de outros tensoativos tão amplamente utilizados na solubilização de drogas e na formulação de produtos de higiene pessoal (NAGAKI;YOKOYAMA, 1985).

Existe literatura substancial a respeito da hidrólise de sulfatos de cadeia aromática, mas poucos são os artigos que tratam da hidrólise de sulfatos de alcoóis primários (BETHELL et al., 2001).

A maioria dos estudos publicados a respeito deste assunto esteve focada nas diferenças observadas na cinética de hidrólise quando conduzida abaixo e logo acima da CMC (concentração micelar crítica) enquanto que a comercialização usual desses tensoativos sulfatados é feita em concentrações de ativos em torno de $30 \%$ em água e, portanto, muito acima da CMC. O efeito do aumento da concentração de tensoativo muito além da CMC, como é o caso do produto alvo do estudo nesta dissertação, teria sido também muito pouco estudado (BETHELL et al., 2001).

Ao longo da pesquisa realizada em busca de informações publicadas em literatura a respeito da reação de hidrólise observou-se que o LASH, embora seja muito estável na sua forma ácida, sofre decomposição térmica quando submetido a altas temperaturas (170$220^{\circ} \mathrm{C}$ ) liberando $\mathrm{SO}_{2}$ durante essa reação (ROBERTS; LEJEUNE, 2002). 
É conhecido que alguns tensoativos sulfatados começam a apresentar um "odor gorduroso" quando estocados por períodos muito longos de tempo, esse fenômeno de alteração do odor característico pode ser atribuído à instabilidade hidrolítica que resulta na formação de um composto volátil. No caso do DSS esse composto corresponderia ao dodecanol liberado a partir da reação de hidrólise do tensoativo em soluções altamente ácidas (MURAMATSU; INOUE, 1976).

É importante o melhor entendimento das variáveis que influenciam a reação de hidrólise dos tensoativos sulfatados pois isso prejudica seu efeito na formulação de uso final devido à queda no teor de tensoativo presente e pela acidificação do meio devido à liberação de íons $H^{+}$provenientes da reação de hidrólise.

\subsection{O comportamento da reação de hidrólise}

A investigação realizada por Bethell et al. (2001) em sua pesquisa avaliou os efeitos na taxa de hidrólise em uma ampla faixa de concentrações (desde valores próximos à CMC até concentrações comerciais) analisando a natureza da catálise envolvida na hidrólise e as possíveis alterações nos mecanismos de reação na faixa de concentrações estudada.

Ao fazer o acompanhamento da reação de hidrólise do DSS, em pH inicialmente neutro e temperatura de $100^{\circ} \mathrm{C}$, a $1 \%$ de concentração e a $10 \%$ de concentração em massa foi observado um comportamento sigmóide, conforme ilustrado na Figura 2, que reflete o que foi observado também por Kurz (1962) que a reação ocorreria em duas etapas: uma etapa lenta - hidrólise não-catalisada - seguida de uma etapa rápida - catalisada por ácido. Foi observado que o tempo para a ocorrência da hidrólise completa para a solução mais concentrada foi muito menor. 


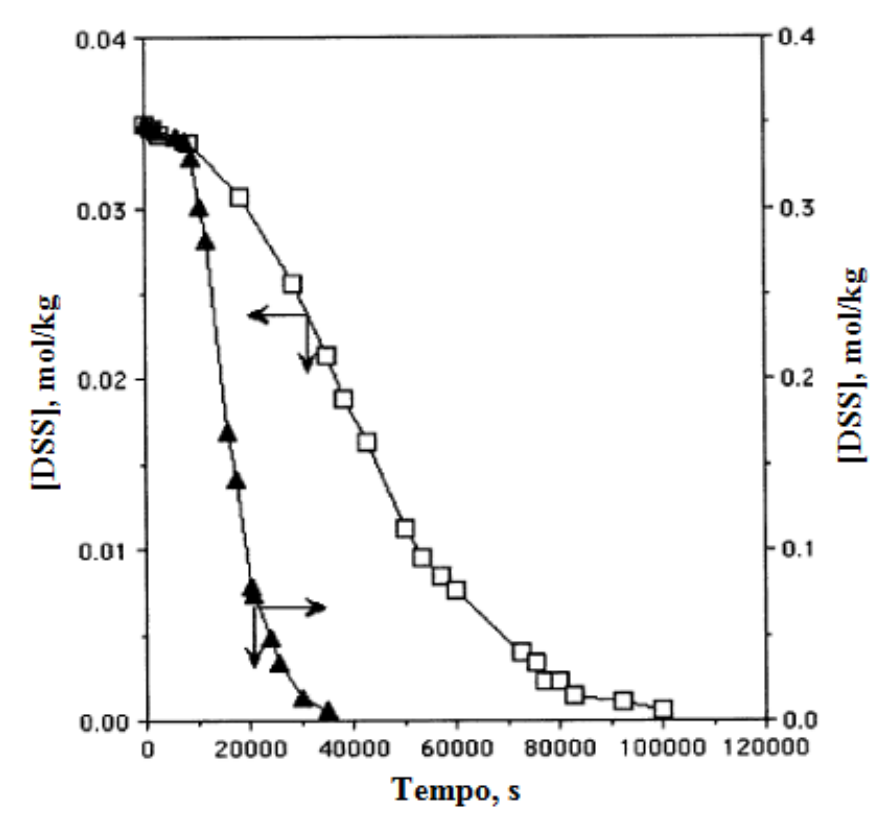

Figura 2- Variação na concentração de DSS no tempo para a reação de hidrólise a $100^{\circ} \mathrm{C}$ em solução inicialmente neutra; (ם) 1\% DSS; (ム)10\% DSS (BETHELL et al., 2001)

O esquema simplificado dessas etapas é descrito por Bethell et al. (2001) nas equações (6) - (8)

$$
\begin{aligned}
& \mathrm{HSO}_{4}^{-}+\mathrm{H}_{2} \mathrm{O} \leftrightarrow \mathrm{H}_{3} \mathrm{O}^{+}+\mathrm{SO}_{4}^{2-} \\
& \mathrm{CH}_{3}\left(\mathrm{CH}_{2}\right)_{10} \mathrm{CH}_{2} \mathrm{OSO}_{3}^{-}+\mathrm{H}_{2} \mathrm{O} \rightarrow \mathrm{CH}_{3}\left(\mathrm{CH}_{2}\right)_{10} \mathrm{CH}_{2} \mathrm{OH}+\mathrm{HSO}_{4}^{-} \\
& \mathrm{CH}_{3}\left(\mathrm{CH}_{2}\right)_{10} \mathrm{CH}_{2} \mathrm{OSO}_{3}^{-}+\mathrm{H}_{2} \mathrm{O} \stackrel{\mathrm{H}_{3} \mathrm{O}^{+}}{\longrightarrow} \mathrm{CH}_{3}\left(\mathrm{CH}_{2}\right)_{10} \mathrm{CH}_{2} \mathrm{OH}+\mathrm{HSO}_{4}^{-}
\end{aligned}
$$

O progresso da reação de hidrólise é lento no início (etapa não-catalítica) - equação (7) e gera íons hidrogênio - equação (6) - que causam um decréscimo no valor do $\mathrm{pH}$, o que acelera a reação de hidrólise (etapa ácido-catalítica) representada na equação (8).

A hidrólise apresenta-se como autocatalítica, pois os íons $\mathrm{HSO}_{4}^{-}$liberados na etapa lenta atuam como catalisadores na próxima etapa da reação (etapa mais rápida) pois a presença desses íons em solução resulta em um aumento da acidez na mistura reacional.

$\mathrm{O}$ valor de $\mathrm{pKa}$ para o $\mathrm{HSO}_{4}^{-}$determinado experimentalmente a $25^{\circ} \mathrm{C}$ por Bethell et al. (2001) foi de 1,78, considerado constante para várias condições diferentes de reação. 
Um procedimento distinto foi adotado na pesquisa realizada por Garnett et al. (1983a) pois para os experimentos realizados foi necessária a introdução de um parâmetro empírico de dissociação do $\mathrm{HSO}_{4}^{-}$para o ajuste e determinação da constante cinética da reação de hidrólise pois assumiu-se a constante de ionização do $\mathrm{HSO}_{4}^{-}$não era conhecida para todas as situações estudadas.

É importante ressaltar também que a alteração das taxas de reação de hidrólise se deve, em parte, às alterações no meio reativo como, por exemplo, o estado de agregação das micelas e do tensoativo, mudança na atividade de água e interferência na reação de equilíbrio de dissociação do íon $\mathrm{HSO}_{4}^{--}$provocada pela mudança na concentração de tensoativo e presença de eletrólitos por exemplo.

\subsection{A reação de hidrólise na presença de ácido}

A autocatálise, segundo Bethell et al. (2001), não envolve os íons $H_{S O}^{-}$em si e está relacionada com a concentração do íon hidrogênio, derivado de ácidos em geral, presente no meio (catálise ácida) mas, segundo (BATTS, 1966), a reação de hidrólise dos sulfatados seria catalisada somente por ácidos fortes (catálise específica) não sendo catalisada na presença de qualquer ácido.

A curva de forma sigmóide para o gráfico da concentração de ativos ao longo do tempo (Figura 2) desaparece na presença de ácido sulfúrico adicionado pois nesse caso somente a rota ácido-catalítica é observada (BETHELL et al., 2001).

A eficiência de catálise dos diferentes ácidos na reação de hidrólise dos compostos sulfatados de cadeia aromática estudados por Fendler, E. e Fendler, J. (1968) foi a seguinte: $\mathrm{H}_{2} \mathrm{SO}_{4}>\mathrm{HClO}_{4}>\mathrm{HCl}$.

Nos testes realizados na presença de ácido perclórico observa-se uma separação de fases induzida pelo aumento da concentração do produto da reação (1-dodecanol) quando a reação de hidrólise encontra-se próxima de uma conversão de 10\% (GARNETT et al., 1983a). 
A hidrólise de DSS seria independente do pH na faixa de 4,0-10,0 e a taxa de reação seria acelerada em pH menor do que 4,0 e retardada em valores de $\mathrm{pH}$ acima de 10,0 (NAGAKI; YOKOYAMA, 1985).

A reação de hidrólise apresenta catálise dependente da concentração do íon hidrogênio tanto para soluções concentradas quanto para soluções diluídas. A hidrólise ácido-catalítica prossegue, em qualquer concentração de ativos, por meio de um mecanismo envolvendo a quebra da ligação $S-O$ (BETHELL et al., 2001).

Esse mecanismo é confirmado por Garnett et al. (1983a) onde os autores afirmam que na reação de hidrólise observa-se um equilíbrio na protonação do grupo sulfato seguido de um ataque pela água no enxofre:

$$
\mathrm{ROSO}_{3}^{-}+\mathrm{H}^{+} \leftrightarrow \mathrm{ROSO}_{3} \mathrm{H} \stackrel{\mathrm{H}_{2} \mathrm{O} \quad k_{2}}{\longrightarrow} \mathrm{ROH}+\mathrm{HSO}_{4}^{-}+\mathrm{H}^{+}
$$

O mecanismo envolvido na ocorrência da reação de hidrólise também é discutido por Batts (1966) e o autor descreve que, de acordo com o princípio da reversibilidade microscópica, tanto a esterificação quanto a hidrólise devem passar pelo mesmo estágio de transição e o mecanismo seria:

$$
\begin{aligned}
& { }_{-\mathrm{O}^{-}}^{\mathrm{R}-\mathrm{SO}_{2}}+\mathrm{H}^{+} \stackrel{\text { Rápida }}{\rightleftarrows} \stackrel{\mathrm{R}^{\circ} \mathrm{O}_{+}^{+}}{\rightleftarrows} \mathrm{SO}_{-\mathrm{O}^{-}}
\end{aligned}
$$

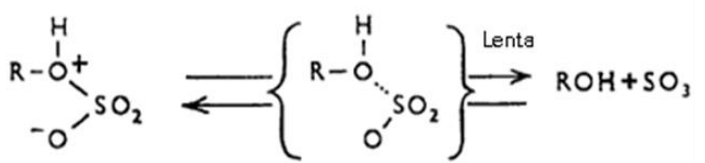

Para uma concentração de tensoativos suficientemente alta, por exemplo $0,35 \mathrm{~mol} / \mathrm{dm}^{3}$, observa-se que a taxa de reação é aproximadamente linear em relação à concentração de $H^{+}$- reação de primeira ordem em relação a $\left[H^{+}\right]$- o que já seria esperado quando a concentração de tensoativo, e portanto de micelas, supera consideravelmente a concentração de íons $H^{+}$. 
Garnett et al. (1983a) concluem que a concentração de íons $H^{+}$na micela é maior para o LESS 2EO do que para o LSS para uma mesma concentração de tensoativo e de íons $H^{+}$. A maior tendência de retenção de íons $H^{+}$nas micelas de LESS 2EO pode ser explicada pela presença de ligações de hidrogênio, ou seja, interações que ocorrem entre os íons de hidrogênio e os átomos de oxigênio da cadeia etoxilada. Isso resultaria, segundo comprovado em testes realizados em baixa concentração de tensoativo, em uma maior taxa de reação (etapa ácido-catalítica) para o LESS 2EO do que para o LSS, mantidas constantes a concentração de tensoativo e a concentração de íons $H^{+}$. Essa afirmação contradiz a informação anteriormente apresentada de que, segundo Groot (1991), o efeito indutivo exercido pela cadeia etoxilada atenuaria a reatividade do grupo $\mathrm{SO}_{3}$.

\subsection{A influência da hidrólise na leitura de tensão superficial}

A hidrólise seria também em parte responsável pela dependência observada das leituras de tensão superficial de soluções aquosas de DSS em relação ao tempo.

Mysels (1986) realizou, em sua pesquisa, um estudo de variação da medida de tensão superficial de uma solução aquosa de DSS em função do tempo para diferentes estágios de purificação. A presença de impurezas, mesmo que em pequenas concentrações, pode afetar significativamente, segundo o autor, as medidas e na prática reduz o valor de tensão superficial medido. Isso pode ser observado na Figura 3 onde são apresentadas as medidas de tensão superficial para soluções que passaram por diferentes estágios de purificação.

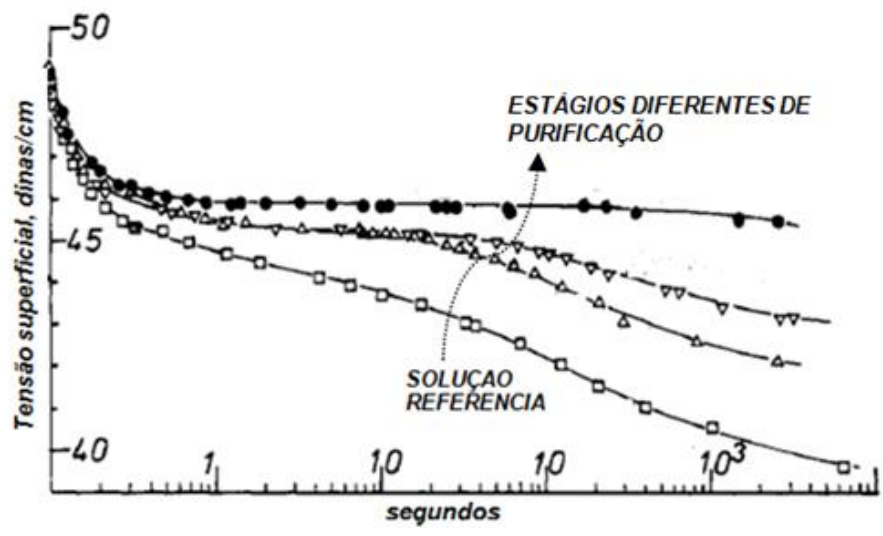

Figura 3- Medidas de tensão superficial de uma solução de DSS em diferentes estágios de purificação $\left(25^{\circ} \mathrm{C}\right)$ e o impacto em um menor tempo para estabilização da medida (MYSELS, 1986) 
A adsorção relativamente rápida do tensoativo nas superfícies é acompanhada por uma lenta adsorção de traços de impurezas de alta atividade superficial, como 1-dodecanol, por exemplo, que afetam, portanto, o resultado da medida.

Ainda que referências indiquem que a reação de hidrólise é bastante lenta existem dúvidas se essa taxa seria suficientemente baixa a ponto de prevenir a liberação de 1dodecanol, de alta atividade superficial, que poderia interferir, ao longo do tempo, na determinação de medidas de tensão superficial de uma solução de DSS (MYSELS, 1986).

O acompanhamento realizado por Mysels (1986) mostra o efeito do impacto do envelhecimento das amostras no tempo de estabilização da medida de tensão superficial conforme observado na Figura 4.

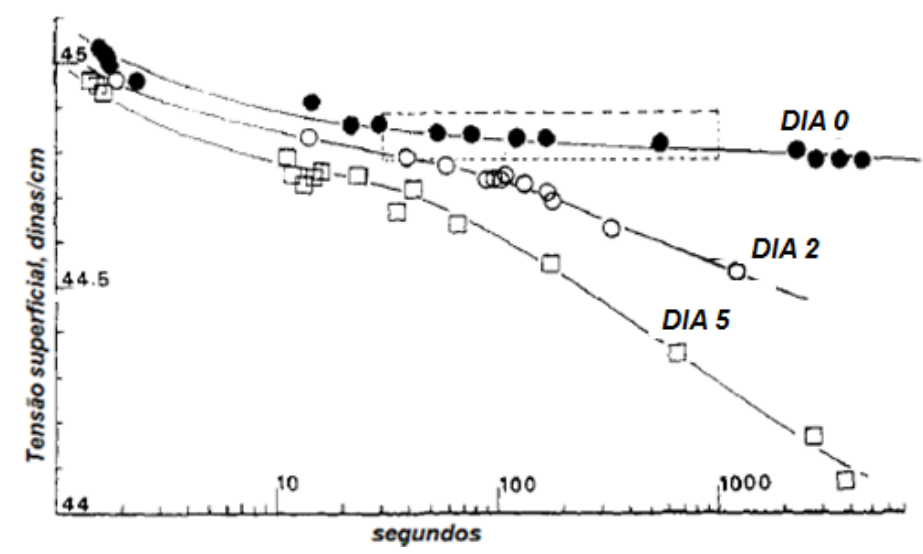

Figura 4- Efeito do envelhecimento das amostras na leitura de tensão superficial (MYSELS, 1986)

A presença de impurezas pode ser identificada: pela presença um ponto de mínimo na curva de tensão superficial em função da concentração do tensoativo ou por um período muito extenso (acima de 1 hora) para estabilização da medida durante a determinação do valor de tensão superficial de uma determinada solução de tensoativo (ROSEN, 1981).

A decomposição de moléculas de alquil sulfato em solução aquosa foi acompanhada pelo comportamento da tensão superficial ao longo do tempo no estudo realizado por Lunkenheimer, Theil e Lerche (1982).

Foi observado que soluções quimicamente puras de DSS não revelam a ocorrência de decomposição em um período de até 100 minutos. No entanto, essa taxa de reação de 
hidrólise aumenta significativamente na presença de suspensão ácida de alumina, o que não é observado na presença de suspensões básicas de alumina (LUNKENHEIMER, THEIL e LERCHE, 1982).

\subsection{A influência da temperatura na reação de hidrólise}

Os tensoativos sulfatados também são comercializados a 70\% de ativos em água. Nesse caso comportam-se como uma pasta viscosa à temperatura ambiente e que adquire maior fluidez em temperaturas mais altas, em torno de $80^{\circ} \mathrm{C}$, tornando-se um líquido mais fácil de manipular e transportar. No entanto a estocagem prolongada desse produto em temperaturas mais altas resulta em hidrólise completa (BETHELL et al., 2001).

Desconsiderando-se as variações da composição da cadeia graxa a hidrólise completa de uma solução aquosa de DSS a 70\% de ativos em $\mathrm{pH}$ inicialmente neutro ocorreria em um período de $12 \mathrm{~h}$ a $80^{\circ} \mathrm{C}$ (BETHELL et al., 2001). Essa é uma referência importante quanto ao período de duração da reação de hidrólise

Um aumento extraordinário da dependência da taxa de hidrólise em relação à temperatura quando a mesma encontra-se acima de $40^{\circ} \mathrm{C}$ já teria sido reportado, segundo Muramatsu e Inoue (1976), para uma amostra comercial de LSS em solução ácida.

\subsection{O efeito da concentração e da micelização na taxa de reação de hidrólise}

A partir de uma determinada concentração de tensoativo em água inicia-se a formação de micelas. Um modelo realístico para a micela, citado por Buurma, Herranz e Engeberts (2004), envolve duas zonas distintas: um centro hidrofóbico e uma região externa contendo cabeças polares dos tensoativos e com alta concentração local de contra-íons e água de hidratação, essa região é denominada camada de Stern.

Apesar de não existir consenso sobre a estrutura detalhada para as micelas a teoria mais aceita é de um modelo estrutural aproximadamente esférico com as seguintes características (BUNTON; MHALA; MOFFATT., 1989): 
a) Um núcleo formado pelas cadeias hidrocarbônicas do anfifílico

b) Uma região com espessura aproximadamente igual ao diâmetro do grupo polar do surfactante contendo, além dos grupos polares, uma alta concentração local de contra-íons e água de hidratação (camada de Stern)

c) Uma dupla camada elétrica difusa que contém os contra-íons restantes e se estende pela fase aquosa (camada de Gouy-Chapman)

Segundo Motsavage e Kostenbauder (1963) o centro da micela, onde se encontram as cadeias carbônicas, é seco e por isso a reação de hidrólise ocorreria somente na parte molhada da micela, na região da camada de Stern. A região da camada de Stern pode ser entendida como uma fase separada que contém alta concentração de contra-íons e de cabeças polares dos tensoativos além de água, conforme já mencionado (MOTSAVAGE e KOSTENBAUDER, 1963).

O efeito de forte dependência da taxa de reação de hidrólise com o estado de agregação do tensoativo teria levado a um aumento de 30-40 vezes na taxa de reação conforme pesquisa realizada por Kurz (1962). Esse efeito é confirmado por Motsavage e Kostenbauder (1963) pois as soluções de DSS testadas em concentração acima da CMC sofreram hidrólise a uma taxa de reação cerca de 30 vezes maior do que soluções do mesmo tensoativo abaixo da CMC.

A micelização do DSS não afetaria a taxa da reação não-catalisada (KURZ, 1962).

No estudo realizado por Nagaki e Yokoyama (1985) foi utilizada uma concentração de tensoativo acima da CMC, o que resultou em uma constante cinética cerca de 50 vezes maior quando comparada com a constante pré-micelar, com os tensoativos livres no meio.

As micelas iônicas que se formam em soluções aquosas originam regiões altamente organizadas e que apresentam baixa polaridade e alto potencial eletrostático quando comparadas com o restante do meio e é possível explorar como a estrutura da micela altera a velocidade das reações. 
O aumento na constante cinética de hidrólise no estado de micela pode ser explicado pelo aumento da concentração de prótons próximo à superfície da micela resultante da alta concentração de cargas eletrostáticas de valor negativo na superfície da micela formada por tensoativo aniônico segundo Nagaki e Yokoyama (1985).

É esperado um aumento na taxa de reação de hidrólise conforme se aumenta a cadeia graxa do tensoativo refletindo a redução observada na CMC (ROSEN, 2004).

No entanto, no estudo realizado por Garnett et al. (1983a) foi observado um decréscimo de 30\% na taxa de reação de hidrólise e uma solução aquosa de DSS, na presença de uma concentração fixa de ácido perclórico, ao aumentar sua concentração de 0,02 para 0,6 mol/1, o que corresponderia a uma concentração muito acima da CMC e, portanto, diferente da condição testada por Kurz (1962) e em outros trabalhos mencionados. Esse efeito de redução da velocidade de hidrólise estaria atribuído a uma diluição da concentração do íon hidrogênio na camada de Stern das micelas. Esse mesmo efeito é explicado por Rosen (2004) pois quando o número de micelas ultrapassa o total requerido para solubilizar todo o substrato ocorre uma diluição do substrato por micela conforme aumenta-se a concentração do tensoativo, isso causa uma redução na taxa de reação e é por isso que em muitos casos observa-se um ponto de máximo para a taxa da reação a uma concentração próxima ou logo acima da CMC e em seguida uma queda abrupta com o aumento da concentração de tensoativos para valores muito acima da CMC. O que foi comprovado por Garnett et al. (1983a) em sua pesquisa, pois eles observaram que a constante cinética atinge um valor máximo em uma concentração imediatamente acima da CMC e depois diminui conforme aumenta-se a concentração de DSS. Esse comportamento seria atribuído, conforme já mencionado, à diluição dos reagentes e uma redução na concentração dos íons $H^{+}$na camada de Stern por efeito de diluição para o caso de concentrações muito acima da CMC.

É esperado também que a interferência do meio reacional na reação catalítica e na não catalítica apresente diferentes resultados devido à complexidade da natureza das soluções de tensoativos. Em uma solução de até $10 \%$ em massa de DSS a complexidade é menor pois observa-se somente a agregação em micelas e, ao aumentarmos a concentração, a distorção do formato esférico das micelas para formas alongadas e elipsoidais aumentaria a complexidade da solução, influenciando as taxas de reação catalítica e não-catalítica de diferentes formas (BETHELL et al., 2001). 
As velocidades de reação abaixo da CMC são em geral extremamente baixas e, portanto muito difíceis de serem acompanhadas apresentando, em algumas condições, o tempo de meia vida de 10-100 anos (MURAMATSU; INOUE, 1976).

No estudo realizado nesta dissertação foi avaliada a reação de hidrólise para o LESS 2EO em uma concentração de ativos muito acima da $\mathrm{CMC}$, que corresponde à concentração utilizada para comercialização do produto.

\subsection{A influência da adição de eletrólitos na reação de hidrólise}

O efeito de adição de eletrólitos na taxa de reação de hidrólise também é bastante investigado em literatura por se tratar de um sistema composto por micelas iônicas no qual se espera que a presença de eletrólitos cause alguma interferência pois nessa situação a CMC é reduzida.

Na maioria dos casos é observado um efeito inibitório na presença de eletrólitos. No estudo desenvolvido por Kurz (1962) observou-se um efeito negativo, ou seja, um efeito inibitório, na taxa de hidrólise ácido-catalítica ao aumentar-se a concentração de eletrólitos. Esse resultado pode ser explicado pela substituição do íon $H^{+}$na superfície da micela aniônica - que possui carga negativa - pela competição com outros cátions, reduzindo assim a velocidade da reação, esse mesmo efeito inibitório para a adição de eletrólitos foi observado por Batts (1966) e também por Nagaki e Yokoyama (1985).

O efeito da adição de eletrólitos também foi inibitório no estudo realizado por Garnett et al. (1983b) para soluções diluídas de DSS na presença de $\mathrm{HClO}_{4}$ e alta temperatura 70$90^{\circ} \mathrm{C}$. A taxa de reação foi retardada pela presença de cátions na seguinte seqüência: $C a>M g>C s>K>N a>L i$. Essa série é conhecida como série de Hofmeister e quanto maior a densidade de carga do cátion maior é sua eficiência ao deslocar o hidrogênio catalítico da superfície da micela e retardar a reação.

$\mathrm{O}$ efeito inibitório do aumento da concentração de $\mathrm{NaCl}$ é mantido tanto nas soluções diluídas quanto na solução de tensoativo acima da CMC (GARNETT et al., 1983b). 
Garnett et al. (1983a) evidenciaram que as micelas de LESS 2EO atraem os íons $H^{+}$ mais fortemente do que as micelas de LSS pois foi observado, na pesquisa por eles realizada, que a redução na taxa de reação de hidrólise do DESS 2EO foi menor do que o efeito inibitório pela presença de eletrólitos observado para o DSS.

A presença de excesso de contra-íons, quando adicionados a um sistema no qual um reagente iônico está envolvido, retarda a atividade catalítica da micela e, quanto maior o íon, mais intenso é esse efeito observado. Isso se deve à competição entre o excesso de íons e o substrato reativo, nesse caso o $\mathrm{H}^{+}$, pelas posições disponíveis para associar-se à micela (MYERS, 1999).

\subsection{A influência da adição de materiais não iônicos na hidrólise do DSS}

Como a formação de micelas aumenta a taxa de hidrólise, espera-se que a adição de componentes capazes de formar micelas mistas com DSS também influencie a velocidade da reação de hidrólise (MOTSAVAGE; KOSTENBAUDER, 1963).

Moléculas polares que possuem uma extensa cadeia graxa, como é o caso do 1dodecanol, são solubilizadas na micela de tensoativo com a mesma orientação das moléculas de DSS - considerando o posicionamento das porções hidrofílica e lipofílica da molécula - e com sua cadeia graxa alinhada de forma paralela à cadeia graxa das moléculas de DSS (ABE; OGINO, 1961).

A presença de aditivos não iônicos na solução de tensoativo como o 1-dodecanol - teor de álcool graxo de partida não consumido durante a reação de sulfatação - resulta em um aumento da taxa de reação para soluções abaixo da CMC (MOTSAVAGE; KOSTENBAUDER, 1963).

O resultado encontrado nos estudos realizados por Nagaki e Yokoyana (1985) e Abe e Ogino (1961) para soluções abaixo da CMC foi o mesmo encontrado por Motsavage e Kostenbauder (1963). Segundo Nagaki e Yokoyana (1985) ocorreria a formação de um complexo do DSS com o 1-dodecanol quando presentes em uma determinada razão molar. 
Esse complexo seria formado por ligações de hidrogênio entre o álcool e as moléculas do sulfatado e a hidrólise do DSS na forma desse complexo ocorreria mais rapidamente. É importante ressaltar que esse efeito foi observado para concentrações de tensoativo abaixo da CMC.

Como esse complexo seria formado por ligação de hidrogênio entre o átomo de oxigênio do grupo sulfato e o grupo $O H$ dos alcoóis a hidrólise mais rápida do DSS no seu estado complexado seria explicada pelo fato de um próton estar sendo fornecido pela ligação de hidrogênio.

Os testes realizados por Nagaki e Yokoyama (1985) para uma solução aquosa de tensoativo acima da CMC mostraram uma queda no valor da constante cinética da reação ácido-catalítica ao aumentar-se a concentração de 1-dodecanol. Essa queda na taxa de reação seria explicada pela redução na concentração de íons de $H^{+}$na superfície da micela como resultado da redução da densidade de carga negativa em sua superfície devido à adição de 1dodecanol à micela. A densidade de carga negativa decresce conforme aumenta a proporção de 1-dodecanol e aumenta sua área ocupada na superfície da micela.

No estudo realizado por Kurz (1962) para uma solução de DSS acima da CMC resultou, no entanto, em um aumento na taxa de reação. Esse resultado parece incoerente com os demais resultados observados de inibição da reação de hidrólise na presença de 1-dodecanol. No entanto, o estudo realizado por Kurz (1962) utilizou uma solução de DSS com concentração muito próxima à CMC e na presença de alta concentração de 1-dodecanol elevada e a explicação é que nesse caso teria havido pouca micela para solubilizar todo o 1dodecanol.

Esse fenômeno de solubilização no qual uma solução de tensoativo em concentração acima da CMC dissolve uma variedade de compostos orgânicos resultando em uma solução transparente através da solubilização das substâncias é bastante conhecido e foi também descrito por Ogino, Abe e Takesita (1976).

Bravo, Leis e Pena (1982) citam que a influência dos alcoóis em estruturas micelares iônicas estaria sendo muito estudada. As moléculas de álcool são inseridas na micela de forma intercalada entre as moléculas de tensoativo, afastando as porções iônicas das 
moléculas de tensoativo, o que reduz a densidade de cargas da micela, conforme já mencionado.

\subsection{O impacto de outras variáveis na taxa de reação}

Na pesquisa realizada por Bethell et al. (2001) também foi avaliada a interferência do tipo de contra-íon do tensoativo aniônico. Essa variável só apresentou efeito significativo na reação autocatalítica pois o tipo do contra-íon altera a acidez dos grupos polares dos agregados micelares. $\mathrm{O}$ efeito da interferência do contra-íon do álcool etoxilado sulfatado não será incluído no estudo, pois o contra-íon de maior importância comercial é o contra-íon de sódio.

No artigo de Moyo, Nhlapo e Focke (2008) os autores citam que a reação de hidrólise de sulfatados que ocorre em pH baixo já é conhecida mas que essa hidrólise também ocorreria em pH elevado. A hidrólise em meio alcalino também é mencionada por Kurz (1962) e ocorreria pela quebra da ligação $C-O$.

A hidrólise, no entanto, é muito mais rápida em soluções ácidas do que em meio com alto pH não sendo possível observar a ocorrência de hidrólise em soluções altamente alcalinas mesmo na temperatura de $150^{\circ} \mathrm{C}$ segundo Burwell (1952).

O estudo realizado por Calhoun e Burwell (1955) a respeito da cinética de hidrólise em soluções aquosas de alto $\mathrm{pH}$ chegou à conclusão de que essa reação seria melhor estudada na presença de solventes mais favoráveis à ocorrência dessa reação ou utilizando-se espécies nucleofílicas de substituição mais ativas, o que leva à conclusão de que a hidrólise em meio alcalino não é favorecida em condições normais de comercialização do LESS 2EO e que a maior ameaça de hidrólise para o produto seria mesmo a hidrólise ácida.

Outras possíveis variáveis que poderiam influenciar o valor da taxa de reação de hidrólise foram estudadas em literatura como, por exemplo, a interferência da luz. Muramatsu e Inoue (1976) conduziram experimentos de cinética de hidólise no escuro e na presença de luz e os resultados foram equivalentes, comprovando o que já havia sido observado pelos testes realizados por Benkovic, S. e Benkovic, P. (1966) na presença e ausência de luz. 
Um estudo a respeito da interferência da área superficial na taxa de reação foi realizado por Muramatsu e Inoue (1976) através de um teste comparativo medindo a taxa de reação na presença e na ausência de lã de vidro mergulhada na solução aquosa de DSS, observou-se que não houve alteração na taxa de reação de hidrólise com o aumento da área superficial.

Outra variável que teria influencia a reação de hidrólise seria a cadeia graxa do tensoativo. Os sulfatados de cadeia aromática, segundo Kice (1966), apresentam a taxa de decomposição de hidrólise em meio ácido muito mais alta do que os sulfatados de cadeia não-aromática.

A taxa de reação de hidrólise também seria influenciada, segundo Kice (1966), pela concentração do teor de dioxana na solução de tensoativo. Isso seria explicado pois a constante de dissociação ácida de qualquer ácido neutro decresce significativamente na presença de dioxana na concentração de $40 \%$ a $80 \%$ e isso resultaria em um decréscimo na taxa de hidrólise dos compostos estudados.

Os teores de dioxana encontrados nas amostras comerciais de LESS 2EO que serão testadas neste trabalho são menores do que $30 \mathrm{ppm}$ e portanto, muito abaixo da faixa testada por Kice (1966) na qual foi observada uma influência na taxa de reação de hidrólise. Em vista desses resultados, essa variável não foi incluída no planejamento de experimentos realizado.

Os resultados do estudo realizado por Benkovic, S. e Benkovic, P. (1966) evidenciaram que não haveria influência da presença de metais na taxa de reação de hidrólise dos compostos sulfatados. Os testes foram conduzidos na presença e na ausência de EDTA (ácido etilenodiamino tetra-acético) - composto orgânico que age como agente quelante formando complexos muito estáveis com diversos íons metálicos - e os resultados obtidos foram equivalentes.

\subsection{Modelo teórico para estimar o comportamento da reação}


O aumento na taxa de reação provocado pela presença de micelas é usualmente denominado de catálise micelar (HOLMBERG et al., 2002). Ainda que o termo "catálise" não seja o mais correto essa uma nomenclatura muito utilizada pela literatura para retratar o efeito marcante de aumento da velocidade das reações provocado pela presença de micelas (MARTINEK et al., 1977).

A catálise micelar aproxima-se de um modelo de catálise enzimática, pois o que ocorre é uma extração dos reagentes da fase aquosa para a fase micelar, o que resulta em um aumento da concentração dos reagentes na fase micelar e, consequentemente, em um aumento na taxa de reação (MARTINEK et al., 1977). O aumento na taxa de reação deve-se, portanto, ao efeito de aproximação dos reagentes pela micela (BUNTON; WOLFE,1973).

Vários modelos - dentre eles o de catálise enzimática - foram desenvolvidos ao longo dos anos para analisar quantitativamente o efeito catalítico ou inibitório de micelas. Esses modelos partem do princípio de que existe uma partição dos reagentes entre a fase aquosa e a pseudo-fase micelar resultando em um aumento da concentração do substrato em um nível microscópico (ROMSTED,1977).

No caso estudado nesta dissertação, em que o substrato e a micela apresentam cargas opostas, o modelo de troca iônica em pseudo-fase - TIPF ou PPIEM (pseudo-phase ion exchange model) - tem se mostrado adequado ao tratamento de vários tipos de reações químicas (GARNETT et al., 1983a; QUINA; CHAIMOVICH, 1979; ROMSTED, 1977).

O modelo considera que a reação ocorre em duas fases distintas - fase micelar e fase aquosa - com diferentes constantes de velocidade. O substrato, quando apresenta carga oposta à micela, se liga, da mesma forma que o contra-íon, à micela ocorrendo uma troca iônica entre o substrato e o contra-íon ligado à micela para manter a carga (ou dissociação iônica) da micela.

Neste trabalho os dados experimentais foram analisados utilizando-se o tratamento apresentado a seguir (GARNETT et al., 1983a). Este tratamento é baseado no modelo de troca iônica em pseudo-fase descrito por Quina e Chaimovich (1979) e Romsted (1975). 
Conforme mencionado anteriormente a reação ácido-catalítica de hidrólise dos alquil sulfatos envolve a quebra da ligação $S-O$ e acontece através de pré-equilíbrio da reação de protonação do grupo sulfato seguida de um ataque no $S$ pela água segundo a reação já previamente descrita na equação (9).

Assim sendo a taxa de reação poderia ser escrita da seguinte forma em um meio sem formação de micelas:

$$
-\frac{d\left[\mathrm{ROSO}_{3} \mathrm{H}\right]}{d t}=\text { rate }=k_{2} \cdot\left[\mathrm{ROSO}_{3} \mathrm{H}\right] \cdot\left[\mathrm{H}_{2} \mathrm{O}\right]
$$

Ou ainda:

$$
-\frac{d\left[\mathrm{ROSO}_{3} \mathrm{H}\right]}{d t}=\mathrm{rate}=k_{2} \cdot \mathrm{K} \cdot\left[\mathrm{ROSO}_{3}^{-}\right] \cdot\left[\mathrm{H}^{+}\right] \cdot\left[\mathrm{H}_{2} \mathrm{O}\right]
$$

Onde:

$$
K=\frac{\left[\mathrm{ROSO}_{3} H\right]}{\left[\mathrm{ROSO}_{3}^{-}\right] \cdot\left[\mathrm{H}^{+}\right]}
$$

Pode-se considerar $\left[\mathrm{H}_{2} \mathrm{O}\right]$ praticamente constante (em excesso) no meio e dessa forma tem-se que:

$$
-\frac{d\left[\mathrm{ROSO}_{3} \mathrm{H}\right]}{d t}=\text { rate }=k_{2, \text { obs }} \cdot\left[\mathrm{ROSO}_{3}^{-}\right] \cdot\left[\mathrm{H}^{+}\right]
$$

Onde:

$$
k_{2, o b s}=k_{2} \cdot K \cdot\left[H_{2} \mathrm{O}\right]
$$

No caso de alquil sulfatos de cadeia longa a formação de micelas também atua como catalisador e a reação ocorre por duas rotas (GARNETT et al., 1983a): 


$$
\begin{gathered}
p \mathrm{ROSO}_{3}^{-}+q \mathrm{X}^{+} \rightleftharpoons \mathrm{X}_{q}\left(\mathrm{ROSO}_{3}\right)_{p}^{-(p-q)} \\
\mathrm{H}^{+} \underbrace{k_{\text {w }}}_{\text {produtos }} \mathrm{H}^{+}\rfloor k_{s}
\end{gathered}
$$

Onde:

$$
k_{w}=k_{2, o b s}
$$

A constante cinética $k_{w}$ representa a constante de reação de hidrólise de um alquil sulfato em um meio aquoso, enquanto $k_{s}$ representa a constante de reação de hidrólise na presença de micelas.

A taxa de reação de hidrólise que ocorre na presença de micelas pode ser descrita como:

$$
\begin{aligned}
-\frac{d\left[\mathrm{ROSO}_{3} H\right]}{d t}= & k_{2, o b s} \cdot\left[\mathrm{ROSO}_{3}^{-}\right] \cdot\left[\mathrm{H}^{+}\right]=k_{w} \cdot\left[\mathrm{H}^{+}\right]_{w} \cdot\left[\mathrm{ROSO}_{3}^{-}\right]_{w} \cdot\left[\mathrm{H}_{2} \mathrm{O}\right]_{w}+ \\
& k_{s} \cdot\left[\mathrm{H}^{+}\right]_{s} \cdot\left[\mathrm{ROSO}_{3}^{-}\right]_{s} \cdot\left[\mathrm{H}_{2} \mathrm{O}\right]_{s}
\end{aligned}
$$

Ou ainda como:

$$
-\frac{d C_{T}}{d t}=k_{2, o b s} \cdot C_{T} \cdot H_{T}=k_{w} \cdot \bar{H}_{w} \cdot \bar{C}_{w} \cdot(1-C \cdot V)+k_{s} \cdot \bar{H}_{s} \cdot \bar{C}_{s} \cdot C \cdot V_{s}
$$

Onde $C_{T}$ e $H_{T}$ representam, respectivamente, as concentrações totais de surfactante e de íon hidrogênio. A concentração de surfactante na micela é representada por $C$. Sabe-se que:

$$
C=C_{T}-C M C
$$

A pseudo-fase aquosa é representada pelo índice $w$ e a camada de Stern pelo índice $s$. Assim sendo, $V_{s}$ representa o volume molar das cabeças polares dos tensoativos na camada de Stern das micelas (volume efetivo ou volume da camada de Stern) e $V$, o volume molar do tensoativo. Assim sendo, $(1-C \cdot V)$ representa, em unidade de volume da solução, o 
volume da pseudo fase aquosa e $C \cdot V_{s}$, o volume de água da camada de Stern. O volume efetivo $V_{s}$ corresponde à cerca de metade do volume total da micela (GARNETT et al., 1983a).

$\bar{H}_{w}$ representa a concentração local de íons hidrogênio e $\bar{C}_{w}$ a concentração de monômeros de tensoativo na pseudo-fase aquosa, enquanto $\bar{H}_{s}$ e $\bar{C}_{s}$ são as correspondentes concentrações na camada de Stern e indicam a concentração local de íons hidrogênio e de tensoativo.

Como:

$$
\begin{aligned}
& \bar{C}_{w}=\frac{C M C}{(1-C \cdot V)} \\
& \bar{C}_{s}=\frac{C}{C \cdot V_{s}}=\frac{1}{V_{s}} \\
& \bar{H}_{w}=\frac{H_{w}}{(1-C \cdot V)} \\
& \bar{H}_{s}=\frac{H_{s}}{C \cdot V_{s}}
\end{aligned}
$$

Segue-se que:

$$
-\frac{d C_{T}}{d t}=k_{2, o b s} \cdot C_{T} \cdot H_{T}=\frac{k_{w} \cdot H_{w} \cdot C M C}{(1-C \cdot V)}+\frac{k_{s} \cdot H_{s}}{V_{s}}
$$

Onde $H_{w}$ e $H_{s}$ representam, respectivamente, as concentrações analíticas de íons hidrogênio livres no meio e de íons hidrogênio associados à micela. 
Em soluções concentradas, como é o caso neste estudo, a parcela de contribuição mais significativa para a taxa de reação de hidrólise é o segundo termo da equação (25). Assim sendo tem-se que (GARNETT et al., 1983a):

$$
-\frac{d C_{T}}{d t}=k_{2, o b s} \cdot C_{T} \cdot H_{T}=\frac{k_{s} \cdot H_{s}}{V_{s}}
$$

Em reações catalisadas por micelas a concentração total de íons hidrogênio associados à micela é influenciada predominantemente pela troca iônica e deslocamento do contra-íon do tensoativo da camada de Stern da micela:

$$
X_{s}^{+}+H_{w}^{+} \leftrightarrow X_{w}^{+}+H_{s}^{+}
$$

A distribuição de íons hidrogênio entre a camada de Stern e a pseudo-fase aquosa é então governada pela constante de troca iônica $K_{H / X}$ :

$$
K_{H / X}=\frac{H_{s} \cdot X_{w}}{X_{s} \cdot H_{w}}=\frac{\bar{H}_{s} \cdot \bar{X}_{w}}{\bar{X}_{s} \cdot \bar{H}_{w}}
$$

Onde $X_{w}$ e $X_{s}$ são as correspondentes concentrações dos contra-íons do tensoativo livres no meio e associados à micela.

A magnitude da constante de troca iônica, no caso em estudo, representa a habilidade dos íons $\mathrm{H}^{+}$de expulsar os contra-íons $\mathrm{Na}^{+}$da superfície da micela (KHAN; ISMAIL, 2003).

Admitindo-se $\beta$ como sendo o grau de associação do contra-íon à micela e sabendo que:

$$
\beta=\frac{q}{p}
$$

O íon $H^{+}$e o contra-íon $X^{+}$do tensoativo neutralizam uma fração $\beta$ da carga total das cabeças polares dos tensoativos micelizados: 
$\bar{H}_{s}+\bar{X}_{s}=\beta \cdot \bar{C}_{s}$

A concentração total de íons hidrogênio - $H_{T}$ - e a concentração total de contra-íons $X_{T}$ - devem satisfazer as equações de balanço de massa:

$$
\begin{aligned}
& H_{T}=\bar{H}_{s} \cdot C \cdot V_{s}+\bar{H}_{w} \cdot(1-C \cdot V) \\
& X_{T}=\bar{X}_{s} \cdot C \cdot V_{s}+\bar{X}_{w} \cdot(1-C \cdot V)
\end{aligned}
$$

Usando as equações (28), (30), (31) e (32) encontra-se $H_{s}$ em função de $H_{T}, X_{T}, C$ e $K_{H / X}$ conforme apresentado a seguir.

A partir da equação (28) tem-se uma expressão para $\bar{X}_{w}$ que, substituída na equação (32) resulta em:

$$
X_{T}=\bar{X}_{s} \cdot C \cdot V_{s}+K_{H / X} \cdot \frac{\bar{H}_{w} \cdot \bar{X}_{s}}{\bar{H}_{s}} \cdot(1-C \cdot V)
$$

A partir dessa equação isola-se $\bar{X}_{s}$ :

$$
\bar{X}_{s}=\frac{X_{T} \cdot \bar{H}_{s}}{\bar{H}_{s} \cdot C \cdot V_{s}+K_{H / X} \cdot \bar{H}_{w} \cdot(1-C \cdot V)}
$$

Utilizando uma expressão para $\bar{H}_{w}$ elaborada a partir da equação (31) e substituindo-se essa expressão na equação (34) apresentada acima se chega à seguinte equação:

$$
\bar{X}_{s}=\frac{X_{T} \cdot \bar{H}_{s}}{\bar{H}_{s} \cdot C \cdot V_{s}+K_{H / X} \cdot\left(H_{T}-\bar{H}_{s} \cdot C \cdot V_{s}\right)}
$$

Substituindo-se essa equação para $\bar{X}_{s}$ na equação (30) tem-se: 
$\bar{H}_{s}+\frac{X_{T} \cdot \bar{H}_{s}}{\bar{H}_{s} \cdot C \cdot V_{s}+K_{H / X} \cdot\left(H_{T}-\bar{H}_{s} \cdot C \cdot V_{s}\right)}=\beta \cdot \bar{C}_{s}$

Essa equação pode ser simplificada utilizando-se as relações descritas nas equações (22) e (24):

$H_{s}+\frac{X_{T} \cdot H_{s}}{K_{H / X} \cdot H_{T}+H_{s} \cdot\left(1-K_{H / X}\right)}=\beta \cdot C$

A partir dessa equação tem-se:

$$
H_{s}=\frac{-A \pm\left[A^{2}+4 \cdot K_{H / X} \cdot\left(1-K_{H / X}\right) \cdot \beta \cdot C \cdot H_{T}\right]^{\frac{1}{2}}}{2 \cdot\left(1-K_{H / X}\right)}
$$

Onde

$$
A=K_{H / X} \cdot H_{T}+X_{T}+\beta \cdot C \cdot\left(K_{H / X}-1\right)
$$

Portanto, de acordo com a equação (38), $H_{s}$ varia de forma não linear com $H_{T}$. Somente a raiz positiva da equação (38) tem significado físico.

\subsubsection{Modelo teórico na presença de eletrólitos}

Quando há presença de eletrólitos adicionados ao meio é possível realizar algumas simplificações no modelo descrito anteriormente (GARNETT et al., 1983a).

Sabendo-se que a adição de eletrólitos desloca os íons $H^{+}$da camada de Stern das micelas, resultando em $H_{T}>>H_{s}$ e em $K_{H / X} \approx 1$, pode-se simplificar a equação (37) da seguinte forma: 


$$
H_{s}+\frac{X_{T} \cdot H_{s}}{K_{H / X} \cdot H_{T}}=\beta \cdot C
$$

Dessa forma, obtém-se uma equação de primeira ordem em relação a $H_{s}$ :

$$
H_{s}=\frac{\beta \cdot C \cdot K_{H / X} \cdot H_{T}}{K_{H / X} \cdot H_{T}+X_{T}}
$$

Essa equação (41) substitui a equação (38) na determinação de $H_{s}$ quando houver presença de eletrólito adicionado no meio, como é o caso deste trabalho.

Como o valor de CMC é reduzido na presença de eletrólitos, conforme comprovado na pesquisa realizada por Corrin e Harkins (1947), tem-se:

$$
C=C_{T}-C M C \approx C_{T}
$$

\subsubsection{Considerações a respeito dos parâmetros do modelo}

Estudos sobre considerações geométricas da superfície micelar mostram que $\bar{C}_{s}$ depende do empacotamento de monômeros na micela e que uma faixa de variação esperada seria 5-7 $\mathrm{mol} / \mathrm{dm}^{3}$ para números de agregação na faixa entre 62 e 87 e supondo micelas de formato esférico. Isto corresponderia a uma faixa de variação do valor de $V_{s}$ entre 0,20 e 0,14 $\mathrm{dm}^{3} / \mathrm{mol}$, sendo o valor de $0,14 \mathrm{dm}^{3} / \mathrm{mol}$ o mais indicado para condições de temperatura próximas à ambiente e na ausência de eletrólitos segundo Garnet et al. (1983a).

$\mathrm{O}$ valor de $V_{s}$ mais adequado quando a reação ocorre em altas temperaturas e em alta concentração de eletrólito seria de $0,2 \mathrm{dm}^{3} / \mathrm{mol}$ (GARNETT et al., 1983a). No estudo realizado por Bunton e Wolfe (1973) o valor adotado para $V_{s}$ foi de 0,26 1/mol para o DSS.

O volume efetivo da camada de Stern pode, em uma aproximação inicial, ser considerado equivalente ao volume total da micela. $\mathrm{O}$ volume da micela, por sua vez pode ser estimado por meio da massa molar do tensoativo. Diferentes surfactantes apresentam 
aproximadamente a mesma densidade micelar e seu valor varia entre 0,9 e $1,1 \mathrm{~g} / \mathrm{cm}^{3}$ (MARTINEK et al., 1977.).

Admite-se que $\beta<1$ e um valor de referência para esse parâmetro seria de $0,75+/-0,10$ para o DSS em condições de temperatura próximas à ambiente. É esperado que o valor de $\beta$ seja independente da natureza e da concentração do contra-íon para íons de mesma carga (GARNETT et al., 1983a). Uma redução no valor de $\beta$ seria esperada com o aumento da temperatura (BARRY; WILSON, 1978; GARNETT et al., 1983a). No entanto acredita-se que por não ser uma variação muito significativa ela não será considerada neste estudo.

Outras referências para o valor de $\beta$ na temperatura de $25^{\circ} \mathrm{C}$ são apresentadas para o DSS no estudo realizado por Sasaki et al. (1975). O valor encontrado para $\beta$ foi de 0,73 $\left(25^{\circ} \mathrm{C}\right)$. E segundo os autores o valor de $\beta$ não apresentaria tendência consistente de variação na presença de eletrólitos ou com o aumento da concentração do tensoativo.

O grau de dissociação $\alpha$ pode ser correlacionado com o grau de associação do contra-íon à micela $(\beta)$ da seguinte forma:

$$
\alpha=1-\beta
$$

A extensão das alterações observadas para $\beta$ seria muito pequena e o valor de $\alpha$ estaria na faixa de 0,1-0,3 para a grande maioria dos tensoativos existentes. Segundo Romsted (1977) seria necessário um aumento de 10 a 100 vezes na concentração de eletrólitos no meio para que uma diferença significativa no valor de $\alpha$ fosse observada.

A eventual transição das micelas do formato esférico para o formato cilíndrico seria acompanhada por uma perda de água na superfície da micela e resultaria em um maior valor para $\beta$ e também para $K_{H / X}($ KHAN, 2010).

No estudo realizado por Garnett et al. (1983a) o valor de $k_{s}$ encontrado par ao DSS foi de $1,8 \cdot 10^{-5} \mathrm{dm}^{3} /($ mol.s $)$ a $90^{\circ} \mathrm{C}$. 
A constante de troca iônica não seria afetada pela adição de $\mathrm{HCl}$, essa hipótese pode ser adotada quando a concentração de tensoativo está muito acima da CMC e da concentração de HCl (BUNTON; ROMSTED; SMITH, 1978).

No estudo realizado por Quina e Chaimovich (1979) foram avaliadas derivações do modelo de troca iônica em soluções micelares e foi explorado, através de cálculos realizados utilizando-se as equações apresentadas, os efeitos esperados para determinadas condições experimentais. Os valores de $\mathrm{CMC}, \beta$ e $K_{H / X}$ foram supostos constantes e não dependentes da concentração de tensoativo no meio ainda que haja controvérsias, como, por exemplo, a respeito do valor de $K_{H / X}$ que seria dependente das concentrações relativas de $\mathrm{Na}^{+}$e $\mathrm{H}^{+}$, da concentração total desses íons e da concentração total de tensoativo.

No estudo realizado por Chaimovich et al. (1979) ainda que em princípio seja possível determinar a concentração de $\mathrm{OH}^{-}$, ou de forma análoga, $\mathrm{H}^{+}$livre no meio, por meio de leituras de $\mathrm{pH}$ ou medidas de condutividade esses métodos não teriam dado resultado satisfatório nos ajustes realizados utilizando-se o modelo de troca iônica.

Na pesquisa realizada por Quina et al. (1980) as variações nos parâmetros da simulação não permitiram um bom ajuste ao modelo. Os desvios entre os valores calculados e os dados experimentais só diminuíram para valores de $\beta$ muito pequenos, menor do que 0,1 . Esses ajustes foram realizados impondo que o valor de $K_{O H / B r}$ fosse o mesmo em todas as condições.

No estudo realizado por Barry e Wilson (1978) são apresentados valores encontrados para CMC e para o grau de dissociação $\alpha$ na faixa de $0,24-0,48$ para temperaturas na faixa entre 278 e $333 \mathrm{~K}$ para alguns tensoativos com estrutura semelhante ao composto aqui estudado. No estudo realizado por Corrin e Harkins (1947) também são apresentados dados de determinação de $\mathrm{CMC}$ na temperatura de $25^{\circ} \mathrm{C}$ para o DSS. 
Na pesquisa realizada por Bunton e Wolfe (1973) é feita a seguinte aproximação para $H_{w}$ :

$$
H_{w} \approx 10^{-p H}
$$

A estimativa para o valor de $H_{T}$ não seria muito precisa na presença de buffers, segundo Romsted (1977), como é o caso do presente estudo onde se tem no meio a presença de fosfato de sódio.

A presença de eletrólitos no meio altera não só o formato das micelas - o que pode, por si só, afetar a taxa de reação na superfície da micela - como também interfere na aproximação realizada ao relacionar-se a concentração $\mathrm{H}^{+}$com o valor do $\mathrm{pH}$ conforme indicado na equação (44).

A presença de alcoóis de cadeias lineares em soluções de tensoativos também provoca alterações um aumento do tamanho da micela e um decréscimo, portanto, da sua densidade de carga o que resulta em um aumento do grau de ionização $\alpha$ e conseqüentemente uma redução na concentração de íons na superfície da micela, influenciando a taxa de reação de processos modificados pela presença de micelas. A constante de troca iônica também seria dependente da concentração de álcool no meio, mas através de testes realizados por Rodríguez et al. (2002) foi possível observar que o valor da constante de troca iônica apresenta pouca variação quando comparada à variação observada para o grau de ionização na presença e na ausência de álcool.

\subsubsection{Desvantagens e limitações do modelo teórico}

O tratamento utilizando o modelo de troca iônica teria se mostrado insatisfatório para altas concentrações de $\mathrm{HCl}$ no meio, o que seria esperado porque as hipóteses a respeito da estrutura micelar são afetadas quando há um grande número de íons $H^{+}$interagindo de com a micela aniônica e deslocando os íons $\mathrm{Na}^{+}$da camada de Stern (BUNTON; WOLFE, 1973). 
É importante mencionar que no estudo realizado por Garnett et al. (1983a) foram observadas diferenças significativas entre os valores previstos pelo modelo e os dados experimentais, isso, segundo os autores, pode ser explicado pelos desvios em relação à idealidade nas soluções de alta força iônica e pelo fato de ter sido adotado um valor fixo para o parâmetro $\beta$ que pode apresentar variações ao longo da reação.

Outra desvantagem, observada por Khan (2010) é a de que o perfil de velocidade calculado pode apresentar mais de uma combinação dos vários parâmetros.

De um modo geral a aplicabilidade do modelo está relacionada à dificuldade em avaliar uma relação entre a concentração dos reagentes na fase micelar e alterações no meio reacional quando os parâmetros que possibilitam essa relação, como a CMC, o grau de ionização, a constante de troca iônica são determinados de forma independente, ou seja, em condições diferentes das do meio reacional, e são considerados invariáveis com a adição de tensoativos ou eletrólitos.

O modelo apresenta problemas, mas descreve ou explica adequadamente algumas reações, especialmente aquelas onde as propriedades micelares são pouco afetadas pelas espécies que participam da reação.

O modelo falha, segundo Kahn (2010), quando os íons que estão competindo apresentam diferente afinidade pela micela iônica e também quando a reação acontece na presença de alta concentração de contra-íons (acima de 0,2M).

Segundo estudo realizado por Bunton, Romsted e Smith (1978) o modelo de pseudo-fase seria satisfatório para os casos em que a concentração de tensoativo encontra-se acima da CMC e desde que não existam no meio agentes que interfiram na estrutura micelar.

\subsection{Modelo experimental de redes neurais artificiais}

O modelo de redes neurais artificiais consiste em um conjunto de técnicas computacionais inspirados na estrutura neural de organismos inteligentes e que são capazes 
de reconhecer padrões através da experiência. O potencial para uso de redes neurais artificiais $(\mathrm{RN})$ no tratamento de dados experimentais é muito interessante pois torna-se possível simular processos não-lineares.

A maioria dos processos químicos apresenta fortes não-linearidades que dificultam a obtenção de modelos fenomenológicos, a ponto de, em alguns casos, conseguir-se apenas um modelo extremamente simplificado, válido em condições muito específicas. É exatamente nessa área que as redes neurais surgem como uma técnica interessante de ser empregada, devido à sua característica de "aprender" o que ocorre no processo. Pode-se contornar, assim, em muitos casos, as dificuldades de obtenção de modelos fenomenológicos representativos do processo

Trata-se de um modelo empírico pois as redes neurais conseguem simular o que acontece no sistema sem efetivamente modelar os fenômenos físico-químicos que o governam e, de acordo com Kóvacs (1996), são consideradas aproximadoras universais.

As etapas para o desenvolvimento de um modelo de rede neural são: análise do processo e construção da base de dados, configuração de uma estrutura de rede neural e, por último, treinamento ou aprendizado da rede.

A fase de aprendizado ou treinamento exige a apresentação da base de dados à rede por milhares de vezes. A metodologia para a fase de treinamento de redes neurais que tem sido mais amplamente utilizada, segundo Haykin (1999), é conhecida como método de retropropagação (backpropagation) e deriva do método de otimização do gradiente descendente.

A rede neural mais comumente empregada na modelagem e simulação de processos químicos é a FFNN (feedforward network). Nesta rede, os neurônios de uma camada são conectados a todos os neurônios da camada seguinte. A informação segue uma única direção e o modelo é formado por três camadas conforme ilustrado na Figura 5. 


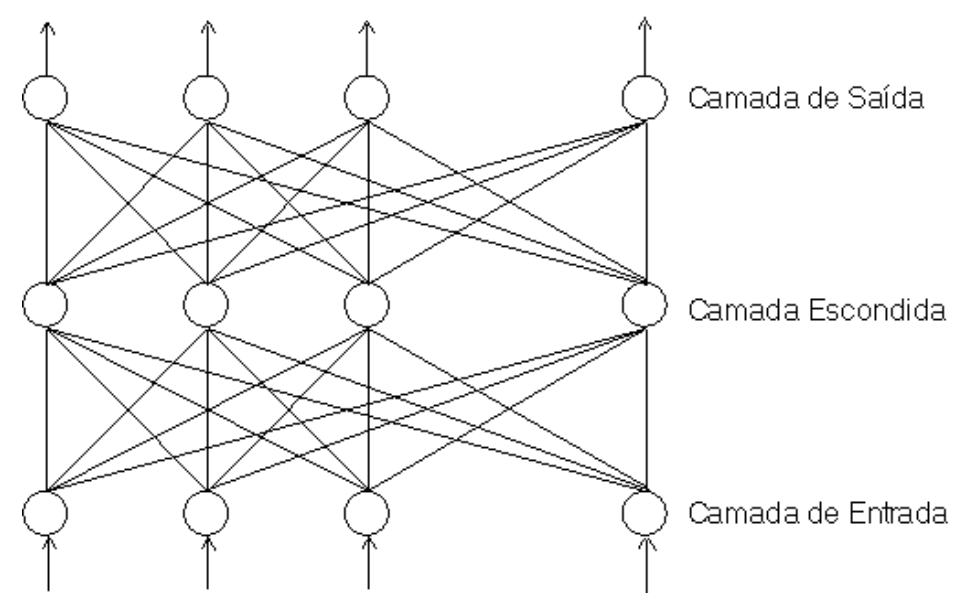

Figura 5- Esquema de arquitetura de rede neural artificial com três camadas

A primeira camada, denominada camada de entrada, é camada na qual se encontram as variáveis de entrada ou independentes, essa camada não executa nenhum processamento. A camada intermediária é chamada camada oculta, trata-se de uma camada de processamento. A camada de saída é a última camada e na qual se encontram as variáveis de saída ou dependentes.

Cada informação que sai de um neurônio de uma camada $i$ é ponderada por um dado peso - $W_{i, j}$ - e enviada a todos os neurônios da camada seguinte $j$. A convergência da rede neural está ligada à melhor escolha possível do conjunto de pesos $W$.

A fim de diminuir as dificuldades de convergência, todos os dados do conjunto de aprendizagem são normalizados entre zero e um. Além dos dados de entrada, alimenta-se também um valor de referência (bias) à rede.

Cada neurônio é um processador que calcula a soma ponderada de todos os sinais interconectados da camada anterior somada a um bias ou limite de ativação. Todas as variáveis de entrada $X_{i}$ são ponderadas com um valor $W_{i, j}$ e somadas, conforme a equação (45):

$$
S_{j}=\sum_{i=1}^{n} W_{i, j} \cdot X_{i}+W_{n+1, j}
$$


A saída do neurônio - $O_{j}$ - é gerada pela função de transferência, esta função pode ser expressa de várias formas e normalmente é usada a função sigmoidal conforme apresentado na equação (47):

$$
\begin{aligned}
& O_{j}=f\left(S_{j}\right) \\
& f\left(S_{j}\right)=\frac{1}{1+e^{-S_{j}}}
\end{aligned}
$$

\subsubsection{Algoritmo de treinamento de redes neurais}

O treinamento de uma rede neural (ou aprendizado) consiste de uma adaptação dos pesos - $W_{i, j}$ - aplicados sobre as informações entre as camadas de neurônios, de forma a minimizar o erro quadrático, expresso na forma da função $E$, definido como:

$$
E=\sum_{m=1}^{r} \sum_{k=1}^{p}\left(Y_{k, c a l c}^{(m)}-Y_{k, \exp }^{(m)}\right)^{2}
$$

Esta função representa o valor acumulado para todos os dados experimentais (de 1 a $r$ ) que fazem parte do conjunto de aprendizado (learning set), das somas dos erros quadráticos entre os valores experimentais e os calculados pela rede neural, para todas as saídas da rede

(de 1 a $p$ ). Onde $Y_{k, \exp }^{(m)}$ é proveniente do conjunto de dados alimentados em pares e $Y_{k, c a l c}^{(m)}$ é a saída obtida pela função de transferência aplicada aos neurônios da camada de saída.

O algoritmo mais utilizado para determinar o conjunto de pesos é o de retropropagação que consiste na minimização do resíduo quadrático - $E$ - com respeito a $W_{i, j}$. O gradiente $\frac{\delta E}{\delta W_{i, j}}$ é calculado, e, consequentemente, a direção a ser seguida no processo de minimização do resíduo é definida. Em cada passo da otimização, $m$, a atualização dos pesos pode ser dada pela equação (49).

$$
W_{i, j}^{(m+1)}=W_{i, j}^{(m)}+\Delta W_{i, j}^{(m)}
$$


Para a camada de saída, a variação dos pesos referentes ao neurônio de saída $k$, incidentes sobre a saída do neurônio $j$, da camada oculta, a cada iteração $m$, é dada pela equação (50):

$$
\Delta W_{j, k}^{(m)}=\eta \cdot f^{\prime}\left(S_{k}\right) \cdot\left(Y_{k}^{(m)}-O_{k}^{(m)}\right) \cdot O_{j}^{(m)}
$$

Onde $\eta$ representa um fator de aceleração, também conhecido como fator de amortecimento ou taxa de aprendizado.

Para a camada oculta, a variação dos pesos referentes ao neurônio oculto $j$, incidentes sobre a entrada $X_{i}$, a cada iteração $m$, é dada pela equação (51):

$$
\Delta W_{j, k}^{(m)}=\eta \cdot f^{\prime}\left(S_{j}\right)\left\{\left[\sum_{k=1}^{p} f^{\prime}\left(S_{k}\right) \cdot\left(Y_{k}^{(m)}-O_{k}^{(m)}\right) \cdot W_{j, k}^{(m-1)}\right] \cdot X_{i}^{(m)}\right\}
$$

Nas equações (50) e (51) $f^{\prime}$ é a derivada da função sigmoidal, dada pela equação (52):

$$
f^{\prime}\left(S_{j}\right)=\frac{e^{-\left(S_{j}\right)}}{\left(1+e^{-\left(S_{j}\right)}\right)^{2}}
$$

A cada iteração os pesos entre a camada oculta e de saída são corrigidos, na seqüência são corrigidos os pesos entre as camadas de entrada e oculta. Inicialmente os pesos são escolhidos aleatoriamente. Após a apresentação do primeiro par $(x, y)$ os pesos são corrigidos e então o segundo par é apresentado, os pesos são novamente corrigidos e assim por diante.

Os critérios de parada podem ser o número de apresentações ou um valor limite para a diferença entre o erro calculado na apresentação anterior e a atual. 


\section{MATERIAIS E MÉTODOS}

\subsection{Planejamento experimental}

As variáveis de interesse para o estudo e que apresentam reconhecida interferência na taxa de reação de hidrólise segundo as informações encontradas em literatura foram analisadas utilizando-se um planejamento experimental fracionado em dois níveis conforme apresentado na Tabela 2.

Tabela 2- Variáveis avaliadas e níveis adotados no planejamento experimental

\begin{tabular}{|c|c|c|}
\hline Variável & Descrição & Faixa \\
\hline Temperatura & $\begin{array}{l}\text { O transporte, manuseio e estocagem do produto alvo do estudo é } \\
\text { realizado sem aquecimento. No entanto, tanto nos tanques de estocagem } \\
\text { quanto nos veículos de transporte e embalagens expostas ao sol, a } \\
\text { temperatura pode atingir valores elevados }\left(70-80^{\circ} \mathrm{C}\right) \text {. Também é possível } \\
\text { que o produto atinja temperaturas mais elevadas durante a reação de } \\
\text { neutralização do sulfatado ácido. A faixa de temperatura avaliada neste } \\
\text { estudo está compatível com as faixas de temperatura estudadas na } \\
\text { literatura pesquisada para que seja observada diferença no teor de ativos } \\
\text { em um curto espaço de tempo. }\end{array}$ & $80-100^{\circ} \mathrm{C}$ \\
\hline$X 2$ & $\begin{array}{l}\text { O pH especificado para o produto acabado é de 7, } 0 \text { - 9,0 e é ajustado } \\
\text { após a neutralização com } \mathrm{NaOH} \text { pela adição de ácido fosfórico. No } \\
\text { planejamento de experimentos será avaliado qual o efeito da maior } \\
\text { acidez do meio na taxa de reação de hidrólise do produto acabado. O teor } \\
\text { de acidez inicial do meio nos experimentos realizados foi ajustado } \\
\text { através da adição de ácido clorídrico - } \mathrm{HCl} \text { - ao início da reação. }\end{array}$ & $4,0-7,0$ \\
\hline $\begin{array}{l}\text { Teor de insulfatados } \\
\text { X3 }\end{array}$ & $\begin{array}{l}\text { Esse teor corresponde à fração de material não iônico (álcool etoxilado } \\
\text { 2EO) não reagida durante a reação de sulfatação e presente no produto } \\
\text { acabado em baixas concentrações, usualmente abaixo de } 1 \% \text {. }\end{array}$ & $0,80-1,20 \%$ \\
\hline $\begin{array}{l}\text { Teor de eletrólito } \\
\text { como } \mathrm{NaCl} \\
X 4\end{array}$ & $\begin{array}{l}\text { Teores mínimos de cloreto de sódio são esperados no produto acabado e } \\
\text { indicam o uso de matérias-primas de boa qualidade. }\end{array}$ & $0,04-0,20 \%$ \\
\hline $\begin{array}{l}\text { Teor de eletrólito } \\
\text { como } \mathrm{Na}_{2} \mathrm{SO}_{4} \\
X 5\end{array}$ & $\begin{array}{l}\text { Baixos teores de sulfato de sódio indicam que o processo de sulfatação é } \\
\text { bem controlado e refletem o uso de matérias-primas de boa qualidade e } \\
\text { com baixo teor de umidade presente no meio. }\end{array}$ & $0,40-0,80 \%$ \\
\hline
\end{tabular}


Os testes foram realizados utilizando-se uma amostra comercial de LESS 2EO em solução aquosa a $27 \%$ de ativos. O ajuste do teor de insulfatados e do teor de eletrólitos foi realizado no início dos experimentos com base na análise do teor inicial presente.

As faixas de variação para o planejamento experimental foram adotadas com base na especificação técnica do produto e suas possíveis condições de estocagem adotando uma extrapolação para avaliação do seu efeito na velocidade da reação de hidrólise.

A mistura reacional foi carregada no reator já previamente aquecido para a temperatura desejada. A massa total carregada no reator foi equivalente em todos os experimentos realizados.

É importante também mencionar que foi necessário um ajuste com água em cada experimento para que concentração em massa da matéria ativa na solução aquosa permanecesse constante ainda que diferentes massas de cloreto de sódio, sulfato de sódio, ácido clorídrico e álcool etoxilado 2EO fossem adicionadas em cada experimento.

$\mathrm{O}$ número de ensaios necessários para se fazer um planejamento fatorial $2^{\mathrm{k}}$ completo aumenta rapidamente com $\mathrm{k}$, o número de fatores investigados, assim como o número de interações de ordem alta. Na maioria dos casos, essas interações têm valores pequenos e são destituídas de qualquer importância prática (BARROS; SCARMINIO; BRUNS, 2003).

Como na expansão em série de uma função, os efeitos principais, ou de primeira ordem, tendem a ser maiores que as interações de dois fatores, ou de segunda ordem, que por sua vez são mais importantes que as interações de três fatores, e assim por diante, essa tendência se acentua para efeitos de ordem mais alta: se esses efeitos não são significativos, determinar seu valor não é motivo bastante para fazer todos os ensaios de um planejamento completo e nesses casos opta-se pela realização de um planejamento fatorial fracionado (BARROS; SCARMINIO; BRUNS, 2003).

Outro ponto a ser considerado é que quando o número de fatores aumenta, crescem as chances de que um ou mais deles não afetem significativamente a resposta, seja por meio de efeitos principais, seja por meio de efeitos de interação. 
Segundo Barros, Scarminio e Bruns (2003) quando não se conhece a relação completa de todas as variáveis que afetam significativamente a resposta deve-se estudar, em um estágio inicial, o maior número possível de variáveis para não correr o risco de excluir fatores que podem vir a ser importantes (BARROS; SCARMINIO; BRUNS, 2003). Para não aumentar o número de ensaios, optou-se, neste estudo, por um planejamento fracionado em substituição a um planejamento fatorial completo.

O planejamento fatorial fracionado utilizado foi do tipo $2_{I I I}^{5-2}$, de resolução III, ou seja, os efeitos principais são confundidos com interações duplas. O total de experimentos em um fatorial do tipo $2_{I I I}^{5-2}$ é de 8 . Foi planejada a realização de um total de 11 experimentos incluindo-se três repetições do ponto central.

Os experimentos foram realizados nas condições descritas na Tabela 3 com repetição do ponto central.

Tabela 3- Características do projeto de planejamento experimental

\begin{tabular}{cc}
\hline Fatores & 5 \\
Resolução & 3 \\
Experimentos & 12 \\
Replicatas & 1 \\
Fração & $1 / 4$ \\
Total de pontos centrais & 3 \\
\hline
\end{tabular}

A Tabela 4 descreve as condições experimentais. 
Tabela 4- Dados do planejamento experimental

\begin{tabular}{ccccccccc}
\hline & & & & $\mathrm{X} 1$ & $\mathrm{X} 2$ & $\mathrm{X} 3$ & $\mathrm{X} 4$ & $\mathrm{X} 5$ \\
\cline { 5 - 9 } Ordem & Experimento & Ponto Central & Bloco & $\begin{array}{c}\text { Temperatura } \\
\left({ }^{\circ} \mathrm{C}\right)\end{array}$ & $\begin{array}{c}\mathrm{pH} \\
\text { inicial }\end{array}$ & $\begin{array}{c}\text { Teor de insulfatados } \\
(\%, \mathrm{AE} 2 \mathrm{EO})\end{array}$ & $\begin{array}{c}\text { Teor de eletrólito } \\
(\%, \mathrm{NaCl})\end{array}$ & $\begin{array}{c}\text { Teor de eletrólito } \\
\left(\%, \mathrm{Na}_{2} \mathrm{SO}_{4}\right)\end{array}$ \\
\hline 1 & 1 & 1 & 1 & 80 & 4,0 & $0,80 \%$ & $0,20 \%$ & $0,80 \%$ \\
2 & 4 & 1 & 1 & 100 & 4,0 & $0,80 \%$ & $0,04 \%$ & $0,40 \%$ \\
3 & 3 & 1 & 1 & 80 & 7,0 & $0,80 \%$ & $0,04 \%$ & $0,80 \%$ \\
4 & 7 & 1 & 1 & 100 & 7,0 & $0,80 \%$ & $0,20 \%$ & $0,40 \%$ \\
5 & 8 & 1 & 1 & 80 & 4,0 & $1,20 \%$ & $0,20 \%$ & $0,40 \%$ \\
6 & 5 & 1 & 1 & 100 & 4,0 & $1,20 \%$ & $0,04 \%$ & $0,80 \%$ \\
7 & 6 & 1 & 1 & 80 & 7,0 & $1,20 \%$ & $0,04 \%$ & $0,40 \%$ \\
8 & 10 & 1 & 1 & 100 & 7,0 & $1,20 \%$ & $0,20 \%$ & $0,80 \%$ \\
9 & 11 & 0 & 1 & 90 & 5,5 & $1,00 \%$ & $0,12 \%$ & $0,60 \%$ \\
10 & 9 & 0 & 1 & 90 & 5,5 & $1,00 \%$ & $0,12 \%$ & $0,60 \%$ \\
11 & 2 & 0 & 1 & 90 & 5,5 & $1,00 \%$ & $0,12 \%$ & $0,60 \%$ \\
\hline
\end{tabular}

As relações geradoras de confundimentos do experimento são: $\mathrm{D}=\mathrm{AB}$ e $\mathrm{E}=\mathrm{AC}$ e dessa forma tem-se: $\mathrm{I}=\mathrm{ABD}=\mathrm{ACE}=\mathrm{BCDE}$.

Supondo que as interações de três ou mais fatores teriam efeito desprezível (BOX; HUNTER, W.; HUNTER, J., 1978) tem-se na Tabela 5 um resumo dos confundimentos:

Tabela 5- Tabela de confundimentos

\begin{tabular}{ccl}
\hline $\mathrm{X} 1$ & $\mathrm{~A}$ & $\mathrm{~A}=\mathrm{BD}=\mathrm{CE}$ \\
$\mathrm{X} 2$ & $\mathrm{~B}$ & $\mathrm{~B}=\mathrm{AD}$ \\
$\mathrm{X} 3$ & $\mathrm{C}$ & $\mathrm{C}=\mathrm{AE}$ \\
$\mathrm{X} 4$ & $\mathrm{D}$ & $\mathrm{D}=\mathrm{AB}$ \\
$\mathrm{X} 5$ & $\mathrm{E}$ & $\mathrm{E}=\mathrm{AC}$ \\
$\mathrm{X} 2 * \mathrm{X} 3$ & $\mathrm{BC}$ & $\mathrm{BC}=\mathrm{DE}$ \\
$\mathrm{X} 2 * \mathrm{X} 5$ & $\mathrm{BE}$ & $\mathrm{BE}=\mathrm{CD}$ \\
\hline
\end{tabular}

As respostas utilizadas para a análise dos resultados são apresentadas na Tabela 6 . 
Tabela 6- Respostas utilizadas na análise dos resultados

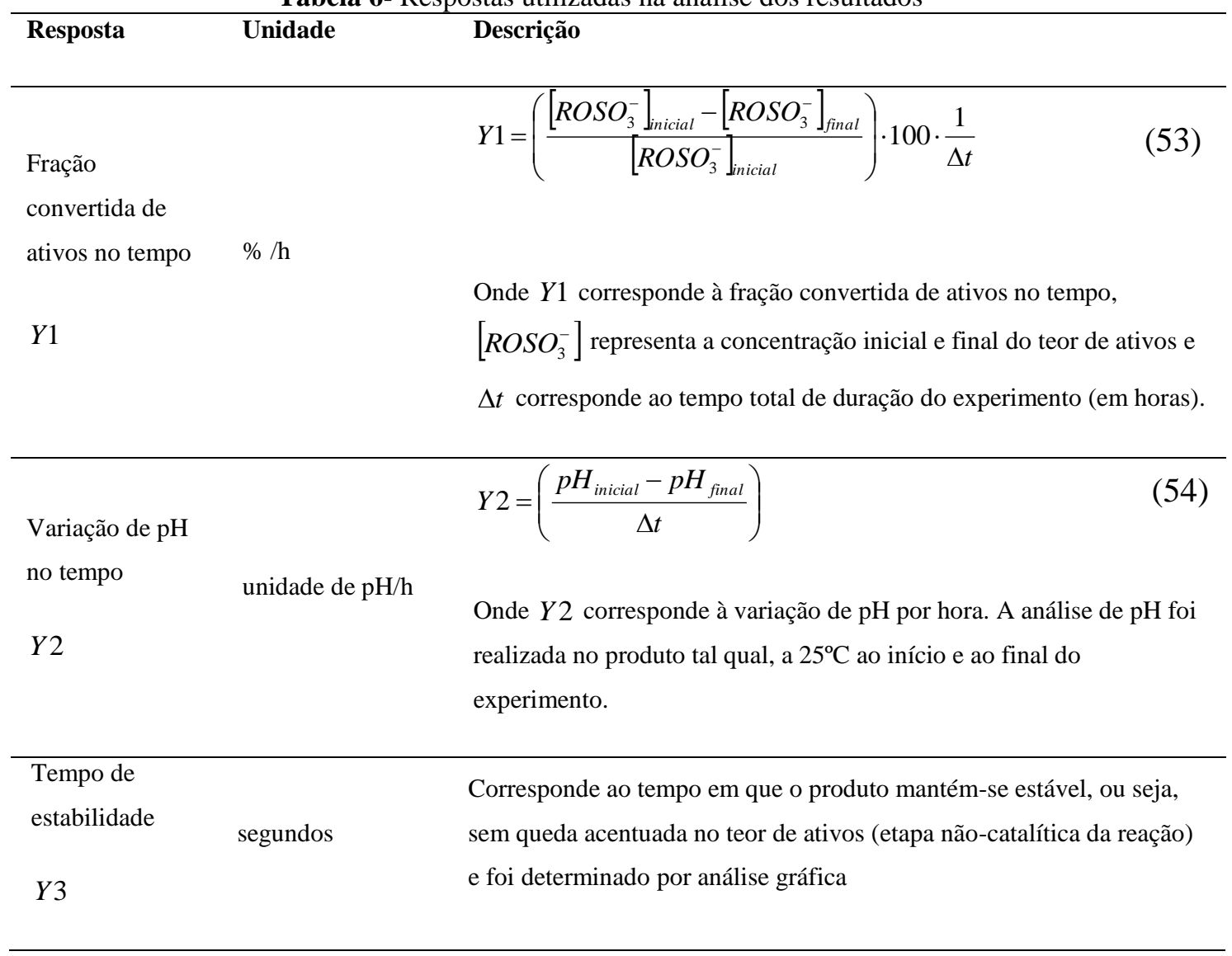

\subsection{Materiais}

Os testes foram realizados utilizando uma amostra comercial de LESS $2 \mathrm{EO}$ em solução aquosa a $27 \%$ de concentração (ALKOPON N Oxiteno).

Neste trabalho foi utilizada uma amostra comercial em vez de uma amostra sintetizada e purificada. Segundo estudo realizado por Bethell et al. (2001) as amostras comerciais de DSS testadas não apresentaram distinção de resultados quando comparadas com amostras de DSS sintetizadas em laboratório a partir de 1-dodecanol.

A especificação técnica para o produto alvo do estudo é descrita na Tabela 7. 
Tabela 7- Especificação do produto acabado

\begin{tabular}{lcc}
\hline Requisito de Qualidade & Min & Max \\
\hline Aparência, $25^{\circ} \mathrm{C}$ & 7,0 & líquido \\
pH, 10\% de massa do produto em água, $25^{\circ} \mathrm{C}$ & 9,0 \\
Matéria ativa, \% em massa & 26,2 & 27,8 \\
Sulfato de sódio, \% em massa & 0,6 \\
Insulfatados, \% em massa & 0,9 \\
Cloreto de sódio, \% em massa & 0,10 \\
Ferro, ppm & 3 \\
Dioxana, base $100 \%$, ppm & 100 \\
\hline
\end{tabular}

O lote foi analisado antes do início dos testes para cálculo das massas necessárias para ajuste nos teores de eletrólitos e insulfatados. Os resultados são apresentados a seguir:

- Matéria ativa (PM 384): $(27,2+/-0,30) \%$

- Teor de insulfatados: $(0,80+/-0,34) \%$

- Teor de cloreto de sódio: $(0,04+/-0,01) \%$

- Teor de sulfato de sódio: $(0,35+/-0,01) \%$

- $\mathrm{pH}, 25^{\circ} \mathrm{C}: 7,3+/-0,4$

No início de cada experimento foi retirada uma amostra em $t=0$ para análise completa de alguns requisitos após o ajuste de massas.

O erro expresso para cada uma dessas análises foi calculado com base na avaliação de reprodutibilidade e repetibilidade realizada para o método através de uma série de ensaios com o objetivo de validação dessas metodologias de análise.

Os outros componentes presentes na amostra são subprodutos e impurezas, tais como dioxana, ferro e preservante, que estão presentes em concentração muito baixa e, de acordo com o que foi observado na literatura estudada, teriam efeito desprezível na taxa de reação de hidrólise nessas concentrações.

$\mathrm{O}$ álcool etoxilado 2EO utilizado para o ajuste do teor de insulfatados foi uma amostra comercial (ULTROL L 20 Oxiteno).

O ácido clorídrico, o cloreto de sódio e o sulfato de sódio, todos com alto grau de pureza, foram fornecidos pela empresa CARLO ERBA. 
As soluções de $\mathrm{NaOH}$ utilizadas na titulação das alíquotas de reação para determinação da conversão da reação foram preparadas em bancada em diferentes concentrações a partir de água deionizada e $\mathrm{NaOH}$ fornecida pela empresa SOVEREIGN.

\subsection{Equipamentos}

O reator utilizado nos experimentos foi um vaso hermético de vidro com liga de aço inox à base de níquel com resistência ao ácido clorídrico em altas concentrações e temperaturas elevadas. Também apresenta alta resistência à fissuração por esforços e corrosão.

Esse reator é equipado com agitador do tipo âncora, com funil para carregamento de matérias-primas e com termoelemento para acompanhamento da temperatura ao longo da reação. Esse equipamento possui camisa de aquecimento e resfriamento com água e banho termostático acoplado (Figura 6).

As amostragens realizadas ao longo da reação para acompanhamento da conversão foram feitas através do ponto de amostragem localizado na base do reator.

Para a pesagem das matérias-primas e ajuste do teor de eletrólitos e de insulfatados foi utilizada balança analítica calibrada. A titulação das amostras coletadas em processo para determinação do teor de conversão da reação foi realizada utilizado-se um pHmetro calibrado. 


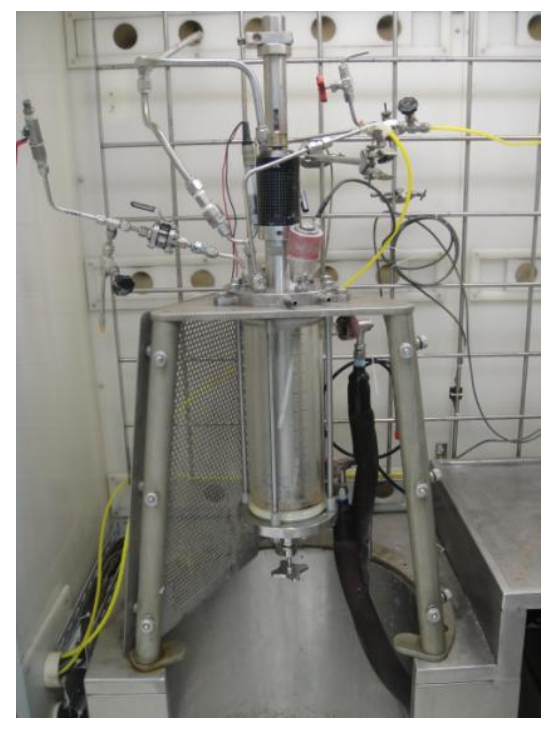

Figura 6- Foto do reator utilizado para realização dos experimentos

\subsection{Métodos de análise}

\subsubsection{Determinação do teor de ativos aniônicos por titulação com solução catiônica}

O método tem como princípio a técnica de volumetria em duas fases, na qual o agente aniônico é titulado com um reagente catiônico na presença de mistura de indicadores. Um dos indicadores forma com o agente aniônico um composto colorido solúvel na fase clorofórmio e, o outro reage com excesso de titulante na fase aquosa indicando o ponto final da titulação.

Para determinação do teor de ativos uma solução aquosa da amostra é agitada na presença de uma mistura de indicadores - azul de dissulfina e brometo de dimidium - e clorofórmio, em que um composto colorido (rosa), solúvel no solvente orgânico, é formado entre o surfactante aniônico e indicador catiônico (brometo de dimidium).

Uma solução padrão de surfactante catiônico - cloreto de benzalcônio (Hyamine 1622) é então adicionada aos poucos, agitando vigorosamente o sistema a cada adição. $\mathrm{O}$ surfactante catiônico desloca o indicador catiônico do complexo colorido e, assim, a coloração rosa muda para violeta até o aparecimento da cor azul. O ponto final é dado pelo volume anterior ao da coloração azul, pois na coloração azul já existe um excesso de solução 
padrão de surfactante catiônico, isso porque um excesso de solução padrão catiônica provoca a formação de um composto azul com o indicador aniônico (azul de dissulfina), solúvel em clorofórmio. Durante a transição do ponto final a fase orgânica passa de rosa para cinza, e, em seguida para azul.

O teor de ativos é então calculado com base no volume gasto da solução padrão e sua concentração, no volume de diluição e na massa utilizada de amostra e é reportado de acordo com o peso molecular do tensoativo aniônico analisado.

Essa análise foi utilizada para caracterizar a amostra inicial da amostra utilizada nos testes de hidrólise. A mesma análise foi realiza ao início e ao final de cada experimento para determinação da fração convertida de ativos no tempo $(Y 1)$.

O peso molecular utilizado no método de determinação de ativos para o produto é de 384 $\mathrm{g} / \mathrm{mol}$, que corresponde ao peso molecular médio do tensoativo LESS 2EO $\mathrm{R}\left(\mathrm{OCH}_{2} \mathrm{CH}_{2}\right)_{2} \mathrm{OSO}_{3} \mathrm{H}$ - no entanto, para as determinações de teor de ativo neste trabalho foi utilizado o peso molecular de $361 \mathrm{~g} / \mathrm{mol}$ que corresponde ao peso molecular do álcool etoxilado sulfatado desconsiderando-se o contra-íon de sódio - $\mathrm{R}\left(\mathrm{OCH}_{2} \mathrm{CH}_{2}\right)_{2} \mathrm{OSO}_{3}^{-}$- e que neste trabalho será referido de forma simplificada por $\mathrm{ROSO}_{3}^{-}$.

\subsubsection{Determinação do teor de insulfatados por cromatografia de troca iônica}

A amostra é solubilizada em etanol, filtrada e submetida a uma etapa de purificação de íons através de cromatografia de troca iônica, com resina de leito misto. Após a purificação a resina é separada por filtração e por evaporação elimina-se o etanol do filtrado e o resíduo é quantificado como teor de insulfatados da amostra.

A amostra é pesada, são feitas várias lavagens com etanol e por último a amostra é diluída com etanol, homogeneizada e filtrada. Após a filtração a solução é misturada com uma resina e é adicionada uma maior quantidade de etanol ao béquer, deixando a mistura sob agitação. A amostra então é novamente filtrada e a resina é lavada com etanol, sendo o filtrado recolhido no mesmo recipiente onde se encontra o filtrado. 
O etanol é então totalmente evaporado utilizando-se um banho a $80^{\circ} \mathrm{C}+/-5^{\circ} \mathrm{C}$ e o resíduo é então secado em estufa a $105^{\circ} \mathrm{C}+/-5^{\circ} \mathrm{C}$ por 10 minutos. O resíduo é transferido para o dessecador e é pesado após resfriado.

O teor de insulfatados é calculado a partir do peso do resíduo e do peso inicial da amostra de produto.

Essa análise foi utilizada para caracterizar o teor a amostra inicial de insulfatados $A E 2 E O$ - da amostra utilizada nos testes de hidrólise. Seu resultado foi utilizado para determinar a massa de álcool etoxilado a ser adicionada para correção do teor de insulfatados de acordo com o estipulado para cada experimento.

\subsubsection{Determinação do teor de cloretos pelo Método de Mohr}

O método baseia-se na precipitação do íon cloreto pelo nitrato de prata, formando cloreto de prata (branco) e a seguir precipitando-se o íon cromato, formando o cromato de prata (vermelho), porque este último tem produto de solubilidade maior.

A amostra é solubilizada em água e seu pH é corrigido se necessário da seguinte forma: se o pH for menor que 4,0 neutraliza-se com gotas de solução de $\mathrm{NH}_{4} \mathrm{OH}$, se o $\mathrm{pH}$ for maior que 9,0 neutraliza-se com gotas de solução de $\mathrm{HNO}_{3}$.

A titulação é feita com uma solução padronizada de nitrato de prata e utilizando-se o cromato de potássio como indicador até o aparecimento do primeiro precipitado de cor vermelho tijolo.

O teor de $\mathrm{NaCl}$ é reportado então com base no volume da solução padrão de nitrato de prata gasto na titulação, na normalidade da solução padrão utilizada e na massa de amostra pesada.

Essa análise foi utilizada para caracterizar a amostra utilizada nos testes de hidrólise. Seu resultado foi utilizado para determinar a massa a ser adicionada para correção desse teor de acordo com o estipulado para cada experimento. 


\subsubsection{Determinação do teor de sulfatos por volumetria de precipitação}

O procedimento utilizado foi o de determinação do sulfato por titulação com nitrato de chumbo. O método baseia-se na análise por volumetria de precipitação com o ponto final da titulação detectado pela formação de um complexo colorido.

O sulfato presente na amostra é titulado com solução de nitrato de chumbo formando um precipitado de sulfato de chumbo. O final da titulação é detectado pelo aparecimento de uma coloração púrpura, devido a um excesso de íons chumbo que complexa com o indicador ditizona.

A amostra em análise é diluída em água e é feito um ajuste do $\mathrm{pH}$ da solução adicionando-se $\mathrm{NH}_{4} \mathrm{OH}$ e, em seguida, $\mathrm{HNO}_{3}$, utilizando-se o indicador azul de bromofenol até que a solução adquira a coloração verde claro.

É adicionada então a solução de indicador ditizona e é feita uma titulação com uma solução de nitrato de chumbo padronizada até mudança de coloração de verde para o vermelho púrpura, que persista por no mínimo 1 minuto.

O teor de sulfato de sódio é calculado com base na normalidade da solução de nitrato de chumbo, no volume gasto do titulante e na massa de amostra.

Essa análise foi utilizada para caracterizar a amostra utilizada nos testes de hidrólise. Seu resultado foi utilizado para determinar a massa a ser adicionada para correção desse teor de acordo com o estipulado para cada experimento.

Esse método também foi utilizado para avaliação de uma estimativa da perda de ativos por hidrólise na reação comparando o teor de sulfato de sódio na amostra inicial e na amostra final. Isso porque o $\mathrm{HSO}_{4}^{-}$livre no meio nas amostras retiradas ao longo da reação é convertido em sulfato de sódio após a neutralização com $\mathrm{NaOH}$. 
Calcula-se o teor total de ativos consumido na reação considerando que cada mol de $\mathrm{SO}_{4}^{2-}$ liberado no meio corresponde a um mol de $\mathrm{ROSO}_{3}^{-}$consumido na reação de hidrólise de acordo com equações (6) a (8).

Os teores analisados como $\mathrm{Na}_{2} \mathrm{SO}_{4}$ são convertidos a teor de $\mathrm{SO}_{4}^{2-}$ usando-se as respectivas massas molares conforme descrito na equação (55).

$$
\% \mathrm{ROSO}_{3}^{-}=\left(\left(\% \mathrm{Na}_{2} \mathrm{SO}_{4}\right)_{\text {final }}-\left(\% \mathrm{Na}_{2} \mathrm{SO}_{4}\right)_{\text {inicial }}\right) \cdot \frac{\mathrm{MM}_{\mathrm{SO}_{4}^{2-}}}{M M_{\mathrm{Na}_{2} \mathrm{SO}_{4}}} \cdot \frac{M M_{\mathrm{ROSO}_{3}^{-}}}{M M_{\mathrm{SO}_{4}^{2-}}}
$$

Onde $\% \mathrm{Na}_{2} \mathrm{SO}_{4}$ representa o teor analisado de sulfato de sódio ao início e ao final da reação, \% $\mathrm{ROSO}_{3}^{-}$corresponde ao teor de ativo consumido na reação, $\mathrm{MM}_{\mathrm{SO}_{4}^{2-}}, \mathrm{MM}_{\mathrm{Na}_{2} \mathrm{SO}_{4}}$, $\mathrm{MM}_{\mathrm{ROSO}_{3}^{-}}$correspondem às massas molares do íon $\mathrm{SO}_{4}^{2-}$, do sal $\mathrm{Na}_{2} \mathrm{SO}_{4}$ e do ativo $\mathrm{ROSO}_{3}^{-}$.

\subsubsection{Determinação do valor de pH em soluções aquosas}

Nessa análise é feita a determinação do pH utilizando-se um potenciômetro (pHmetro), calibrado com solução padrão, em uma amostra tal qual ou diluída em água. Caso a amostra seja diluída em água deve-se utilizar água à temperatura ambiente ou $25+/-5^{\circ} \mathrm{C}$ e com $\mathrm{pH}$ entre 6,7 e 7,3 previamente destilada ou deionizada e fervida para eliminação de gás carbônico.

Caso a amostra precise ser diluída em água deve-se homogeneizar completamente a solução preparada sob agitação suave, preferencialmente com barra magnética, em frasco fechado para evitar aeração e reabsorção do gás carbônico do ar.

O eletrodo é então mergulhado na amostra, que deve estar sob agitação, aguarda-se a estabilização da leitura. 
O resultado é registrado e o eletrodo precisa então ser lavado com água antes de realizar nova medição.

A análise de $\mathrm{pH}$ foi realizada ao início da reação e também nas amostras retiradas ao longo da reação para acompanhamento.

\subsubsection{Determinação do teor de ativos por titulação com solução básica}

Para análise do teor de ativos residual ao longo da reação utilizou-se um procedimento distinto daquele anteriormente descrito de titulação com solução catiônica. Neste caso a titulação foi feita com solução de $\mathrm{NaOH}$.

Esse método, diferentemente dos métodos já descritos, não é um método usualmente utilizado para caracterização desse produto e foi elaborado especificamente para este estudo.

O método foi desenvolvido para determinação da concentração residual de ativos aniônicos durante a hidrólise com base na concentração de íons $\mathrm{H}_{3} \mathrm{O}^{+}$e $\mathrm{HSO}_{4}^{-}$liberados na reação. Para determinação da concentração de íons $\mathrm{H}_{3} \mathrm{O}^{+}$as amostras foram retiradas ao longo da reação, resfriadas para a temperatura ambiente e então tituladas com solução de $\mathrm{NaOH}$ padronizada.

A titulação das amostras foi feita, de acordo com o descrito no estudo realizado por Bethell et al. (2001), para a faixa de pH de 7,00 - 7,10 utilizando uma solução de $\mathrm{NaOH}$, um pHmetro calibrado e uma balança analítica para registro da quantidade utilizada de solução básica.

O cálculo da resposta de concentração residual de ativos foi realizado considerando que cada 1 mol consumido de $\mathrm{ROSO}_{3}^{-}$corresponde a 1 mol de $\mathrm{HSO}_{4}^{-}$liberado no meio, que, por sua vez, corresponde a $1 \mathrm{~mol}$ de $\mathrm{H}_{3} \mathrm{O}^{+}$. Cada mol de $\mathrm{H}_{3} \mathrm{O}^{+}$consome, durante a titulação das amostras, $1 \mathrm{~mol}$ de $\mathrm{NaOH}$. 
Nos casos em que o $\mathrm{HCl}$ foi adicionado no início da reação a quantidade de $\mathrm{H}_{3} \mathrm{O}^{+}$em $t=0$ foi descontada para o cálculo da concentração de $\mathrm{ROSO}_{3}^{-}$residual.

Assim sendo, para cada amostragem, o teor de ativos para um determinado instante da reação foi calculado da seguinte forma:

$$
\left[\mathrm{ROSO}_{3}^{-}\right]_{t}=\left[\mathrm{ROSO}_{3}^{-}\right]_{t=0}-\Delta\left[\mathrm{ROSO}_{3}^{-}\right]
$$

Onde $\left[\mathrm{ROSO}_{3}^{-}\right]_{t}$ corresponde à concentração de ativos (em mol $/ \mathrm{kg}$ ) em um determinado instante, $\left[\operatorname{ROSO}_{3}^{-}\right]_{t=0}$ representa o teor inicial de ativos analisado pelo método de titulação com solução catiônica e $\Delta\left[\mathrm{ROSO}_{3}^{-}\right]$corresponde ao total de ativos consumido pela reação sabendo-se que:

$$
\Delta\left[\mathrm{ROSO}_{3}^{-}\right]=\Delta\left[\mathrm{H}_{3} \mathrm{O}^{+}\right]
$$

Onde $\Delta\left[\mathrm{H}_{3} \mathrm{O}^{+}\right]$corresponde à concentração de íons $\mathrm{H}_{3} \mathrm{O}^{+}$liberados no meio pela reação.

$$
\Delta\left[\mathrm{H}_{3} \mathrm{O}^{+}\right]=\left[\mathrm{H}_{3} \mathrm{O}^{+}\right]_{t}-\left[\mathrm{H}_{3} \mathrm{O}^{+}\right]_{t=0}
$$

Onde $\left\lfloor\mathrm{H}_{3} \mathrm{O}^{+}\right\rfloor$corresponde à concentração total de íons $\mathrm{H}_{3} \mathrm{O}^{+}$em um determinado instante determinada pela titulação com solução de $\mathrm{NaOH}$ e $\left[\mathrm{H}_{3} \mathrm{O}^{+}\right]_{t=0}$ representa a concentração inicial de íons $\mathrm{H}_{3} \mathrm{O}^{+}$.

A concentração de íons $\mathrm{H}_{3} \mathrm{O}^{+}-\left[\mathrm{H}_{3} \mathrm{O}^{+}\right]_{t}$ e $\left[\mathrm{H}_{3} \mathrm{O}^{+}\right]_{t=0}$ - foi determinada a partir do volume consumido da solução de $\mathrm{NaOH}$, considerando a normalidade da solução utilizada e sabendo que lequivalente grama de $\mathrm{NaOH}$ corresponde a 1 mol de $\mathrm{NaOH}$.

O total de moles de $\mathrm{NaOH}$ consumido na titulação foi calculado da seguinte forma:

$$
[\mathrm{NaOH}]_{t}=\frac{N \cdot V_{t} \cdot f_{c}}{M_{\text {amostra }}}=\frac{N \cdot M_{\mathrm{NaOH}} \cdot f_{c}}{M_{\text {amostra }} \cdot d}
$$


Onde $[\mathrm{NaOH}]_{t}$ corresponde à concentração total (em mol $\left./ \mathrm{kg}\right)$ consumidos na titulação de uma amostra, $N$ representa a normalidade da solução básica utilizada, $V_{t}$ corresponde ao volume de solução de $\mathrm{NaOH}$ utilizado na titulação (em L), $M_{\text {amostra }}$ e $M_{\mathrm{NaOH}}$ correspondem respectivamente à massa de amostra e à massa de solução titulante utilizada, $f_{c}$ representa o fator de correção da solução titulante preparada em laboratório e $d$ corresponde à densidade da solução titulante e considerada igual a $1,0 \mathrm{~kg} / \mathrm{L}$.

Como:

$$
\begin{aligned}
& {[\mathrm{NaOH}]_{t}=\left[\mathrm{H}_{3} \mathrm{O}^{+}\right]_{t}} \\
& {[\mathrm{NaOH}]_{t=0}=\left[\mathrm{H}_{3} \mathrm{O}^{+}\right]_{t=0}}
\end{aligned}
$$

A titulação das amostras retiradas ao longo da reação é também importante para interromper a ocorrência da reação de perda de ativos neutralizando os íons $\mathrm{H}_{3} \mathrm{O}^{+}$livres no meio.

E por meio dessa análise chega-se ao teor de ativos residual ao longo da reação.

\subsubsection{Procedimento experimental}

Antes do início de cada experimento o reator foi lavado e secado a fim de evitar a contaminação com a água ou com resíduos de outros produtos.

O acionamento do aquecimento da água da camisa do reator para a temperatura estipulada no experimento foi realizado antes de iniciar o carregamento das matérias-primas. O reator então era carregado com as matérias-primas conforme a quantidade prevista em cada experimento e era acionada a agitação para homogeneização da mistura.

Após concluída a homogeneização, assim que o pH atingia um valor estável, era retirada a amostra inicial para análise do pH. Essa mesma amostra era então resfriada e em seguida titulada com solução de $\mathrm{NaOH}$ para determinação da concentração inicial de íons $\mathrm{H}_{3} \mathrm{O}^{+}$ 
antes do início da reação de hidrólise par aos casos em que houve adição de $\mathrm{HCl}$ ao início da reação para ajuste de $\mathrm{pH}$.

O acompanhamento da reação de hidrólise foi feito em cada experimento por meio de amostragens ao longo da reação, em intervalos de uma a duas horas. Essas amostras eram resfriadas para a temperatura de $25+/-1^{\circ} \mathrm{C}$ para leitura do $\mathrm{pH}$ e em seguida era realizada a titulação com solução de $\mathrm{NaOH}$.

Também foi realizado o registro e o monitoramento da variação da temperatura com o tempo através do termopar instalado no meio reacional para avaliar se a temperatura havia se mantido constante ao longo de todo o experimento.

Antes da retirada de cada amostra a agitação era desligada para observação do aspecto da mistura no reator a fim de verificar a ocorrência de separação de fases.

Conforme a reação evolui e a conversão aumenta a solução pode apresentar gelificação e separação de fases (KURZ, 1962). Esse efeito foi observado em alguns dos experimentos realizados, conforme ilustrado na Figura 7. Nesses casos o experimento teve que ser interrompido no momento da separação de fases porque não haveria mais garantia de que as amostragens, após separação de fases, estivessem homogêneas e representativas.

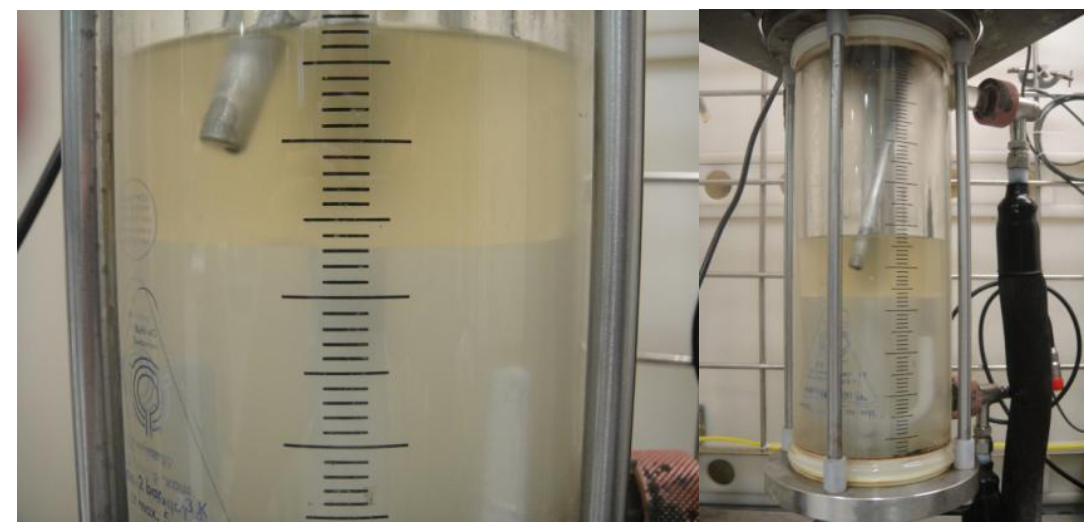

Figura 7- Ilustração da separação de fases observada em alguns experimentos 


\section{RESULTADOS E DISCUSSÃO}

Antes de definir quais seriam as condições a serem avaliadas no planejamento experimental foram realizados alguns testes para avaliação preliminar das variáveis envolvidas.

\subsection{Testes preliminares para avaliação do comportamento de hidrólise}

Em um primeiro experimento o objetivo foi avaliar o comportamento, a $100^{\circ} \mathrm{C}$, da amostra comercial do LESS 2EO em pH inicialmente neutro para definição do procedimento experimental a ser adotado.

A amostra deste teste preliminar foi previamente analisada:

- Matéria ativa (PM 384): (26,2+/-0,30)\%

- Teor de insulfatados: $(1,37+/-0,34) \%$

- Teor de cloreto de sódio: $(0,07+/-0,01) \%$

- Teor de sulfato de sódio: $(0,35+/-0,01) \%$

- $\mathrm{pH}, 25^{\circ} \mathrm{C}: 7,25+/-0,4$

Foram realizadas amostragens periódicas para acompanhamento da reação ao longo do tempo por um período de cerca de 40 horas e os resultados observados são apresentados na Figura 8. 

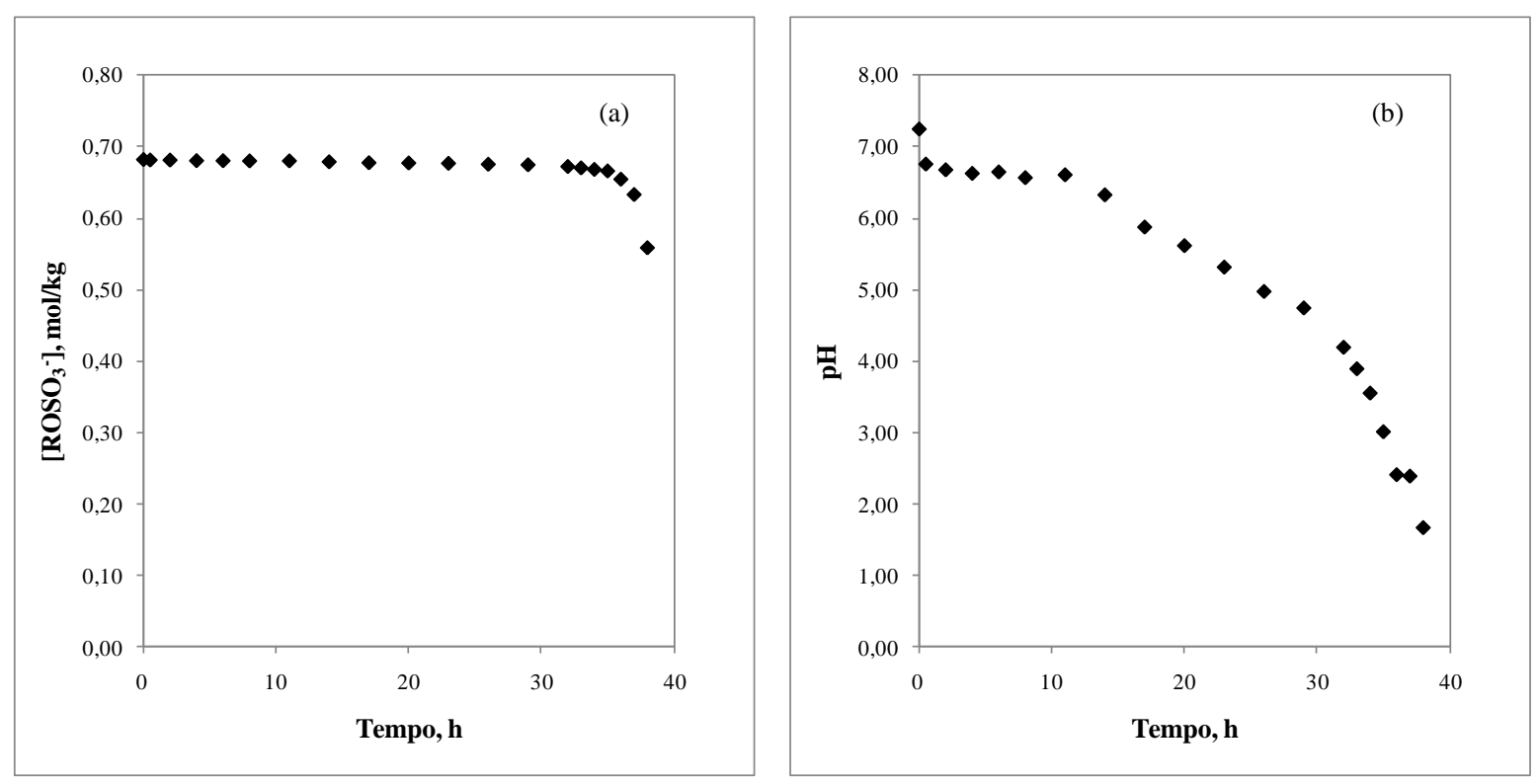

Figura 8- Acompanhamento ao longo da reação de hidrólise a $100^{\circ} \mathrm{C}$ e pH inicialmente neutro (a) variação no teor de ativos (b) variação no valor de $\mathrm{pH}, 25^{\circ} \mathrm{C}$

Observa-se uma diferença com relação à curva sigmóide apresentada no estudo realizado por Bethell et al. (2001) para o DSS - Figura 2 - o que já era esperado pois os produtos testados nas duas situações são produtos diferentes.

A principal diferença observada entre a Figura 2 e a Figura 8 foi que a amostra comercial de LESS 2EO manteve-se estável por um período muito maior até o início da queda no teor de ativos em comparação com o observado por Bethell et al. (2001) para a amostra de DSS. Essa diferença poderia indicar um comportamento de maior resistência à hidrólise do LESS 2EO quando comparado com o DSS o que, segundo Groot (1991), seria o comportamento esperado. Esse efeito também poderia ser atribuído à presença de buffer no produto avaliado neste estudo.

Observa-se, no entanto, que embora o tempo de estabilidade tenha sido maior para o LESS 2EO o comportamento foi semelhante àquele descrito na literatura, ou seja, o progresso da reação de hidrólise lento no início (etapa não-catalítica) com geração de íons hidrogênio que causam um decréscimo no valor do $\mathrm{pH}$, o que acelera a reação de hidrólise (etapa ácido-catalítica), que provoca uma queda acelerada do teor de ativos.

As análises referentes à amostra final são apresentadas a seguir: 
- Matéria ativa (PM 384): (23,0+/-0,30)\%

- Teor de cloreto de sódio: $(0,09+/-0,01) \%$

- Teor de sulfato de sódio: $(1,89+/-0,01) \%$

- $\mathrm{pH}, 25^{\circ} \mathrm{C}: 9,31+/-0,4$

O teor de matéria-ativa na amostra inicial analisado pelo método já conhecido de titulação com solução catiônica foi de 24,6\% (PM 361) e, na amostra final, foi de 21,6\% (PM 361).

O resultado de teor de ativos encontrado na amostra final utilizando o método da titulação com solução de $\mathrm{NaOH}$, método desenvolvido especialmente para este estudo, foi de 20,2\%. Os resultados obtidos estão próximos quando se compara o resultado de 20,2\% com o resultado obtido pelo método já validado e reconhecido da titulação com solução catiônica. A diferença observada é aceitável, especialmente considerando-se que o controle da titulação com solução de $\mathrm{NaOH}$ na amostra final desse experimento não foi feito de forma adequada pois o analista ultrapassou o ponto estipulado para a titulação tendo sido utilizada uma quantidade de solução básica maior do que a necessária.

Para os demais experimentos um cuidado especial foi solicitado ao analista no momento da titulação e, como consequiência, em todas as outras amostragens realizadas durante o planejamento experimental foi respeitada a faixa estipulada de 7,00 - 7,10 para o ponto final da titulação com solução de $\mathrm{NaOH}$ para determinação do teor de ativos residual.

Neste experimento preliminar, observa-se que durante o período de 38 horas em que o experimento foi realizado a $100^{\circ} \mathrm{C}$, partindo-se de uma amostra em $\mathrm{pH}$ neutro, houve perda significativa do teor de ativos já que partiu-se de uma amostra com 24,6\% de ativos e, ao final de 38 horas, o teor de ativos, segundo o mesmo método de análise, era de 21,6\%. Ou seja, houve uma perda de cerca de 3,0\% de ativos, o que representa uma conversão de $12,2 \%$ do teor de ativos em um período de 38 horas.

Nas condições desse teste preliminar e caso essa taxa se mantivesse constante no tempo, estima-se que a hidrólise completa do tensoativo aniônico teria ocorrido em um período de 
13-14 dias que é um período curto tendo em vista que o prazo de validade comercial para esse produto é estipulado em 365 dias.

Entende-se que é muito difícil que o produto comercializado seja mantido a $100^{\circ} \mathrm{C}$ durante um longo período em condições normais de estocagem e de transporte. No entanto, um tambor metálico fechado contendo produto e deixado diretamente exposto ao sol por um longo período de tempo pode facilmente atingir altas temperaturas - em torno de $60-70^{\circ} \mathrm{C}$ segundo monitoramento já realizado - o que, segundo indicações deste teste preliminar pode representar uma real ameaça à estabilidade do produto. Isso ressalta a importância da realização desse estudo avaliando-se a susceptibilidade do produto à ocorrência de hidrólise em diferentes situações e o impacto das diversas variáveis envolvidas na velocidade de ocorrência dessa indesejável reação de decomposição.

Neste teste preliminar foi avaliada a estimativa de cálculo da perda de ativos através da diferença entre os teores de sulfato de sódio analisados na amostra inicial e final conforme mencionado na descrição do método. $\mathrm{O}$ teor total de $\mathrm{ROSO}_{3}^{-}$consumido na reação nesse caso seria de $3,95 \%$

- Teor de sulfato de sódio, final, \%p: 1,89\%

- Teor de sulfato de sódio, inicial, \%p: 0,35\%

Assim sendo, considerando-se o teor inicial - analisado pelo método da titulação com solução catiônica - de 24,6\% e a perda estimada de 3,95\% através da análise de sulfato de sódio, o teor final seria de $20,7 \%$ de ativos, resultado muito próximo ao teor de ativos final encontrado pela análise de matéria-ativa pelo método de titulação com solução catiônica, configurando, portanto outra opção de cálculo de perda do teor de ativos a ser avaliada.

É importante mencionar, no entanto, que para o acompanhamento da evolução da reação o método utilizado precisa ser não só confiável mas também rápido e simples de ser realizado devido ao elevado número de amostragens. Avaliando-se as opções entende-se que o método da titulação com solução básica mostrou-se o mais adequado e por isso esse foi o método escolhido para acompanhamento da reação de hidrólise nas amostras retiradas ao longo da reação nos experimentos realizados na etapa do planejamento experimental. 
Observa-se, nesse teste preliminar, uma queda bastante acentuada no $\mathrm{pH}$ ao longo da reação. Ao correlacionarmos o gráfico de queda no valor do $\mathrm{pH}$ do meio com o gráfico de queda no teor de ativos nota-se que o teor de ativos apresentou pouca variação até o valor de $\mathrm{pH} 3,0$, e que, para valores mais baixos de $\mathrm{pH}$ observa-se uma queda já bastante acentuada no teor de ativos. É como se um valor de $\mathrm{pH}$ em torno de 3,0 indicasse uma quantidade suficientemente grande de íons $H^{+}$livres no meio para iniciar a etapa ácido catalítica de queda acelerada do teor de ativos.

\subsection{Testes preliminares para escolha do equipamento}

Antes de serem iniciados os experimentos planejados foram realizados experimentos preliminares utilizando outro reator que apresentava maior capacidade mas, no entanto, nãohermético e com um sistema de agitação pouco eficiente.

Nesse reator foram testadas condições mais extremas de $\mathrm{pH}(\mathrm{pH}=1,0)$ e de temperatura $\left(80^{\circ} \mathrm{C}\right)$ e com um ajuste no teor de insulfatados para $2,40 \%$, no teor de $\mathrm{NaCl}$ para $1,80 \%$ e no teor de $\mathrm{Na}_{2} \mathrm{SO}_{4}$ para $0,40 \%$.

A mistura desses componentes em suas respectivas concentrações resultou em um produto final com viscosidade muito elevada. Com o produto mantido sob agitação ocorria formação de muitas bolhas, o que dificultou a visualização de separação de fases. $\mathrm{O}$ experimento foi mantido por somente $8 \mathrm{~h}$ pois após esse período o produto adquiriu um aspecto gelatinoso e quebradiço e o experimento teve que ser interrompido.

Esses testes iniciais foram realizados com o objetivo de avaliar os limites das faixas adotadas para as variáveis no planejamento experimental. Nesses experimentos também ficou evidente a importância de utilizar um reator hermético, para evitar perdas de água por vaporização, e com boa capacidade de homogeneização.

Esses testes iniciais também serviram para um direcionamento a respeito das faixas de concentração do teor de insulfatados e teor de eletrólitos utilizadas no planejamento experimental porque foi observado que teores muito altos de eletrólitos ou de insulfatados 
resultam em uma mistura com viscosidade muito elevada e, portanto, em um produto de difícil homogeneização.

\subsection{Respostas do planejamento experimental}

O planejamento fatorial fracionado elaborado para esse estudo foi do tipo $2_{I I I}^{5-2}$, de resolução III, tendo sido realizados um total de 11 experimentos incluindo-se três repetições do ponto central.

O cálculo para a resposta de fração convertida de ativos no tempo - $Y 1$ - foi feito de três formas diferentes para comparação dos resultados, conforme apresentado na Figura 9:

(a) Análise do teor de ativos nas amostras inicial e final pelo método de titulação com solução catiônica.

(b) Análise do teor de sulfato de sódio nas amostras inicial e final.

(c) Análise do teor de ativos residual pelo método de titulação com solução básica.

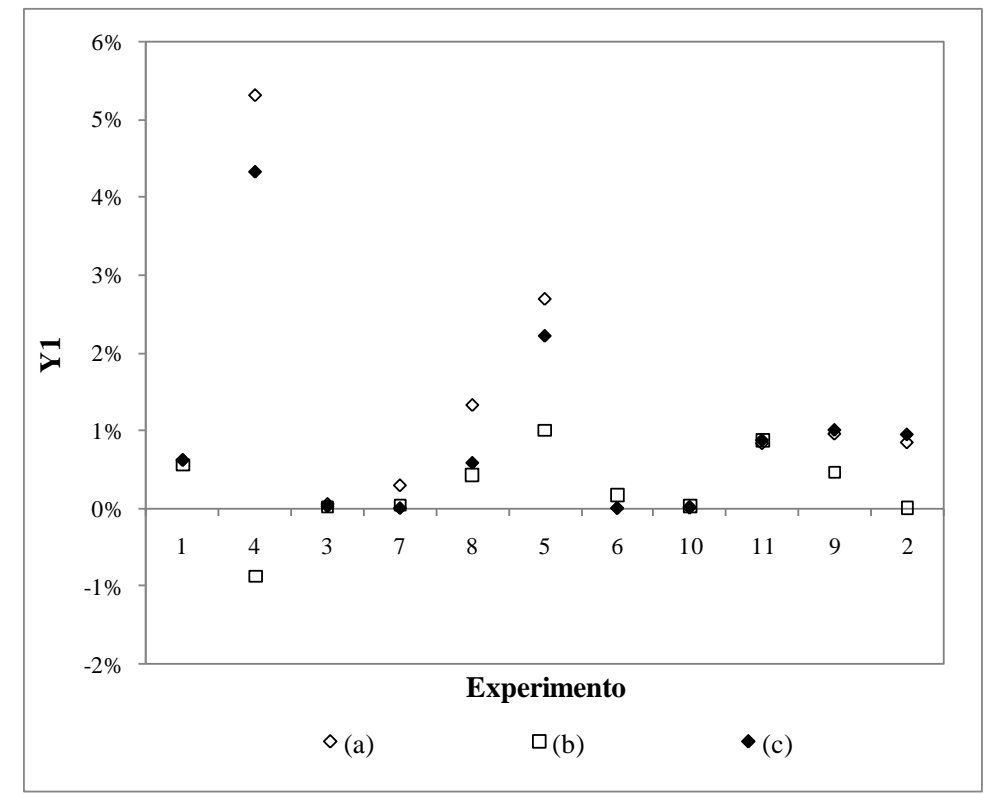

Figura 9- Resultados para a resposta de fração convertida de ativos no tempo $Y 1$ por diferentes métodos (em \% de ativos/h); (a) método de titulação com solução catiônica, (b) análise do teor de sulfato de sódio e (c) análise do teor de ativos residual pelo método de titulação com solução básica

Observa-se que os resultados obtidos pelos três diferentes métodos foram próximos em quase todos os experimentos. Nota-se, no entanto, que o método de cálculo por análise de 
teor de sulfato de sódio é o que parece apresentar maior erro, em especial pelos resultados obtidos nos experimentos 4 e 5 .

O método da análise do teor de ativos por titulação com solução catiônica é um método já conhecido e bastante utilizado. Observa-se que os resultados obtidos dessa forma e os resultados obtidos pelo método de titulação com $\mathrm{NaOH}$ - desenvolvido neste trabalho foram muito semelhantes. Dessa forma pode-se afirmar que o método de titulação com $\mathrm{NaOH}$ é adequado para uso como uma alternativa de método mais rápido na análise das várias amostragens realizadas ao longo da reação para acompanhamento do teor de ativos residual.

No entanto, para a análise das respostas do planejamento experimental e cálculo de $Y 1$ optou-se pelo método de análise de ativos por titulação com solução catiônica. Isso porque dessa forma é possível calcular a variação no teor de ativos mesmo para os casos em que o $\mathrm{pH}$, embora em queda, manteve-se acima de 7,0 como observado em alguns experimentos, não permitindo o uso do cálculo pelo método de titulação com $\mathrm{NaOH}$. Nesses casos somente a análise pelo método de titulação com solução catiônica permitiu o cálculo da fração convertida $(Y 1)$.

Assim sendo os resultados adotados para a resposta de fração convertida de ativos - $Y 1$ foram obtidos analisando-se os teores de ativos no início e no final de cada experimento pelo método da titulação com solução catiônica.

Os resultados obtidos para a resposta de fração convertida de ativos são apresentados na Tabela 8. 
Tabela 8- Resultados obtidos para a resposta de taxa de conversão de ativos

\begin{tabular}{|c|c|c|c|c|}
\hline \multirow[b]{2}{*}{ Ordem } & \multirow[b]{2}{*}{ Experimento } & \multirow[b]{2}{*}{ Ponto Central } & \multirow[b]{2}{*}{ Bloco } & $\mathrm{Y} 1$ \\
\hline & & & & $\begin{array}{c}\text { Fração convertida } \\
(\% / \mathrm{h})\end{array}$ \\
\hline 1 & 1 & 1 & 1 & $0,63 \%$ \\
\hline 2 & 4 & 1 & 1 & $5,31 \%$ \\
\hline 3 & 3 & 1 & 1 & $0,07 \%$ \\
\hline 4 & 7 & 1 & 1 & $0,31 \%$ \\
\hline 5 & 8 & 1 & 1 & $1,34 \%$ \\
\hline 6 & 5 & 1 & 1 & $2,70 \%$ \\
\hline 7 & 6 & 1 & 1 & $0,01 \%$ \\
\hline 8 & 10 & 1 & 1 & $0,02 \%$ \\
\hline 9 & 11 & 0 & 1 & $0,84 \%$ \\
\hline 10 & 9 & 0 & 1 & $0,97 \%$ \\
\hline 11 & 2 & 0 & 1 & $0,86 \%$ \\
\hline
\end{tabular}

Considerando-se a hipótese de a taxa de conversão se mantenha constante ao longo de toda a reação calcula-se o tempo estimado para a conversão completa do teor de ativos para cada condição experimental:

Tabela 9- Estimativa do tempo para conversão total do teor de ativos

\begin{tabular}{cccccc}
\hline & & & & \multicolumn{2}{c}{ Y1 } \\
Ordem & Experimento Ponto Central & Bloco & $\begin{array}{c}\text { Fração convertida } \\
(\% / \mathrm{h})\end{array}$ & $\begin{array}{c}\text { Tempo estimado } \\
\text { (dias) para conversão } \\
\text { completa do teor de } \\
\text { ativos }\end{array}$ \\
\hline 1 & 1 & 1 & 1 & $0,63 \%$ & 7 \\
2 & 4 & 1 & 1 & $5,31 \%$ & 1 \\
3 & 3 & 1 & 1 & $0,07 \%$ & 64 \\
4 & 7 & 1 & 1 & $0,31 \%$ & 14 \\
5 & 8 & 1 & 1 & $1,34 \%$ & 3 \\
6 & 5 & 1 & 1 & $2,70 \%$ & 2 \\
7 & 6 & 1 & 1 & $0,01 \%$ & 328 \\
8 & 10 & 1 & 1 & $0,02 \%$ & 252 \\
9 & 11 & 0 & 1 & $0,84 \%$ & 5 \\
10 & 9 & 0 & 1 & $0,97 \%$ & 4 \\
11 & 2 & 0 & 1 & $0,86 \%$ & 5 \\
\hline
\end{tabular}

Observa-se que a conversão completa do teor de ativos ocorre em um tempo relativamente curto em muitos casos tendo em vista que o prazo de validade comercial para esse produto é estipulado em 365 dias.

As condições nas quais são obtidas as menores frações convertidas indicam quais seriam as melhores condições para retardar a ocorrência da reação de hidrólise do produto. 
A resposta de variação de $\mathrm{pH}$ no tempo foi calculada analisando-se o $\mathrm{pH}$ no início e no fim do experimento. Os resultados obtidos são apresentados na Tabela 10.

Tabela 10- Resultados obtidos para a resposta de variação de pH no te
\begin{tabular}{cccccc} 
Ordem & Experimento Ponto Central & Bloco & $\begin{array}{c}\text { Variação do pH no } \\
\text { tempo } \\
\text { unidade de } \mathrm{pH} / \mathrm{h}\end{array}$ \\
\hline 1 & 1 & 1 & 1 & 0,073 \\
2 & 4 & 1 & 1 & 0,600 \\
3 & 3 & 1 & 1 & 0,067 \\
4 & 7 & 1 & 1 & 0,013 \\
5 & 8 & 1 & 1 & 0,100 \\
6 & 5 & 1 & 1 & 0,473 \\
7 & 6 & 1 & 1 & 0,004 \\
8 & 10 & 1 & 1 & 0,035 \\
9 & 11 & 0 & 1 & 0,111 \\
10 & 9 & 0 & 1 & 0,111 \\
11 & 2 & 0 & 1 & 0,121 \\
\hline
\end{tabular}

É desejável que a variação de $\mathrm{pH}$ no tempo seja a menor possível pois uma variação no $\mathrm{pH}$ do produto comercial é facilmente perceptível pelo cliente durante o uso, não só porque essa é uma análise simples de ser realizada - quando comparada à análise de determinação do teor de ativos por exemplo - mas também porque qualquer variação no $\mathrm{pH}$ das matériasprimas utilizadas impacta diretamente no $\mathrm{pH}$ do produto final.

É importante notar, comparando-se os resultados dos experimentos realizados, que mesmo nos casos em que não foi observada variação acentuada no teor de ativos houve queda significativa no valor de $\mathrm{pH}$. Pode-se concluir que a variação no $\mathrm{pH}$ é percebida antes do início da queda acentuada no teor de ativos, sendo uma medida mais sensível para indicação do início da ocorrência de hidrólise no meio.

A seguir é apresentado um gráfico correlacionando as respostas de fração convertida de ativos $(Y 1)$ e a variação do $\mathrm{pH}(Y 2)$. 


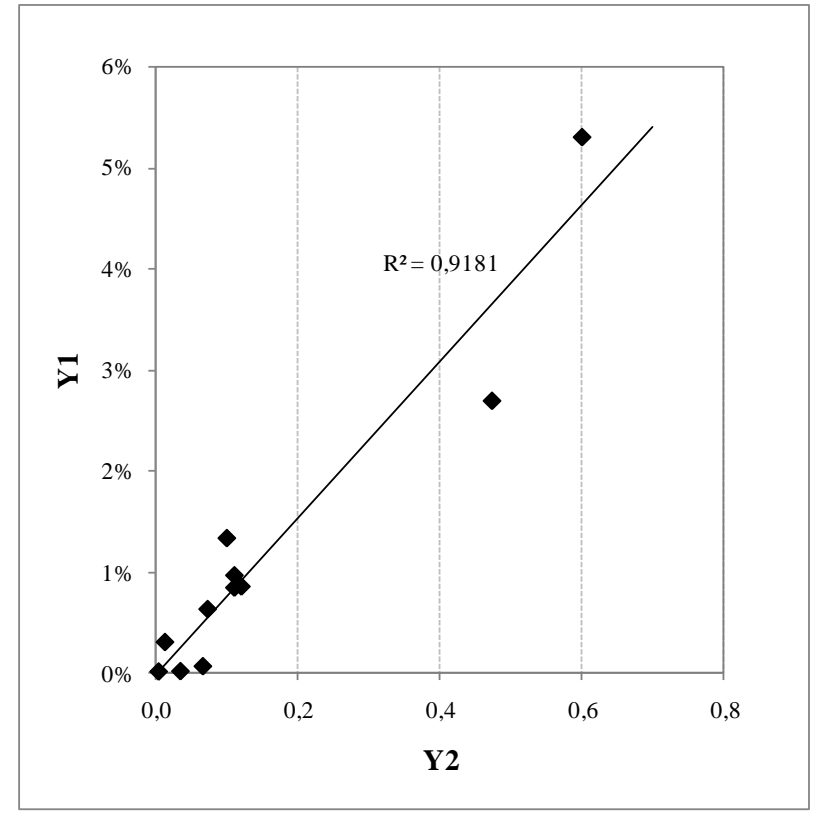

Figura 10- Avaliação da correlação entre as repostas de variação de pH e de fração convertida de ativos

Observa-se uma correlação significativa indicando que quanto maior a variação no pH maior a fração convertida de ativos.

A outra resposta incluída na análise dos resultados do planejamento experimental é o tempo de estabilidade ( $Y 3$ ). Essa resposta é importante pois trata-se de um parâmetro referente ao comportamento observado de variação do teor de ativos ao longo do experimento já que as outras duas respostas ( $Y 1$ e $Y 2)$ consideram somente a variação global observada entre o estado inicial e final.

O tempo de estabilidade corresponde ao intervalo da reação em que o produto apresenta variações muito pequenas na concentração de ativos, o que corresponderia à etapa nãocatalítica da reação, ou seja, o período que antecede o início da queda acentuada no teor de ativos (etapa ácido-catalítica).

A resposta do tempo de estabilidade foi determinada analisando-se os gráficos de variação da concentração de ativos ao longo do tempo para cada experimento.

Para os experimentos nos quais foi possível observar a etapa não-catalítica e a etapa ácido-catalítica, o tempo de estabilidade foi determinado graficamente, a partir da 
intersecção de duas retas ajustadas aos dados utilizando-se o método dos mínimos quadrados como ilustrado na Figura 11.

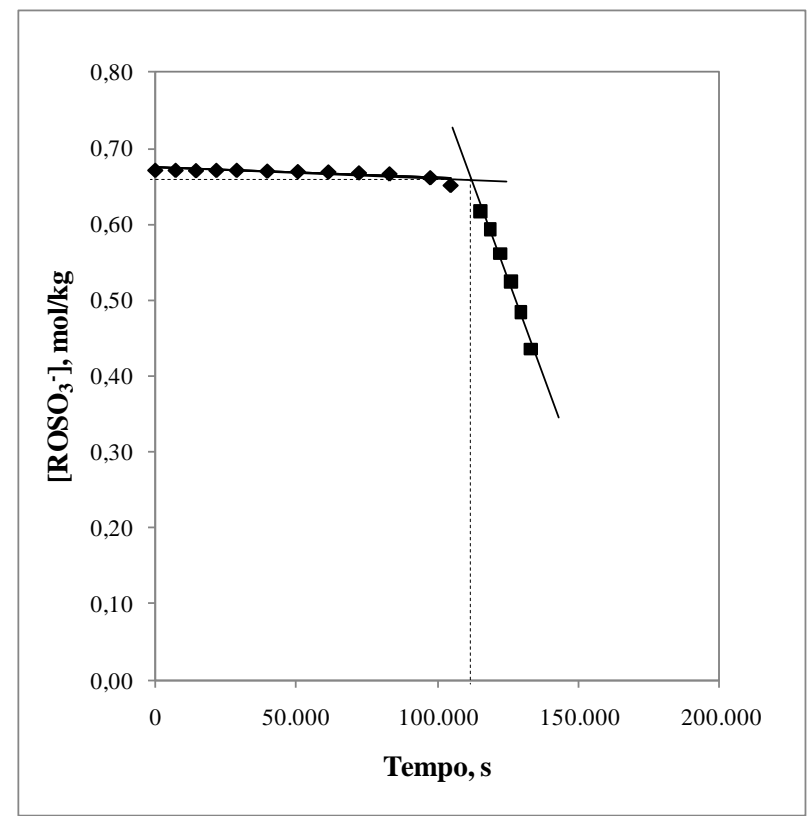

Figura 11- Ilustração de como foi determinado o tempo de estabilidade por meio da intersecção de retas ajustadas aos dados por regressão linear

Em algumas das condições experimentais não foi possível observar, no tempo máximo determinado para acompanhamento do experimento, o momento do início da queda acentuada de ativos, que indicaria o início da etapa ácido-catalítica. Assim sendo, o tempo de estabilidade foi definido, nesses casos, como sendo o tempo máximo de observação do experimento. Um dos experimentos apresentou uma queda acentuada no teor de ativos logo no início da reação, apresentando, portanto, somente a etapa ácido-catalítica. Para esse caso foi adotado tempo de estabilidade igual a zero.

Os resultados obtidos para essa resposta de tempo de estabilidade são apresentados na Tabela 11. 
Tabela 11- Resultados obtidos para a resposta de tempo de estabilidade

\begin{tabular}{ccccc}
\hline & & & & Y3 \\
\cline { 4 - 5 } Ordem & Experimento & Ponto Central & Bloco & $\begin{array}{c}\text { Tempo de } \\
\text { estabilidade } \\
\text { segundos }\end{array}$ \\
\hline 1 & 1 & 1 & 1 & 111.964 \\
2 & 4 & 1 & 1 & $0^{\mathrm{b}}$ \\
3 & 3 & 1 & 1 & $154800^{\mathrm{a}}$ \\
4 & 7 & 1 & 1 & $162000^{\mathrm{a}}$ \\
5 & 8 & 1 & 1 & 49.966 \\
6 & 5 & 1 & 1 & 14.294 \\
7 & 6 & 1 & 1 & $162000^{\mathrm{a}}$ \\
8 & 10 & 1 & 1 & $162000^{\mathrm{a}}$ \\
9 & 11 & 0 & 1 & 117.188 \\
10 & 9 & 0 & 1 & 112.217 \\
11 & 2 & 0 & 1 & 112.023 \\
\hline a: corresponde ao tempo máximo de observação & & \\
b: não apresentou estabilidade, desde o início apresentou queda acentuada do teor de ativos
\end{tabular}

Os gráficos e os ajustes por regressão linear realizados em cada um dos experimentos em que foi possível determinar o tempo de estabilidade através da intersecção de retas são apresentados no Apêndice A, ao final deste trabalho.

A Figura 12 apresenta um gráfico da fração convertida de ativos em função do tempo de estabilidade. Nota-se uma correlação não linear entre essas duas respostas indicando que decréscimos no tempo de estabilidade representam incrementos exponenciais na taxa de perda de ativos.

Um comportamento semelhante é esperado para correlação da variação de $\mathrm{pH}(Y 2)$ com o tempo de estabilidade $(Y 3)$. 


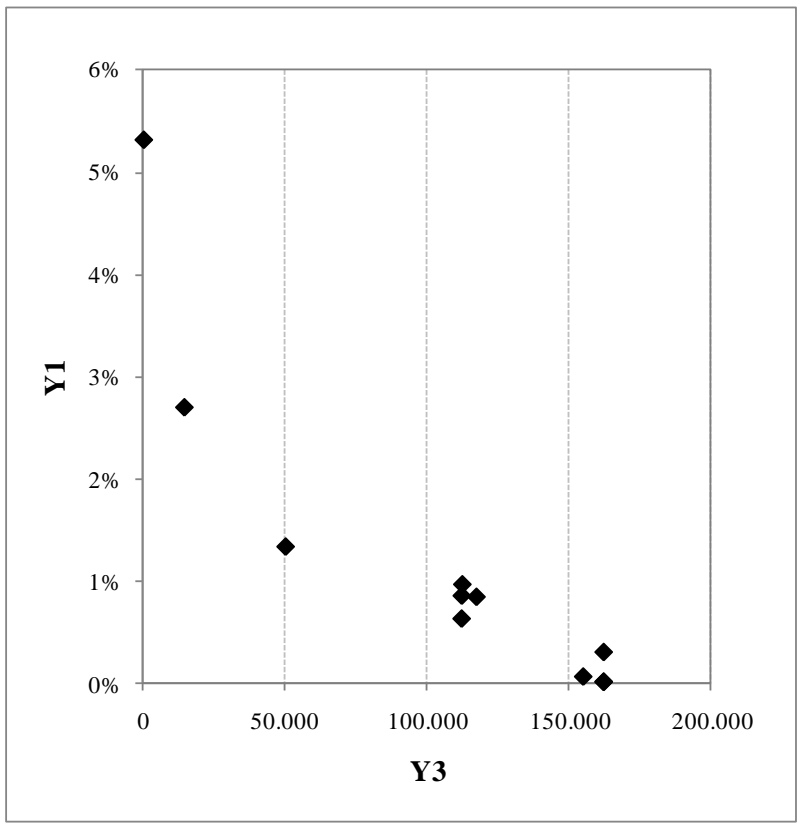

Figura 12- Correlação observada entre as respostas de fração convertida de ativos e o tempo de estabilidade

A Tabela 12 reúne todas as respostas obtidas para cada um dos experimentos

Tabela 12- Resultados para as respostas avaliadas no planejamento experimental

\begin{tabular}{ccccccc}
\hline & & & & \multicolumn{2}{c}{ Y1 } & \multicolumn{2}{c}{ Y2 } & \multicolumn{2}{c}{ Y3 } \\
\cline { 4 - 6 } Ordem & Experimento Ponto Central & Bloco & $\begin{array}{c}\text { Fonvertida de } \\
\text { ativos } \\
\% / \mathrm{h}\end{array}$ & $\begin{array}{c}\text { Variação do pH no } \\
\text { tempo } \\
\text { unidade de } \mathrm{pH} / \mathrm{h}\end{array}$ & $\begin{array}{c}\text { Tempo de } \\
\text { estabilidade } \\
\text { segundos }\end{array}$ \\
\hline 1 & 1 & 1 & 1 & $0,63 \%$ & $7,33 \%$ & 111.964 \\
2 & 4 & 1 & 1 & $5,31 \%$ & $60,00 \%$ & 0 \\
3 & 3 & 1 & 1 & $0,07 \%$ & $6,67 \%$ & 154.800 \\
4 & 7 & 1 & 1 & $0,31 \%$ & $1,33 \%$ & 162.000 \\
5 & 8 & 1 & 1 & $1,34 \%$ & $10,03 \%$ & 49.966 \\
6 & 5 & 1 & 1 & $2,70 \%$ & $47,33 \%$ & 14.294 \\
7 & 6 & 1 & 1 & $0,01 \%$ & $0,44 \%$ & 162.000 \\
8 & 10 & 1 & 1 & $0,02 \%$ & $3,51 \%$ & 162.000 \\
9 & 11 & 0 & 1 & $0,84 \%$ & $11,10 \%$ & 117.188 \\
10 & 9 & 0 & 1 & $0,97 \%$ & $11,10 \%$ & 112.217 \\
11 & 2 & 0 & 1 & $0,86 \%$ & $12,08 \%$ & 112.023 \\
\hline
\end{tabular}

\subsection{Análise dos resultados do planejamento experimental}

A análise dos resultados do delineamento fatorial fracionado foi realizada utilizando-se o software Minitab ${ }^{\circledR}$ para avaliação dos efeitos estatisticamente significativos. 
É importante observar que os experimentos previstos no planejamento experimental foram realizados ao longo de um período de dois meses utilizando-se sempre as mesmas matérias-primas. Como nesse período pode ter havido alguma variação na concentração de ativos da amostra comercial utilizada uma nova análise do teor de ativos, assim como do valor de $\mathrm{pH}$, era realizada ao início de cada experimento e os resultados dessas análises foram utilizados para o cálculo das respostas $Y 1$ e $Y 2$. 


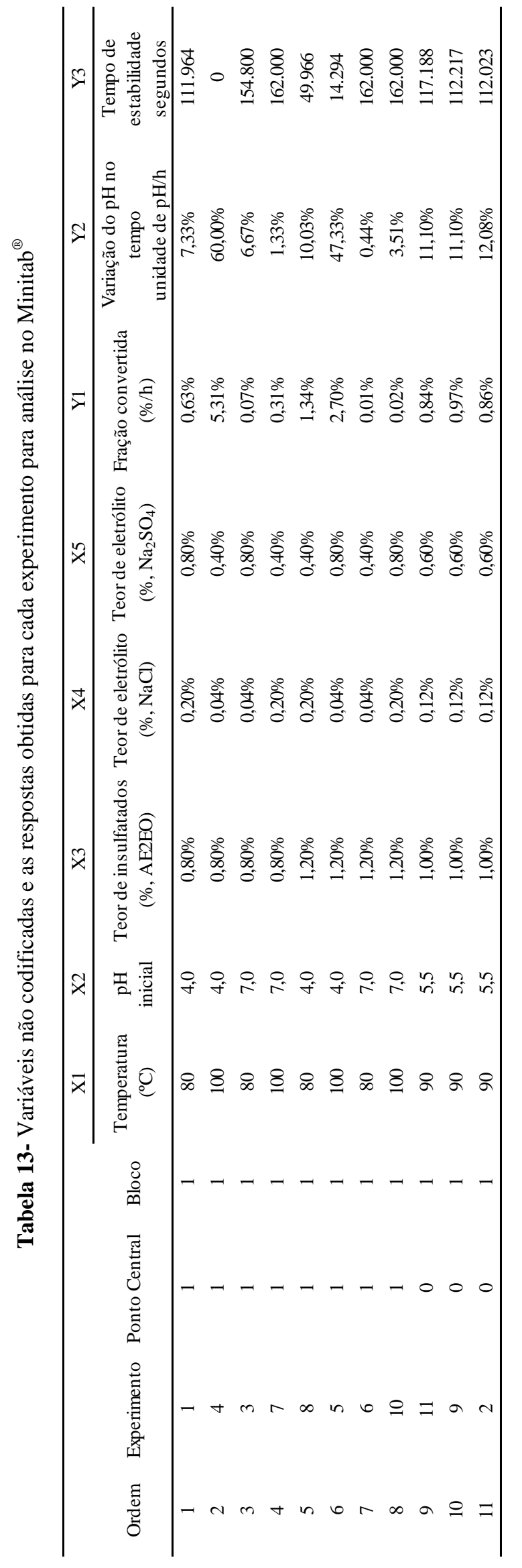


O programa Minitab ${ }^{\circledR}$ sempre utiliza, por definição, as variáveis em sua forma codificada o que permite a comparação dos coeficientes, por estarem em uma mesma escala, para avaliação do fator/variável de maior impacto na resposta.

Os efeitos das variáveis e suas interações sobre as respostas selecionadas foram calculados utilizado o programa Minitab ${ }^{\circledR}$. O modelo estatístico para o projeto fatorial $2_{\text {III }}^{5-2}$ para cada uma das três respostas - $Y 1, Y 2$ e $Y 3$ - é dado pelas equações apresentadas a seguir:

$$
\begin{aligned}
& \hat{Y} 1(X 1, X 2, X 3, X 4, X 5)=a_{0}+a_{1} \cdot X 1+a_{2} \cdot X 2+a_{3} \cdot X 3+a_{4} \cdot X 4+a_{5} \cdot X 5 \\
& +a_{13} \cdot X 1 \cdot X 3+a_{25} \cdot X 2 \cdot X 5
\end{aligned}
$$

Onde $a_{i}, b_{i}$ e $c_{i}$ representam os coeficientes do modelo estatístico e $X 1, X 2, X 3, X 4$ e $X 5$ representam as variáveis do planejamento experimental.

A seguir são apresentados os resultados da estimativa dos efeitos de cada uma das variáveis e suas interações assim como os coeficientes calculados para os modelos estatísticos apresentados nas equações (62) a (64). Para cada modelo estatístico também é apresentado o valor de $R^{2}$ do ajuste do modelo linear.

Na Tabela 14 são apresentados os valores de p-value calculados pelo programa: um resultado de $p$-value menor do que 0,05 indica que o fator foi significativo para o intervalo de confiança de $95 \%$. O valor adotado para o intervalo de confiança de $95 \%$ significa que se admite $5 \%$ de chance de dizer que o efeito do fator não é importante quando, na verdade, ele é. 
Posteriormente, na Tabela 15, são apresentados os dados referentes à análise de variância para cada resposta estudada.

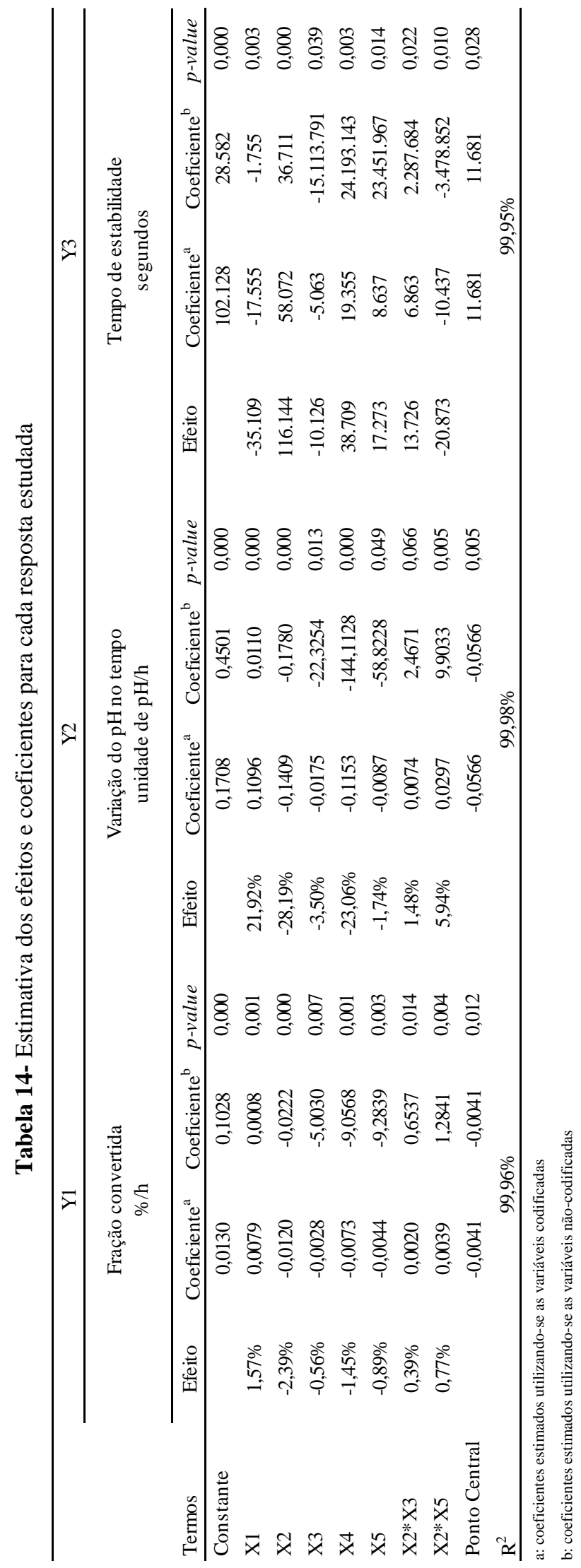




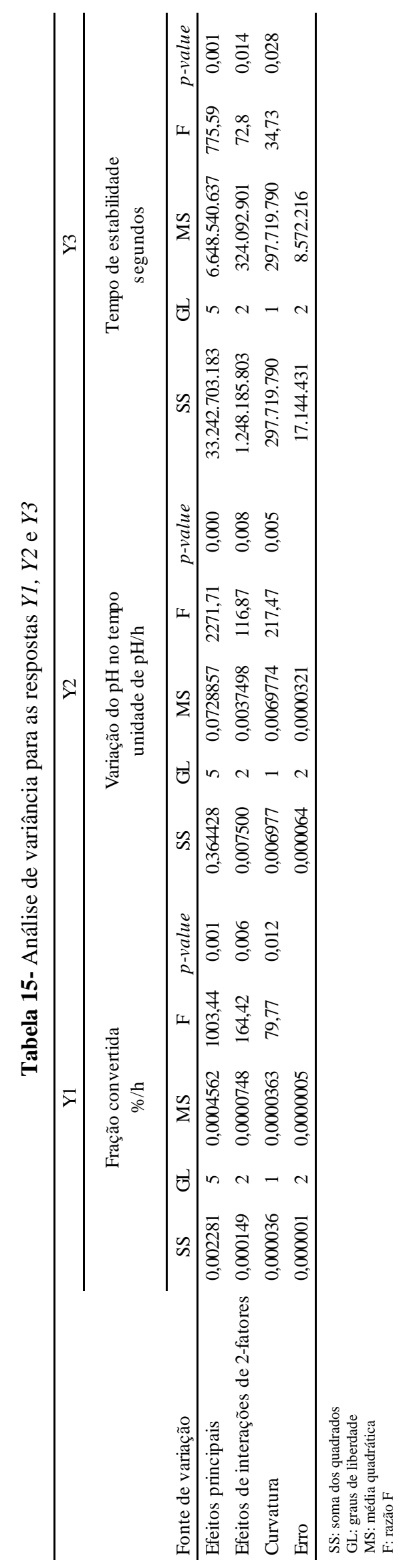


As Figuras 13, 14 e 15 representam os Gráficos de Pareto e ilustram os efeitos estimados para cada resposta estudada.

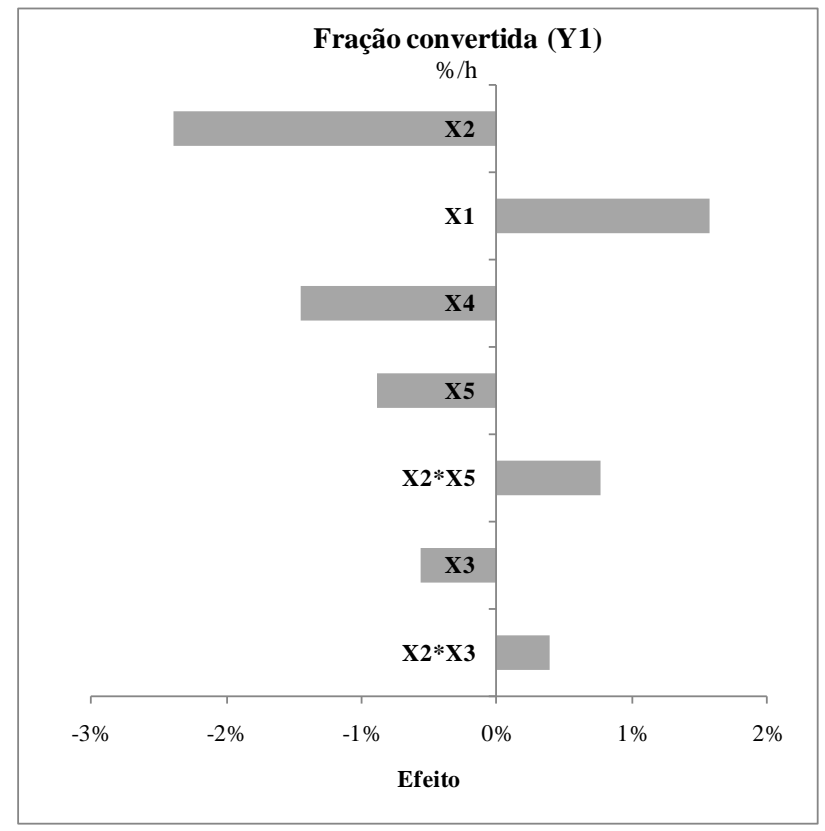

Figura 13- Ilustração dos efeitos para $Y 1$

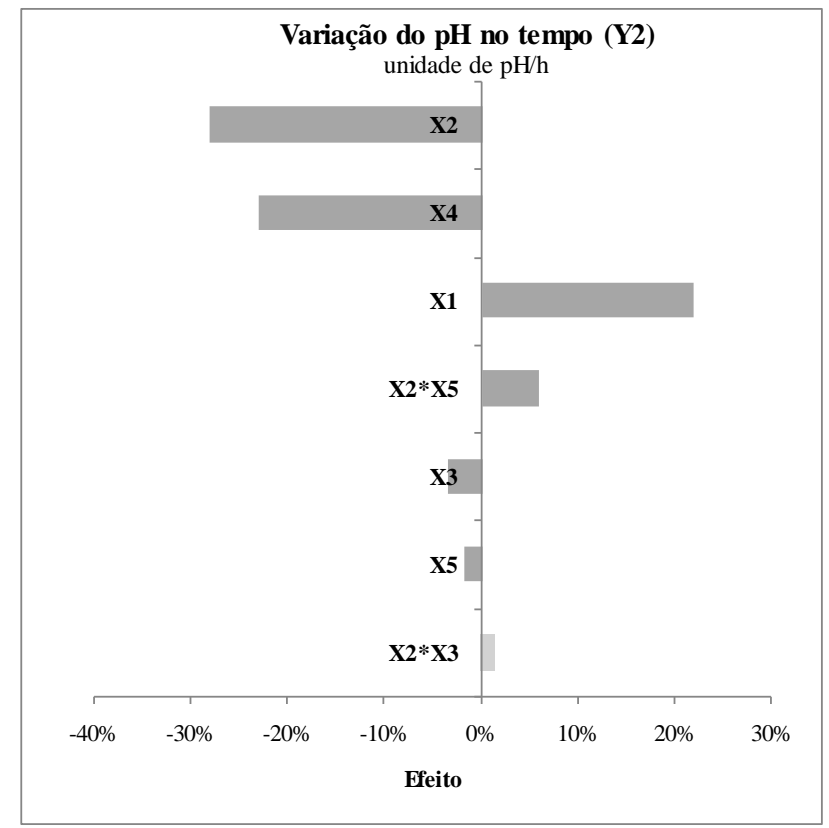

Figura 14- Ilustração dos efeitos para $Y 2$ 


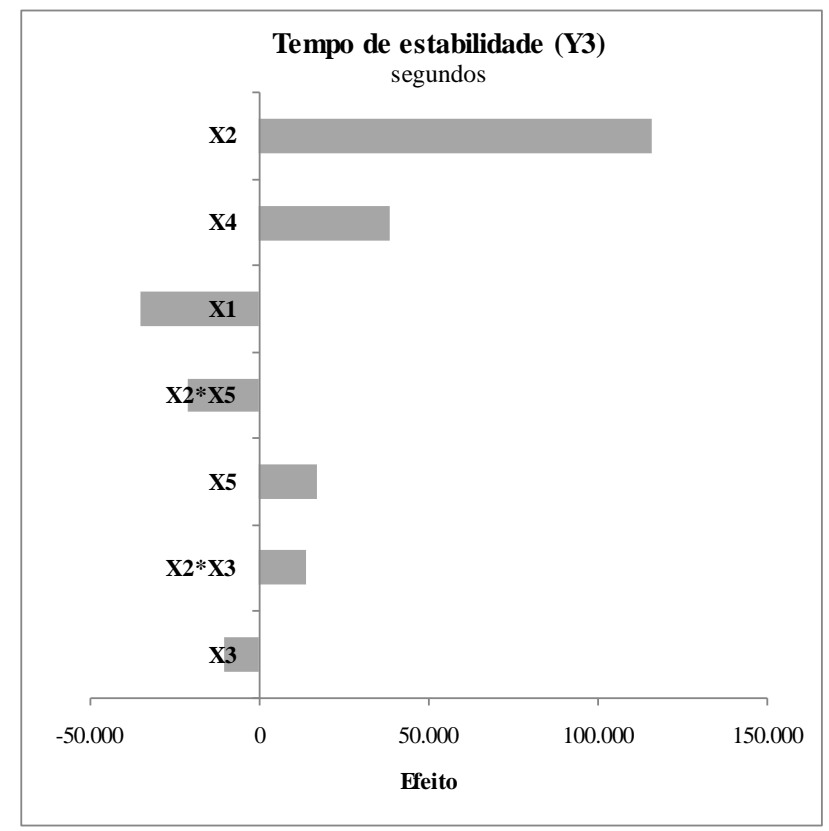

Figura 15- Ilustração dos efeitos para $Y 3$

Os modelos e as análises apresentados na Tabela 16 indicam apenas tendências uma vez que o planejamento realizado foi do tipo fatorial fracionado.

Tabela 16- Comentários e análise dos resultados e de quais seriam as variáveis significativas para cada uma das respostas estudadas

\begin{tabular}{ll}
\hline Resposta & Análise dos resultados (continua) \\
\hline Fração convertida de & Observa-se que todas as variáveis e interações apresentaram uma estimativa de efeito \\
ativos no tempo & estatisticamente significativo na fração convertida de ativos. Isso indica que seria \\
& necessária a realização de experimentos complementares para obter conclusões mais \\
& assertivas a respeito da complexidade da influência dessas variáveis na resposta de \\
& variação do teor de ativos. \\
& No entanto, na Figura 13 destacam-se, ainda que não tenha sido observada significância \\
& estatística, o efeito das variáveis $X 2$, $X 1$ e $X 4$ em ordem de importância e que \\
& correspondem, respectivamente, às variáveis pH inicial, temperatura e teor de cloreto de \\
& sódio. As variáveis $X 2$ e $X 4$ apresentaram efeito negativo, ou seja, quanto menor o pH \\
& inicial e quanto menor o teor de cloreto de sódio, maior a taxa de conversão de ativos. \\
& Quanto à temperatura observa-se que, conforme o esperado, quanto maior a temperatura \\
& maior a taxa de conversão de ativos. \\
& Essas conclusões são coerentes com o que foi observado na literatura pesquisada. É \\
& interessante observar a importância relativa entre essas variáveis tendo o pH apresentado \\
& efeito mais significativo que a temperatura e tendo o teor de cloreto de sódio apresentado \\
& efeito tão significante quanto a temperatura.
\end{tabular}




\begin{tabular}{|c|c|}
\hline Resposta & Análise dos resultados (continuação) \\
\hline $\begin{array}{l}\text { Variação de pH no } \\
\text { tempo }\end{array}$ & $\begin{array}{l}\text { Também nesse caso os efeitos de todas as variáveis e interações analisadas, com exceção } \\
\text { da interação } X 2 \cdot X 3 \text {, apresentaram-se como estatisticamente significativas, o que } \\
\text { indica a necessidade de realização de experimentos adicionais para conclusões mais } \\
\text { assertivas. } \\
\text { Analisando a magnitude do efeito das variáveis na variação do pH observa-se uma } \\
\text { tendência semelhante àquela observada para a resposta de taxa de conversão de ativos no } \\
\text { tempo pois novamente as variáveis de maior efeito foram } X 2, X 4 \mathrm{e} X 1 \text { nessa ordem } \\
\text { de importância, ou seja, considerando-se o efeito na variação do pH as variáveis pH } \\
\text { inicial e teor de cloreto de sódio apresentaram impacto maior do que a temperatura. } \\
\text { Novamente as variáveis } X 2 \text { e } X 4 \text { apresentaram efeito negativo e a variável } X 1 \\
\text { apresentou efeito positivo. }\end{array}$ \\
\hline Tempo de estabilidade & $\begin{array}{l}\text { Assim como nos casos discutidos anteriormente não foi possível observar uma variável } \\
\text { que se destacasse segundo a análise estatística pois todas apresentaram um resultado de } p \text { - } \\
\text { value menor do que } 0,05 \text { e por isso a análise apresentada a seguir foi feita com base no } \\
\text { efeito relativo das variáveis. } \\
\text { Observa-se que as variáveis } X 2, X 4 \text { e } X 1 \text {, nessa ordem de importância relativa, têm } \\
\text { maior efeito no tempo de estabilidade, ou seja, as mesmas três variáveis de maior efeito } \\
\text { para as outras respostas analisadas. Foi observada, nesse caso, a mesma ordem de } \\
\text { importância observada para a resposta } Y 2 \text {. } \\
\text { As variáveis } X 2 \text { e } X 4 \text {, neste caso, apresentaram efeito positivo o que indica que um } \\
\text { aumento no pH inicial do meio e no teor de cloreto de sódio causaram um aumento no } \\
\text { tempo de estabilidade, ou seja, uma inibição na taxa de reação de hidrólise, por isso estão } \\
\text { coerentes com os resultados observados anteriormente. A variável } X 1 \text { apresentou efeito } \\
\text { negativo o que indica que um aumento na temperatura resulta em uma redução no tempo } \\
\text { de estabilidade. }\end{array}$ \\
\hline
\end{tabular}

A partir dessa análise preliminar com base no planejamento fatorial fracionado realizado conclui-se que as variáveis $X 1, X 2$ e $X 4$ apresentam tendência de maior efeito no comportamento da reação de hidrólise, afetando também o tempo de estabilidade.

Outro ponto importante é que a análise dos resultados referentes à repetição do ponto central indica a existência de curvatura e de coeficientes não-lineares que não foram incluídos no projeto experimental. Assim sendo pode-se dizer que os modelos estatísticos encontrados para as respostas $Y 1, Y 2$ e $Y 3$ não são suficientemente adequados para representar o comportamento esperado de hidrólise do produto nas condições estudadas. 


\subsection{Comportamento da reação de hidrólise em cada experimento}

Ao longo de cada um dos experimentos foi realizado um acompanhamento da perda de ativos acumulada em cada instante utilizando-se o método de titulação com solução básica. Os resultados obtidos para a concentração de ativos residual - $\left[\mathrm{ROSO}_{3}^{-}\right](\mathrm{em} \mathrm{mol} / \mathrm{kg})$ - e os resultados de acompanhamento da variação do $\mathrm{pH}$ para cada uma das condições experimentais avaliadas são apresentados nas Figuras 16 a 24 .
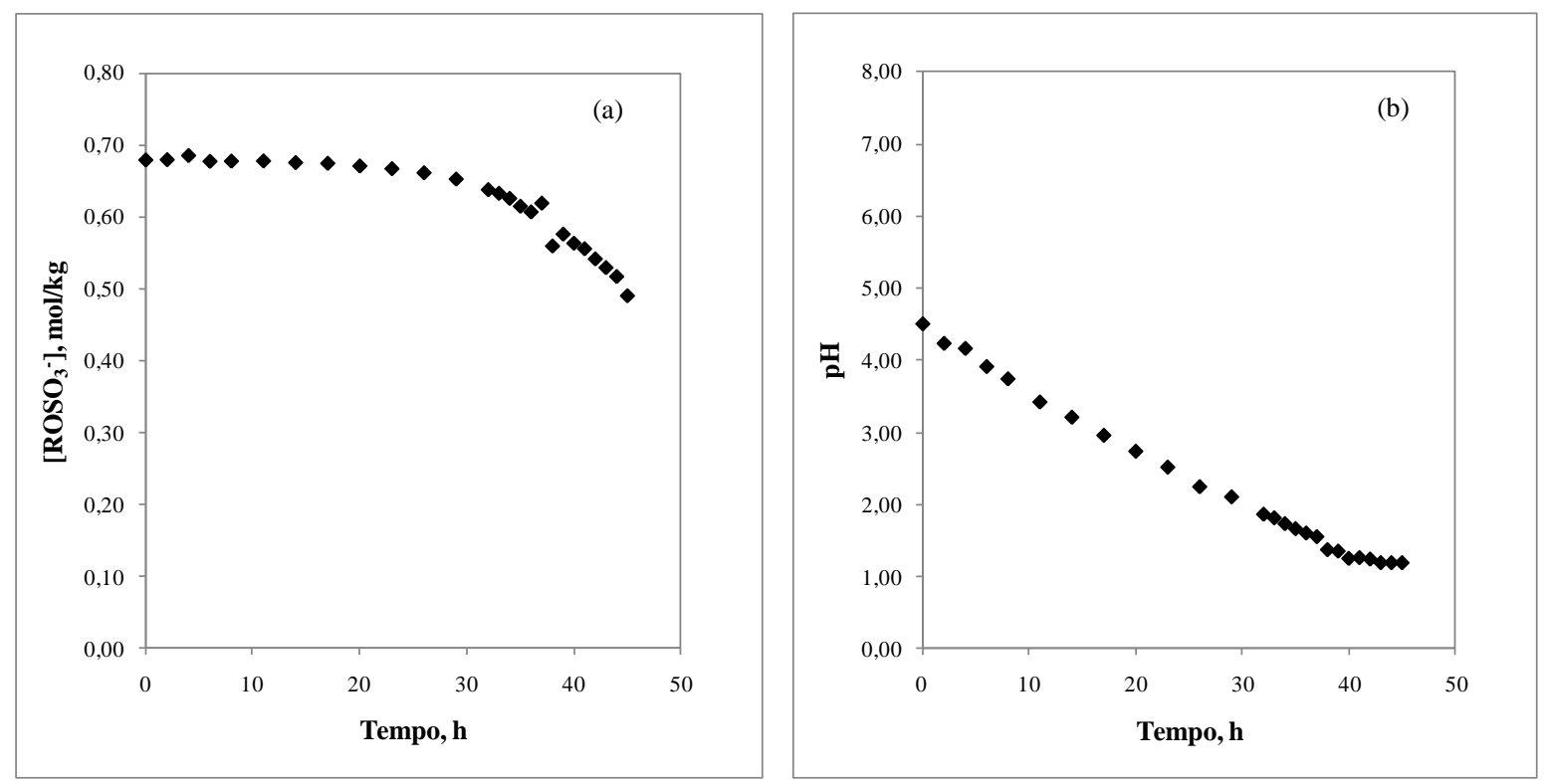

Figura 16- Acompanhamento da reação de hidrólise a nas seguintes condições:

$T=80^{\circ} \mathrm{C} ; \mathrm{pH}=4,0 ; \mathrm{AE} 2 \mathrm{EO}=0,80 \% ; \mathrm{NaCl}=0,20 \% ; \mathrm{Na}_{2} \mathrm{SO}_{4}=0,80 \%$ (EXPERIMENTO 1) (a) variação no teor de ativos (b) variação no valor de $\mathrm{pH}, 25^{\circ} \mathrm{C}$ 

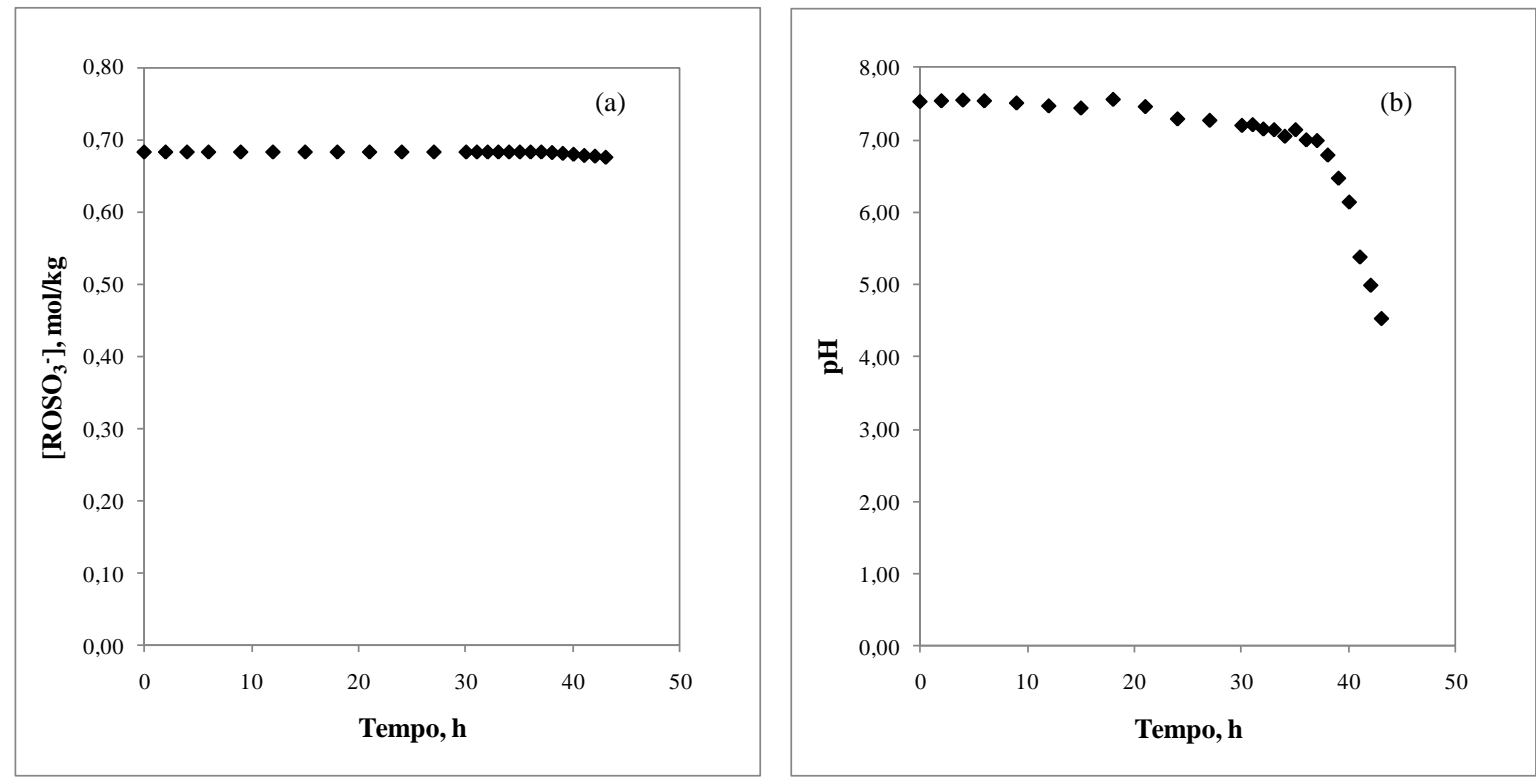

Figura 17- Acompanhamento da reação de hidrólise a nas seguintes condições:

$T=80^{\circ} \mathrm{C} ; \mathrm{pH}=7,0 ; \mathrm{AE2EO}=0,80 \% ; \mathrm{NaCl}=0,04 \% ; \mathrm{Na}_{2} \mathrm{SO}_{4}=0,80 \%$ (EXPERIMENTO 3) (a) variação no teor de ativos (b) variação no valor de $\mathrm{pH}, 25^{\circ} \mathrm{C}$
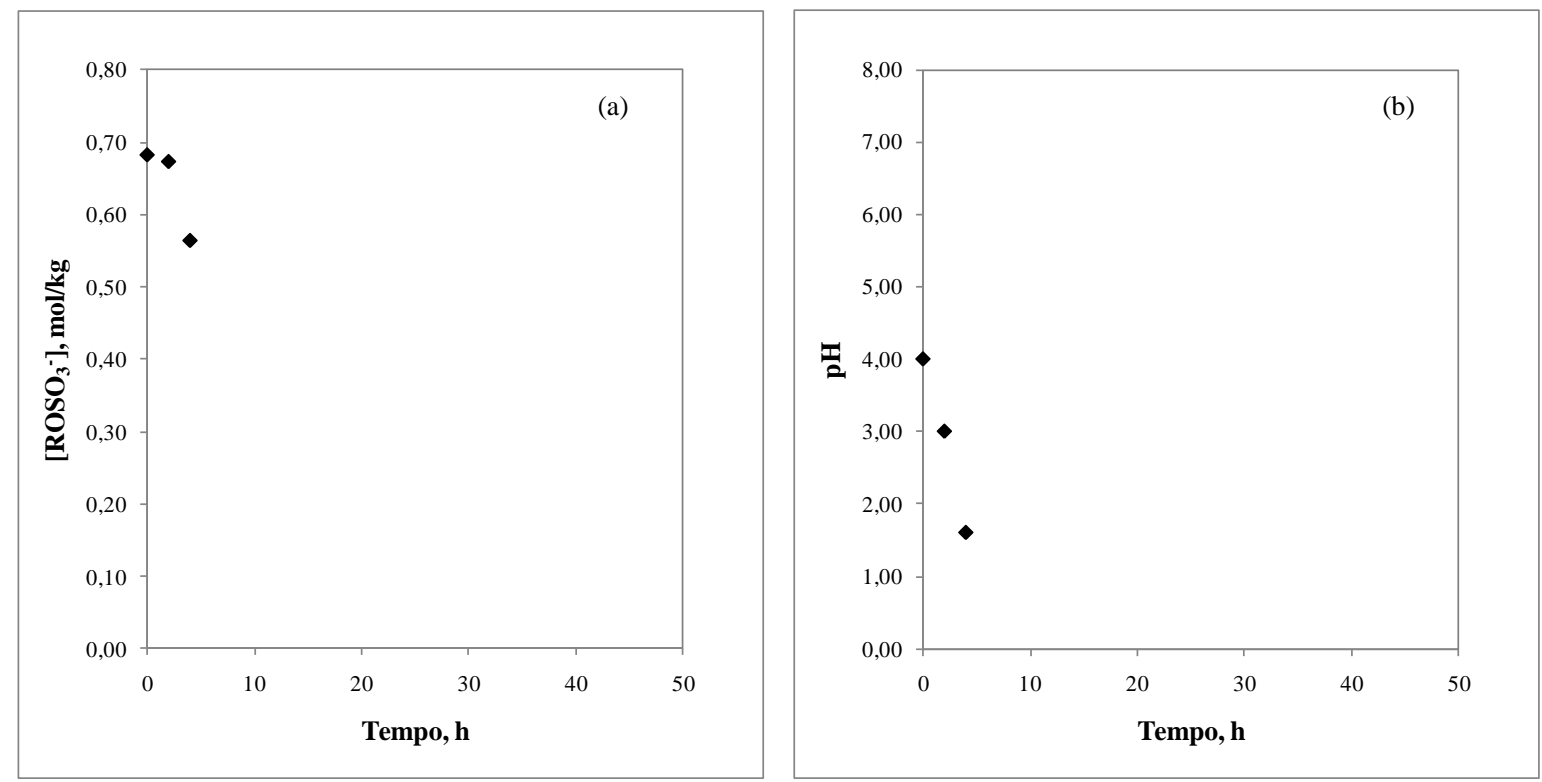

Figura 18- Acompanhamento da reação de hidrólise a nas seguintes condições:

$T=100^{\circ} \mathrm{C} ; \mathrm{pH}=4,0 ; \mathrm{AE2EO}=0,80 \% ; \mathrm{NaCl}=0,04 \% ; \mathrm{Na}_{2} \mathrm{SO}_{4}=0,40 \%$ (EXPERIMENTO 4) (a) variação no teor de ativos (b) variação no valor de $\mathrm{pH}, 25^{\circ} \mathrm{C}$ 

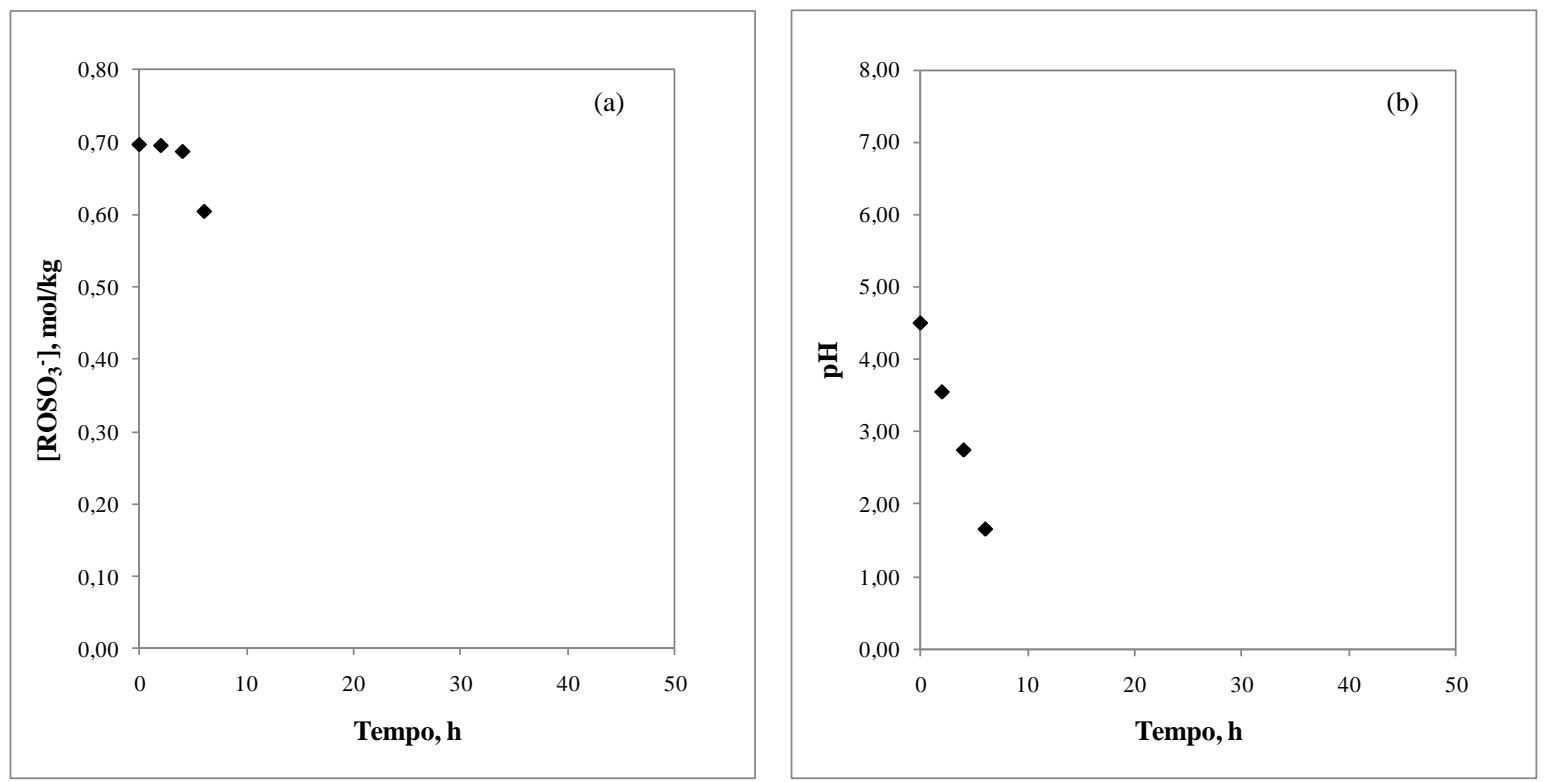

Figura 19- Acompanhamento da reação de hidrólise a nas seguintes condições:

$T=100^{\circ} \mathrm{C} ; \mathrm{pH}=4,0 ; \mathrm{AE} 2 \mathrm{EO}=1,20 \% ; \mathrm{NaCl}=0,04 \% ; \mathrm{Na}_{2} \mathrm{SO}_{4}=0,80 \%$ (EXPERIMENTO 5) (a) variação no teor de ativos (b) variação no valor de $\mathrm{pH}, 25^{\circ} \mathrm{C}$
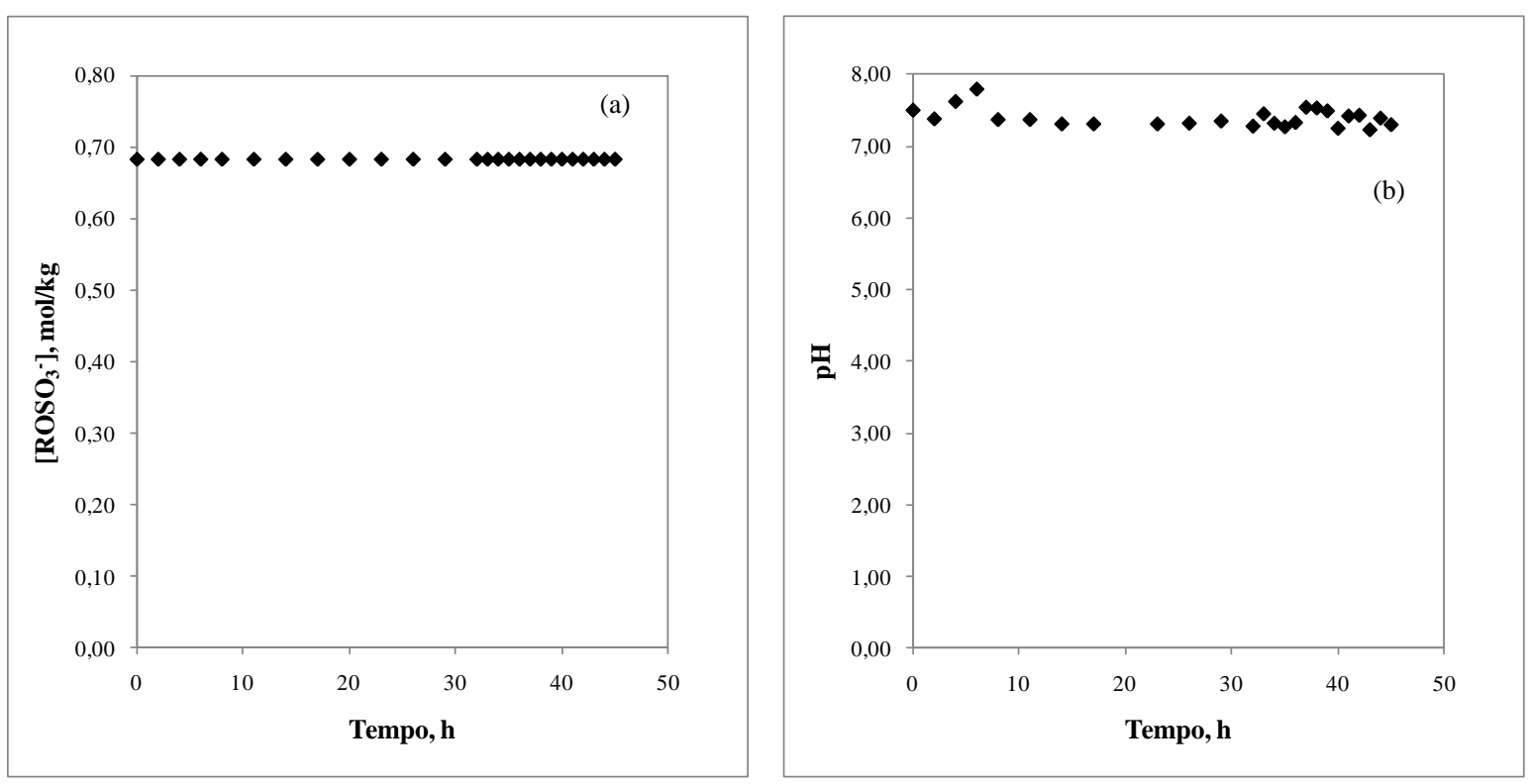

Figura 20- Acompanhamento da reação de hidrólise a nas seguintes condições:

$T=80^{\circ} \mathrm{C} ; \mathrm{pH}=7,0 ; \mathrm{AE2EO}=1,20 \% ; \mathrm{NaCl}=0,04 \% ; \mathrm{Na}_{2} \mathrm{SO}_{4}=0,40 \%$ (EXPERIMENTO 6) (a) variação no teor de ativos (b) variação no valor de $\mathrm{pH}, 25^{\circ} \mathrm{C}$ 

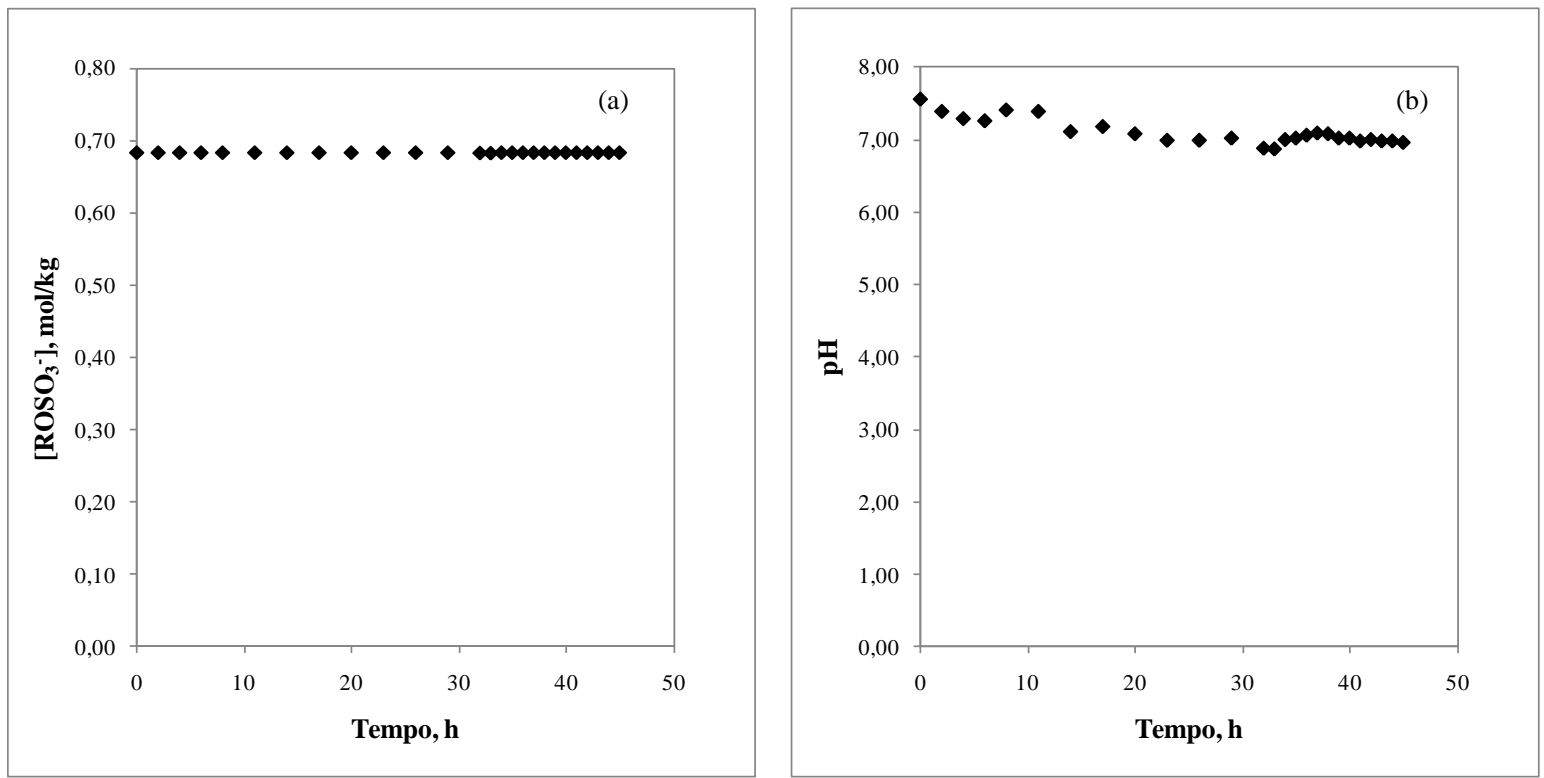

Figura 21- Acompanhamento da reação de hidrólise a nas seguintes condições:

$T=100^{\circ} \mathrm{C} ; \mathrm{pH}=7,0 ; \mathrm{AE2EO}=0,80 \% ; \mathrm{NaCl}=0,20 \% ; \mathrm{Na}_{2} \mathrm{SO}_{4}=0,40 \%$ (EXPERIMENTO 7) (a) variação no teor de ativos (b) variação no valor de $\mathrm{pH}, 25^{\circ} \mathrm{C}$
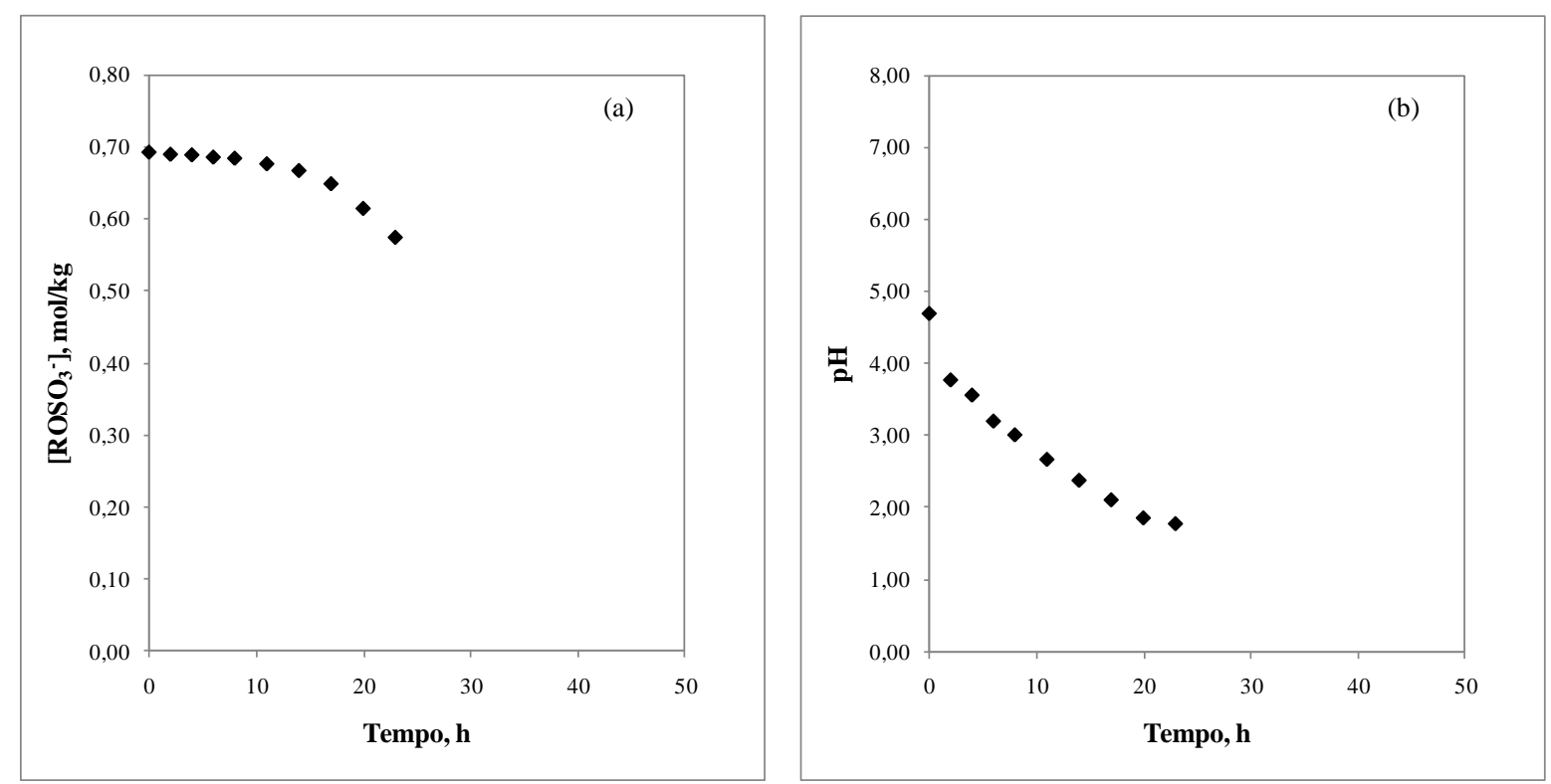

Figura 22- Acompanhamento da reação de hidrólise a nas seguintes condições:

$T=80^{\circ} \mathrm{C} ; \mathrm{pH}=4,0 ; \mathrm{AE} 2 \mathrm{EO}=1,20 \% ; \mathrm{NaCl}=0,20 \% ; \mathrm{Na}_{2} \mathrm{SO}_{4}=0,40 \%$ (EXPERIMENTO 8) (a) variação no teor de ativos (b) variação no valor de $\mathrm{pH}, 25^{\circ} \mathrm{C}$ 

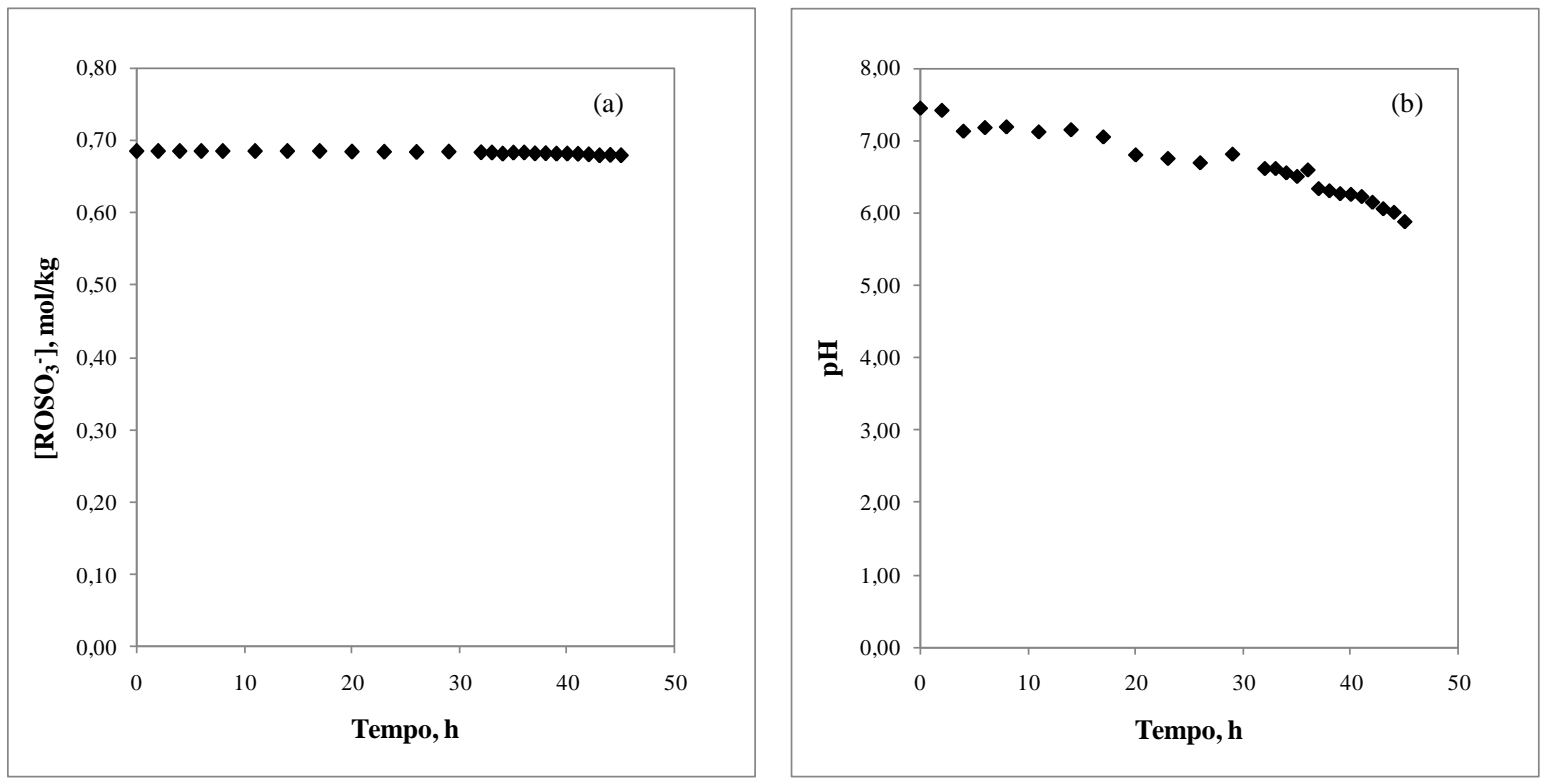

Figura 23- Acompanhamento da reação de hidrólise a nas seguintes condições:

$T=100^{\circ} \mathrm{C} ; \mathrm{pH}=7,0 ; \mathrm{AE} 2 \mathrm{EO}=1,20 \% ; \mathrm{NaCl}=0,20 \% ; \mathrm{Na}_{2} \mathrm{SO}_{4}=0,80 \%$ (EXPERIMENTO 10) (a) variação no teor de ativos (b) variação no valor de $\mathrm{pH}, 25^{\circ} \mathrm{C}$
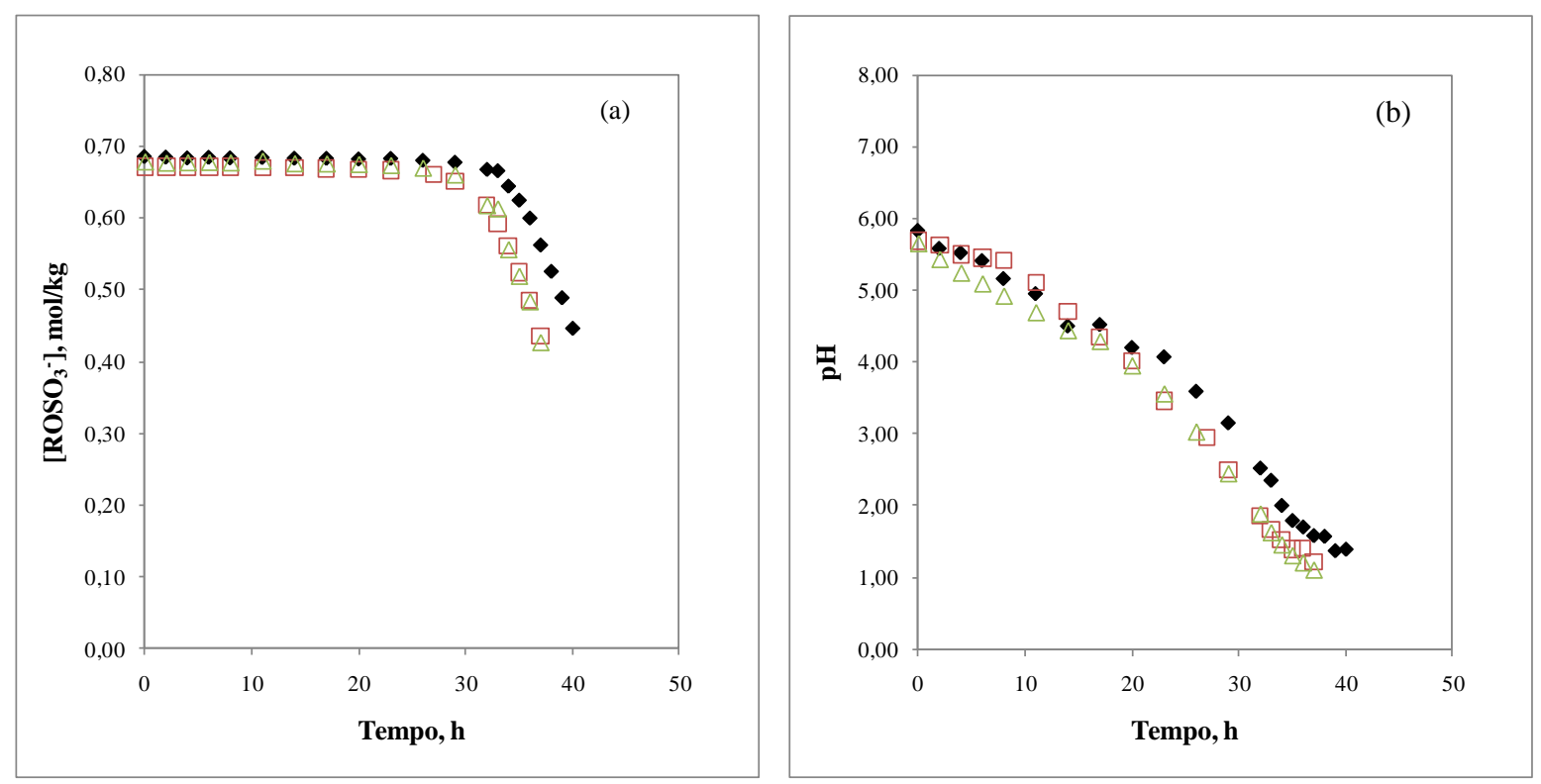

Figura 24- Acompanhamento da reação de hidrólise a nas seguintes condições:

$T=90^{\circ} \mathrm{C} ; \mathrm{pH}=5,5 ; \mathrm{AE2EO}=1,00 \% ; \mathrm{NaCl}=0,12 \% ; \mathrm{Na}_{2} \mathrm{SO}_{4}=0,60 \%$ (EXPERIMENTOS 2,9 e 11) (a) variação no teor de ativos (b) variação no valor de $\mathrm{pH}, 25^{\circ} \mathrm{C}$

Observa-se que só não houve variação significativa no teor de ativos nos experimentos com pH inicialmente neutro.

Em quase todos os casos observa-se um período inicial de estabilidade, ou de variação muito pequena, seguido por uma queda mais acentuada no teor de ativos. Observa-se 
também, analisando os gráficos que o início dessa queda acentuada no teor de ativos coincide com o momento em que o pH já está suficientemente baixo, na faixa de 2,0 a 3,0 conforme já havia sido observado no teste preliminar. Aparentemente a quantidade de íons $H^{+}$livres é suficientemente grande para iniciar a etapa ácido catalítica de queda acelerada do teor de ativos quando o $\mathrm{pH}$ encontra-se nessa faixa.

O intervalo de estabilidade, assim com a intensidade na queda do teor de ativos, variou de acordo com as condições adotadas em cada experimento. No EXPERIMENTO 4 e no EXPERIMENTO 5 observa-se uma queda mais intensa no teor de ativos e um período de estabilidade relativamente pequeno.

A repetição do ponto central (EXPERIMENTOS 2, 9 e 11) mostrou boa reprodutibilidade no comportamento da variação do teor de ativos e do $\mathrm{pH}$.

Nota-se uma queda no valor do $\mathrm{pH}$ em praticamente todos os experimentos, mesmo naqueles iniciados em $\mathrm{pH}$ neutro em que não houve variação significativa no teor de ativos. $\mathrm{O}$ único caso em que se pode dizer que não houve queda no valor de $\mathrm{pH}$ no tempo de observação de $45 \mathrm{~h}$ foi no EXPERIMENTO 7 realizado em $\mathrm{pH}$ neutro e temperatura no limite inferior da faixa.

\subsection{Análise do erro experimental}

A partir da análise e comparação dos dados experimentais obtidos através da repetição do ponto central foi possível avaliar o erro experimental tanto para a medida do teor de ativos quanto para a medida de $\mathrm{pH}$ a partir do cálculo da média e do desvio padrão dos resultados conforme apresentado na Tabela 17. 
Tabela 17- Resultados de cálculo de média e desvio padrão para as medidas realizadas na repetição das condições do ponto central

\begin{tabular}{|c|c|c|c|c|c|c|}
\hline \multirow[b]{2}{*}{$\mathrm{t}(\mathrm{h})$} & \multicolumn{3}{|c|}{$\left[\mathrm{ROSO}_{3} \mathrm{H}\right](\mathrm{mol} / \mathrm{kg})$} & \multicolumn{3}{|c|}{$\mathrm{pH}$} \\
\hline & média & $\begin{array}{l}\text { desvio } \\
\text { padrão }\end{array}$ & $\begin{array}{c}\text { desvio } \\
\text { padrão } \\
\text { relativo }^{\mathrm{a}}\end{array}$ & média & $\begin{array}{l}\text { desvio } \\
\text { padrão }\end{array}$ & $\begin{array}{l}\text { desvio } \\
\text { padrão } \\
\text { relativo }^{\mathrm{a}}\end{array}$ \\
\hline 0 & 0,679 & 0,007 & $1,0 \%$ & 5,72 & 0,10 & $1,7 \%$ \\
\hline 2 & 0,678 & 0,006 & $0,9 \%$ & 5,54 & 0,11 & $2,0 \%$ \\
\hline 4 & 0,677 & 0,006 & $0,9 \%$ & 5,42 & 0,16 & $3,0 \%$ \\
\hline 6 & 0,678 & 0,006 & $0,9 \%$ & 5,31 & 0,20 & $3,8 \%$ \\
\hline 8 & 0,677 & 0,006 & $0,9 \%$ & 5,16 & 0,25 & $4,8 \%$ \\
\hline 11 & 0,678 & 0,007 & $1,0 \%$ & 4,91 & 0,22 & $4,4 \%$ \\
\hline 14 & 0,676 & 0,007 & $1,0 \%$ & 4,54 & 0,14 & $3,1 \%$ \\
\hline 17 & 0,676 & 0,007 & $1,0 \%$ & 4,38 & 0,12 & $2,9 \%$ \\
\hline 20 & 0,675 & 0,007 & $1,0 \%$ & 4,05 & 0,13 & $3,3 \%$ \\
\hline 23 & 0,674 & 0,008 & $1,2 \%$ & 3,69 & 0,33 & $8,9 \%$ \\
\hline 26 & 0,670 & 0,009 & $1,4 \%$ & 3,18 & 0,35 & $11,1 \%$ \\
\hline 29 & 0,663 & 0,013 & $2,0 \%$ & 2,69 & 0,40 & $14,7 \%$ \\
\hline 32 & 0,634 & 0,029 & $4,5 \%$ & 2,08 & 0,38 & $18,2 \%$ \\
\hline 33 & 0,624 & 0,037 & $6,0 \%$ & 1,88 & 0,41 & $21,7 \%$ \\
\hline 34 & 0,587 & 0,049 & $8,4 \%$ & 1,66 & 0,30 & $17,9 \%$ \\
\hline 35 & 0,556 & 0,059 & $10,7 \%$ & 1,49 & 0,26 & $17,5 \%$ \\
\hline 36 & 0,522 & 0,067 & $12,7 \%$ & 1,43 & 0,25 & $17,6 \%$ \\
\hline 37 & 0,474 & 0,076 & $15,9 \%$ & 1,30 & 0,25 & $19,2 \%$ \\
\hline
\end{tabular}

a: o desvio padrão relativo foi calculado em relação à média

Observa-se um maior desvio padrão relativo médio, e, portanto, um maior erro experimental para a medida de $\mathrm{pH}$.

Avaliando-se a variação do erro experimental ao longo do tempo é possível observar um aumento do desvio padrão para a medida do teor de ativos ao longo do tempo, essa correlação do erro experimental com o tempo não é tão forte para a medida de pH como podemos observar nas Figuras 25 e 26 . 

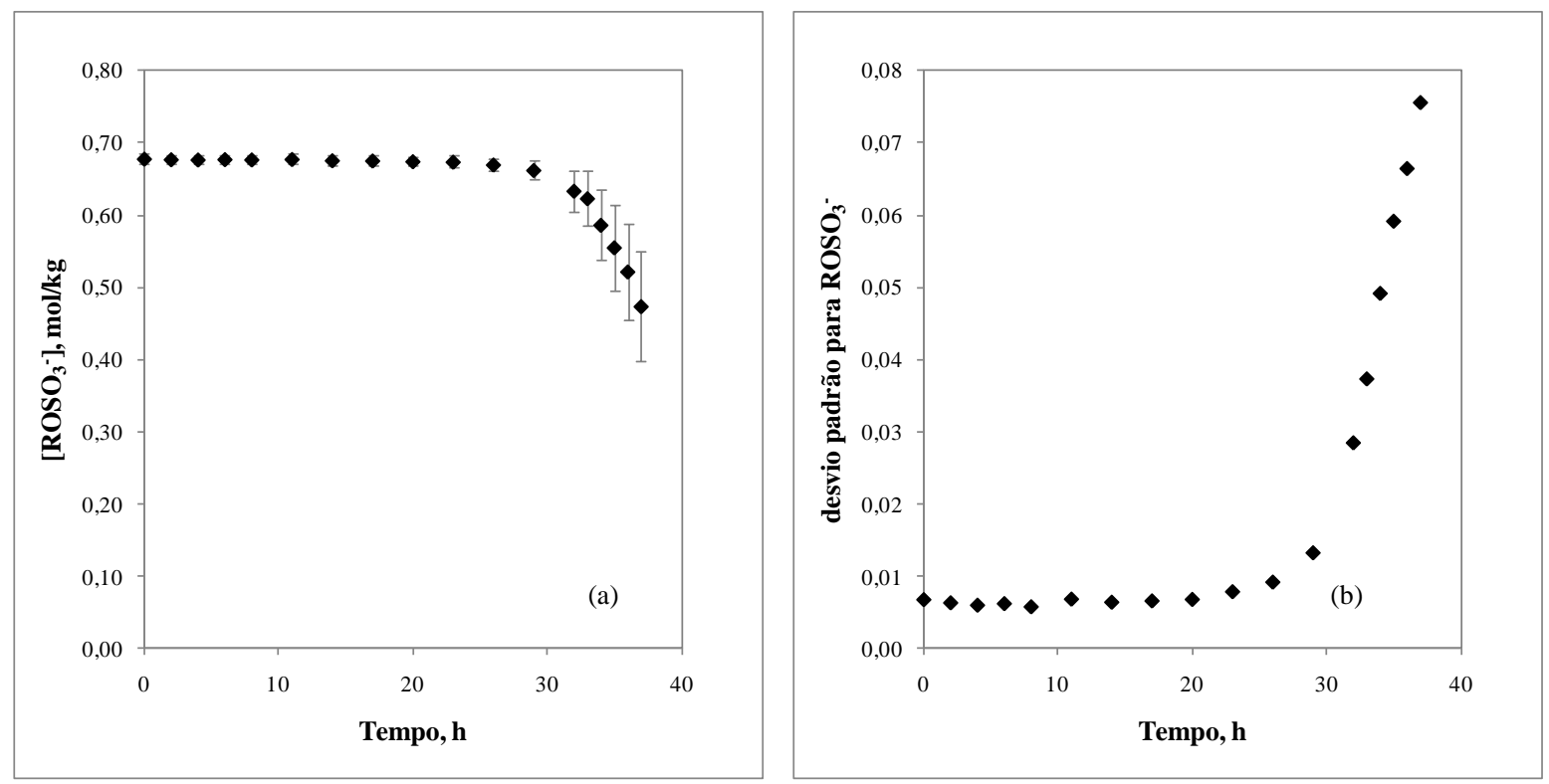

Figura 25- Variação do erro experimental ao longo do tempo para a medida do teor de ativos (a) teor de ativos e desvio padrão (b) desvio padrão em função do tempo para o teor de ativos
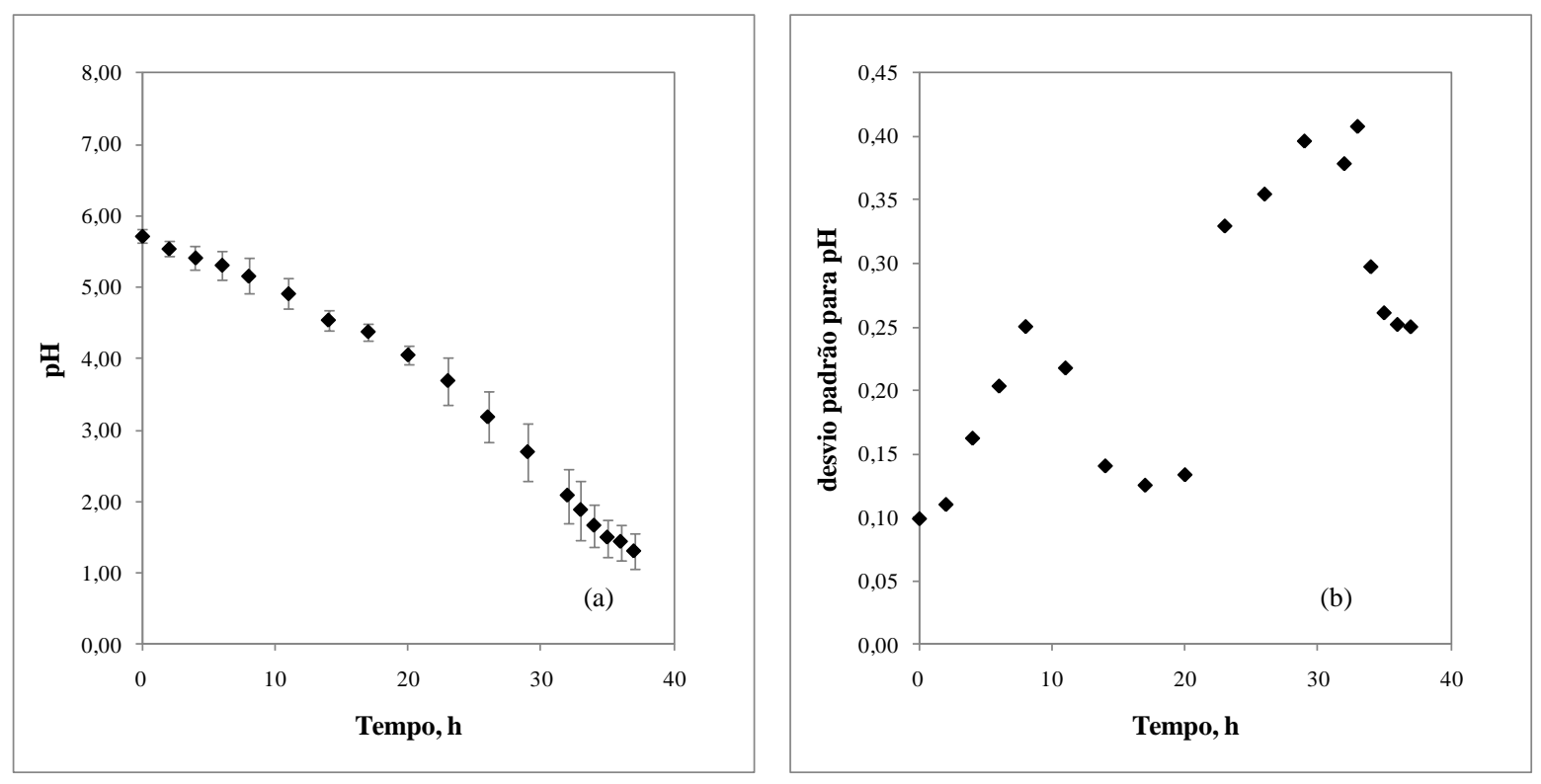

Figura 26- Variação do erro experimental ao longo do tempo para a medida de $\mathrm{pH}$ (a) $\mathrm{pH}$ e desvio padrão (b) desvio padrão em função do tempo para o pH

\subsection{Ajuste dos dados experimentais utilizando um modelo teórico}

O ajuste e estimativa dos parâmetros a partir do modelo de troca iônica em pseudo-fase foi feito utilizando os resultados de variação do teor de ativos e do $\mathrm{pH}$ ao longo do tempo para cada condição experimental. 
Partindo-se da equação (9) apresentada na revisão bibliográfica tem-se:

$$
\begin{aligned}
& \frac{d C_{T}}{d t}=- \text { rate } \\
& \frac{d H_{T}}{d t}=+ \text { rate }
\end{aligned}
$$

Onde:

$$
\text { rate }=f(t)=\frac{k_{s} \cdot H_{s}}{V_{s}}
$$

Os valores de $k_{s}$ e $V_{s}$ foram adotados como constantes ao longo da reação e o valor de $H_{s}$ varia a cada instante $t$.

O cálculo da concentração total de ativos e da concentração total de íons $H^{+}$em cada instante foi feito a partir da seguinte aproximação:

$$
\begin{aligned}
& \frac{\Delta C_{T}}{\Delta t}=- \text { rate } \\
& \frac{\Delta H_{T}}{\Delta t}=+ \text { rate }
\end{aligned}
$$

Como todos os experimentos de acompanhamento da reação de hidrólise foram realizados na presença de eletrólitos, foi utilizada a equação (41) para o cálculo de $H_{s}$.

Os valores de $\beta, K_{H / X}$ e $X_{T}$ foram adotados como constantes ao longo da reação enquanto que a concentração total de ativos - $C$ - e a concentração total de íons $H^{+}-H_{T}$ como variáveis ao longo do tempo. 
O valor de $X_{T}$, que nesse estudo corresponde ao total de íons $\mathrm{Na}^{+}$, foi calculado considerando-se o total de eletrólitos adicionado e a concentração inicial de contra-íons $\mathrm{Na}^{+}$ do tensoativo no início da reação.

A estimativa do valor de $H_{s}$ foi realizada a cada instante partindo-se de $t=0$ e definindo-se o intervalo de tempo, $\Delta t$, de 1 hora.

A concentração inicial de tensoativo corresponde ao teor encontrado na análise de titulação com solução catiônica na amostra inicial.

O total de íons $H^{+}$no início da reação, no entanto, foi estimado partindo-se do valor encontrado para o pH na amostra inicial mas, considerando-se que a concentração estimada através da leitura do $\mathrm{pH}$ corresponde à concentração de íons $H^{+}$na fase aquosa - $H_{w}$ - e não a $H_{T}$. O valor da concentração total de íons $H^{+}$em $t=0-H_{T 0}$ - foi estimado, portanto, a partir do ajuste do modelo aos dados experimentais.

\subsubsection{Ajuste dos parâmetros $k_{s}, V_{s}, \beta, K_{H / X}$ e $H_{T 0}$}

Nessa primeira abordagem o cálculo do valor de $H_{s}$ segundo a equação (41) foi utilizado para determinar a taxa de reação a cada instante, em mol/(kg.h), e com isso foi possível estimar a concentração de ativos e a concentração total de íons $H^{+}$no instante posterior.

O ajuste dos parâmetros $k_{s}, V_{s}, \beta, K_{H / X}$ e $H_{T 0}$ para cada condição experimental foi feito de forma que a diferença entre o valor do teor de ativos obtido em cada experimento e o calculado pelo modelo fosse a menor possível.

$\mathrm{O}$ valor do $\mathrm{pH}$ estimado pelo modelo teórico foi calculado a cada instante conforme sugerido por Bunton e Wolfe (1973) - equação (70) - adotando $H_{w}$ em mol/L:

$$
p H=-\log \left(H_{w}\right)
$$


O ajuste dos parâmetros foi feito utilizando-se o Microsoft Office Excel 2007 Solver $^{\circledR}$, essa ferramenta utiliza o código de otimização não linear de gradiente reduzido generalizado ou generalized reduced gradient (GRG). Esse algoritmo foi desenvolvido em 1960 por Jean Abadie e desde então tem sido melhorado por muitos outros pesquisadores (EDGAR; HIMMELBLAU; LADSON, 2001).

A versão disponível de otimizador não-linear e utilizada pelo Microsoft Office Excel 2007 Solver ${ }^{\circledR}$ é a GRG2 desenvolvida por Leon Ladson, da Universidade do Texas em Austin, e AlanWaren, da Universidade Estadual de Cleveland.

O algoritmo de GRG é bastante versátil e especialmente indicado para problemas de otimização sem restrição ou com conjunto de restrições lineares, embora também funcione bem para o caso de restrições não-lineares (EDGAR; HIMMELBLAU; LADSON, 2001).

Os códigos GRG utilizam um algoritmo descendente básico, conforme descrito de forma geral a seguir para o caso de problemas sem restrição:

(a) Calcula o gradiente de $f(x)$ no ponto atual $x_{c}$ fornecendo $\nabla f\left(x_{c}\right)$

(b) Se o ponto atual $x_{c}$ está perto o suficiente para ser considerado ótimo, fim

(c) Calcula uma direção de busca $d_{c}$ utilizando o gradiente $\nabla f\left(x_{c}\right)$ e outra informação como, por exemplo, a direção de busca anterior

(d) Determina o quanto se deve movimentar, na direção de busca atual $d_{c}$, partindo-se de $x_{c}$. Essa distância a ser percorrida, $a_{c}$, é quase sempre uma aproximação do valor de $a$ que minimiza a função objetivo $f\left(x_{c}+a \cdot d_{c}\right)$ e é utilizada para determinar o próximo ponto $x_{n}=\left(x_{c}+a \cdot d_{c}\right)$

(e) Substitui o ponto atual $x_{c}$ pelo próximo ponto $x_{n}$ e retorna ao passo (a)

Todas as restrições, no código GRG2 empregado pelo Solver ${ }^{\circledR}$, são assumidas como do tipo $l_{i} \leq g_{i}(x) \leq u_{i}$ onde $l_{i}$ e $u_{i}$ são constantes e representam, respectivamente, o limite inferior e superior. 
Há um limite máximo de somente algumas centenas de restrições para os problemas que podem ser resolvidos pelo código GRG2, para problemas acima desse tamanho o desempenho do algoritmo é bastante prejudicado.

Como no estudo em questão serão utilizadas apenas restrições lineares e o número de restrições é relativamente pequeno acredita-se que o algoritmo GRG2 seja adequado para localizar o conjunto ótimo de parâmetros.

A tarefa consiste em minimizar a função objetivo, especificada mais adiante, respeitandose um sistema linear de igualdades ou desigualdades que recebe o nome de conjunto de restrições. As restrições do modelo determinam uma região que recebe o nome de conjunto de soluções viáveis e a melhor solução dentro desse conjunto é denominada solução ótima.

No presente estudo o problema consiste em determinar o conjunto de parâmetros $\left(k_{s}, V_{s}, K_{H / X}, \beta, H_{T_{t=0}}\right)$ que satisfaça todas as restrições e ao mesmo tempo minimize o valor da função objetivo.

$\mathrm{O}$ ajuste dos parâmetros foi feito utilizando-se diferentes abordagens, em um primeiro momento a função objetivo utilizada foi $E_{I}$ descrita na equação (71):

$$
E_{I}=\sum_{t=0}^{t_{f}}\left(\frac{C_{T t}^{\text {calc }}-C_{T_{t}}^{\exp }}{C_{T t}^{\exp }}\right)^{2}+\sum_{t=0}^{t_{f}}\left(\frac{H_{T t}^{\text {calc }}-H_{T t}^{\exp }}{H_{T t}^{\exp }}\right)^{2}
$$

Onde $t_{f}$ representa o instante final do experimento, $C_{T t}^{\text {calc }}$ e $H_{T t}^{\text {calc }}$ correspondem à concentração de ativos e de íons $H^{+}$em um determinado instante calculadas pelo modelo enquanto $C_{T t}^{\exp }$ e $H_{T t}^{\exp }$ correspondem, respectivamente, à concentração experimental de ativos e de íons $H^{+}$nesse mesmo instante

O conjunto de restrições utilizado para o ajuste dos parâmetros nessa primeira abordagem foi o seguinte: 


$$
\left\{\begin{array}{l}
H_{T 0} \geq 10^{-p H_{t=0}^{\exp }} \\
p H_{t=0}^{\text {calc }}-p H_{t=0}^{\exp }=0 \\
k_{s} \geq 0 \\
H_{T}>H_{s}, \forall t \\
\left(C_{T}, H_{T}\right)>0, \forall t
\end{array}\right.
$$

Onde $p H_{t=0}^{\text {calc }}$ corresponde ao $\mathrm{pH}$ calculado pelo modelo para $t=0$ e $p H_{t=0}^{\exp }$ corresponde ao $\mathrm{pH}$ analisado ao início do experimento.

Nesse mesmo conjunto de restrições foram adicionadas as faixas de variação esperadas para cada um dos parâmetros de acordo com a bibliografia consultada:

$$
\left\{\begin{array}{l}
0,6 \leq \beta \leq 0,9 \\
0,14 \leq V_{s} \leq 0,20 \\
0 \leq K_{H / N a} \leq 4
\end{array}\right.
$$

Os ajustes realizados nessa primeira abordagem não foram muito satisfatórios, em especial com relação ao ajuste do $\mathrm{pH}$.

Considerando-se que o erro experimental relativo para a medida do $\mathrm{pH}$ foi maior do que o erro experimental para o teor de ativos, conforme mencionado anteriormente, foi utilizada uma nova função objetivo $E_{I I}$ para ajuste dos parâmetros considerando somente o ajuste do modelo para a variação do teor de ativos conforme descrito na equação (80). 
Outra possível razão que pode explicar esse ajuste do $\mathrm{pH}$ não ter sido bem sucedido é o fato de que o $\mathrm{pH}$ experimental foi medido nas amostras após resfriamento para a temperatura de $25^{\circ} \mathrm{C}$ e não na temperatura de reação $\left(80^{\circ} \mathrm{C}-100^{\circ} \mathrm{C}\right)$.

$$
E_{I I}=\sum_{t=0}^{t_{f}}\left(\frac{C_{T_{t}}^{\text {calc }}-C_{T t}^{\text {exp }}}{C_{T_{t}}^{\exp }}\right)^{2}
$$

Utilizando-se essa nova função objetivo o ajuste dos parâmetros obedecendo-se todas as restrições impostas foi satisfatório para alguns dos experimentos.

Como o ajuste não foi possível em todos os experimentos e considerando que uma das desvantagens do modelo, conforme Kahn (2010), é a de que o perfil de velocidade calculado pode apresentar mais de uma combinação dos vários parâmetros foi feita uma nova abordagem para o ajuste dos dados experimentais ao modelo considerando algumas simplificações conforme apresentado a seguir.

\subsubsection{Ajuste dos parâmetros $Q$ e $H_{T 0}$}

Nessa segunda abordagem o ajuste de parâmetros foi feito partindo-se de uma proposta de simplificação do modelo teórico apresentado conforme descrito a seguir.

Partindo-se da equação (41) proposta para o cálculo de $H_{s}$ na presença de eletrólito adicionado e considerando que, segundo Romsted (1977): $H_{T}<<X_{T}$, observa-se que o termo $K_{H / X} \cdot H_{T}$ seria desprezível frente ao valor de $X_{T}$ já que $K_{H / X} \approx 1$ e, dessa forma, pode-se reescrever a equação (41) da seguinte forma:

$$
H_{s}=\frac{\beta \cdot C_{T} \cdot K_{H / X} \cdot H_{T}}{X_{T}}
$$

Assim sendo tem-se a variação da concentração de ativos e da concentração total de íons hidrogênio ao longo do tempo por meio das equações (82) e (83): 


$$
\begin{aligned}
& C_{T_{t_{i}}}=C_{T_{t i-1}}-\Delta t \cdot\left(\frac{k_{s} \cdot \beta \cdot C_{T_{i-1}} \cdot K_{H / X} \cdot H_{T_{t i-1}}}{V_{s} \cdot X_{T}}\right) \\
& H_{T_{t i}}=H_{T_{t i-1}}+\Delta t \cdot\left(\frac{k_{s} \cdot \beta \cdot C_{T_{i-1}} \cdot K_{H / X} \cdot H_{T_{t i-1}}}{V_{s} \cdot X_{T}}\right)
\end{aligned}
$$

Ou ainda:

$$
\begin{aligned}
& C_{T_{t_{i}}}=C_{T_{t i-1}}-\Delta t \cdot\left(\frac{Q \cdot C_{T_{t i-1}} \cdot H_{T_{t i-1}}}{X_{T}}\right) \\
& H_{T_{t_{i}}}=H_{T_{t i-1}}+\Delta t \cdot\left(\frac{Q \cdot C_{T_{t i-1}} \cdot H_{T_{t i-1}}}{X_{T}}\right)
\end{aligned}
$$

Utilizando as equações (84) e (85) e foi possível realizar um novo ajuste utilizando o Solver ${ }^{\circledR}$ para cálculo do coeficiente $Q$ para cada condição experimental, definido como:

$$
Q=\left(\frac{k_{s} \cdot \beta \cdot K_{H / X}}{V_{s}}\right)
$$

Esse novo ajuste foi realizado considerando-se a mesma função objetivo descrita anteriormente pela equação (80) e as restrições descritas nas equações (72) e (76).

A partir do modelo simplificado não é possível o cálculo do valor de $\mathrm{pH}$ estimado para compararmos com o valor de $\mathrm{pH}$ analisado durante o experimento da mesma forma como foi feito na abordagem anterior pois conhecendo-se $Q$ e $H_{T 0}$ não é possível calcular o valor de $H_{s}$ através da equação (81).

Os ajustes foram realizados para cada condição experimental e valores encontrados para $Q$ e $H_{T 0}$ estão descritos na Tabela 18. 
O ajuste para o ponto central foi feito utilizando-se a média dos resultados de análise do teor de ativos e pH para os três experimentos realizados.

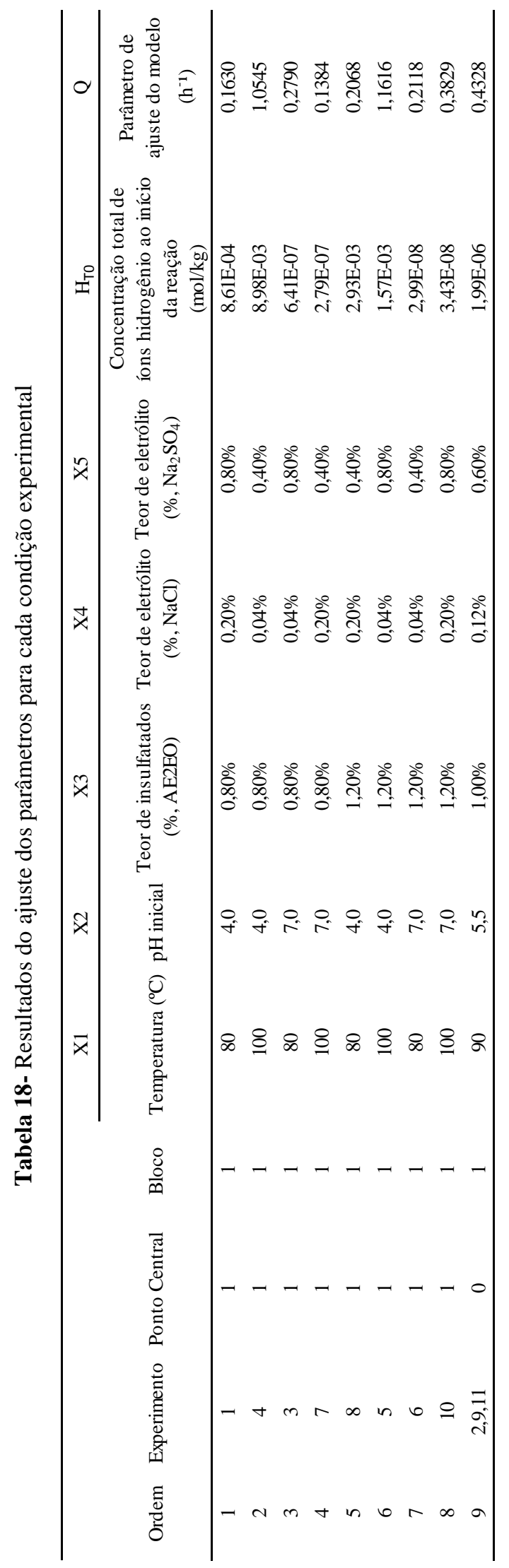


A somatória das funções objetivo - $E_{I I}$ - para todos os experimento considerando-se os valores para os parâmetros apresentados na Tabela 18 foi de 8,96E-03. Esse erro foi bem menor do que a somatória da função objetivo na abordagem realizada anteriormente considerando-se os experimentos em que foi possível realizar o ajuste dos parâmetros de forma individual.

Em seguida foi feito um cálculo da correlação do parâmetro $Q$ com as variáveis $X 1, X 2, X 3, X 4$ e $X 5$, o resultado é apresentado na Tabela 19.

Tabela 19- Resultados da análise de correlação do parâmetro ajustado $Q$ com as variáveis estudadas

\begin{tabular}{cccccc}
\hline & $\mathrm{X} 1$ & $\mathrm{X} 2$ & $\mathrm{X} 3$ & $\mathrm{X} 4$ & $\mathrm{X} 5$ \\
\cline { 2 - 6 } & & & & \\
Temperatura $\left({ }^{\circ} \mathrm{C}\right)$ & $\mathrm{pH}$ inicial & $\begin{array}{c}\text { Teor de insulfatados } \\
(\%, \mathrm{AE} 2 \mathrm{EO})\end{array}$ & $\begin{array}{c}\text { Teor de eletrólito } \\
(\%, \mathrm{NaCl})\end{array}$ & $\begin{array}{c}\text { Teor de eletrólito } \\
(\%, \mathrm{Na} 2 \mathrm{SO})\end{array}$ \\
\cline { 3 - 6 } $\mathrm{Q}$ & & $10,59 \%$ & $\mathbf{- 5 8 , 5 7 \%}$ & $12,10 \%$ \\
\hline
\end{tabular}

Observa-se boa correlação, maior do que $50 \%$, para as variáveis: temperatura, $\mathrm{pH}$ inicial e teor de cloreto de sódio ( $X 1, X 2$ e $X 4$ ). Esse resultado é coerente com aquele observado na análise das variáveis de maior efeito utilizando-se o Minitab ${ }^{\circledR}$. Essas mesmas três variáveis foram as que apresentavam maior efeito na fração convertida do teor de ativos $(Y 1)$.

O sinal do efeito também é compatível, pois foi observado que quanto maior a temperatura, menor o $\mathrm{pH}$ e maior o teor de cloreto de sódio, menor é o valor do parâmetro de ajuste do modelo - $Q$ - e, portanto, mais lenta é a reação de hidrólise.

Na Figura 27 são apresentados os gráficos comparando-se os teores de ativo calculados pelo modelo com os resultados obtidos nos experimentos. 


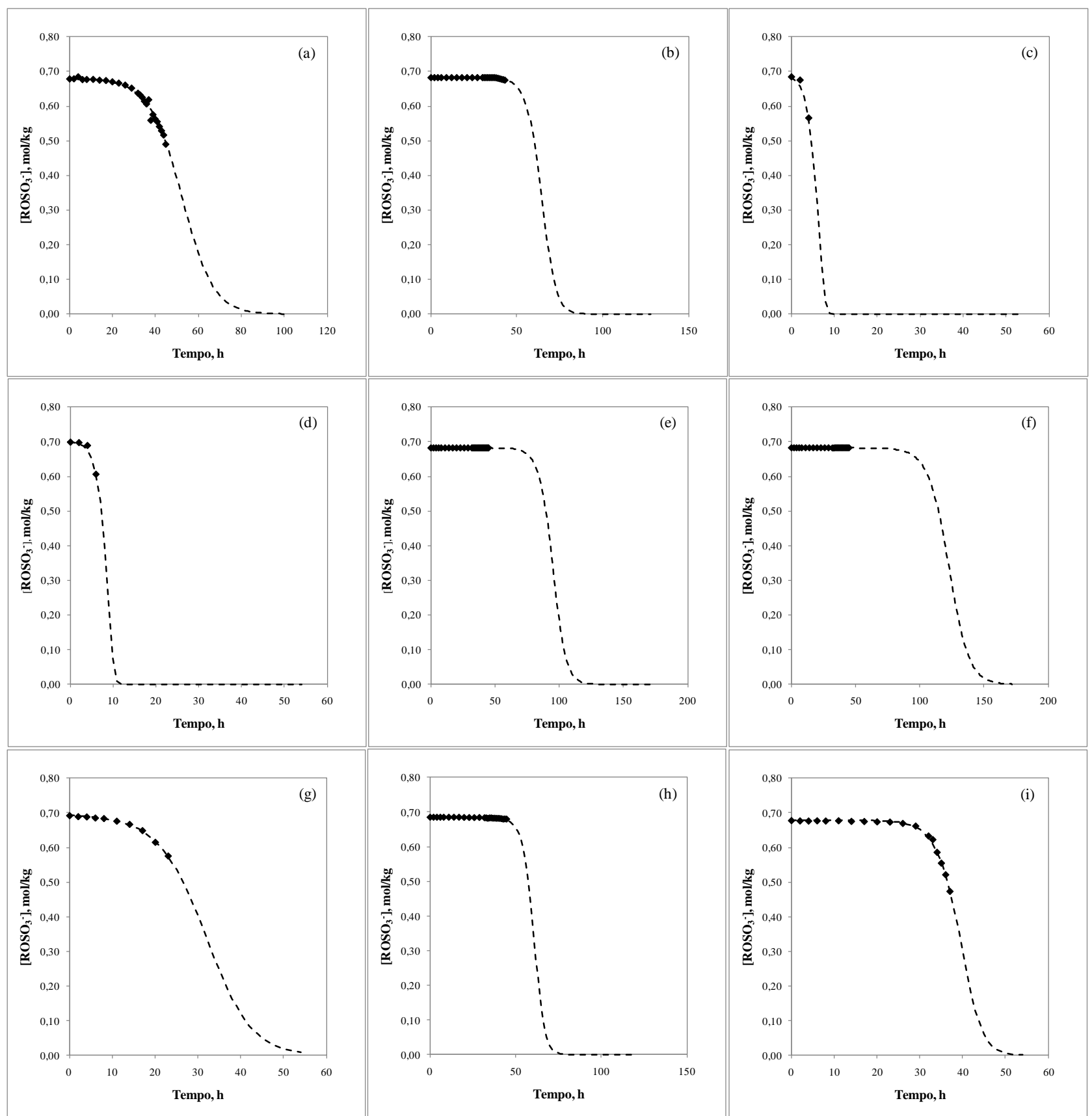

Figura 27- Comparação dos dados experimentais com os ajustes realizados utilizando-se o modelo

(a) $\mathrm{T}=80^{\circ} \mathrm{C} ; \mathrm{pH}=4,0 ; \mathrm{AE2EO}=0,80 \% ; \mathrm{NaCl}=0,20 \% ; \mathrm{Na}_{2} \mathrm{SO}_{4}=0,80 \%$ (EXPERIMENTO 1)

(b) $\mathrm{T}=80^{\circ} \mathrm{C} ; \mathrm{pH}=7,0 ; \mathrm{AE2EO}=0,80 \% ; \mathrm{NaCl}=0,04 \% ; \mathrm{Na}_{2} \mathrm{SO}_{4}=0,80 \%$ (EXPERIMENTO 3)

(c) $\mathrm{T}=100^{\circ} \mathrm{C} ; \mathrm{pH}=4,0 ; \mathrm{AE2EO}=0,80 \% ; \mathrm{NaCl}=0,04 \% ; \mathrm{Na}_{2} \mathrm{SO}_{4}=0,40 \%$ (EXPERIMENTO 4)

(d) $\mathrm{T}=100^{\circ} \mathrm{C} ; \mathrm{pH}=4,0 ; \mathrm{AE2EO}=1,20 \% ; \mathrm{NaCl}=0,04 \% ; \mathrm{Na}_{2} \mathrm{SO}_{4}=0,80 \%$ (EXPERIMENTO 5)

(e) $\mathrm{T}=80^{\circ} \mathrm{C} ; \mathrm{pH}=7,0 ; \mathrm{AE} 2 \mathrm{EO}=1,20 \% ; \mathrm{NaCl}=0,04 \% ; \mathrm{Na}_{2} \mathrm{SO}_{4}=0,40 \%$ (EXPERIMENTO 6)

(f) $\mathrm{T}=100^{\circ} \mathrm{C} ; \mathrm{pH}=7,0 ; \mathrm{AE2EO}=0,80 \% ; \mathrm{NaCl}=0,20 \% ; \mathrm{Na}_{2} \mathrm{SO}_{4}=0,40 \%$ (EXPERIMENTO 7)

(g) $\mathrm{T}=80^{\circ} \mathrm{C} ; \mathrm{pH}=4,0 ; \mathrm{AE2EO}=1,20 \% ; \mathrm{NaCl}=0,20 \% ; \mathrm{Na}_{2} \mathrm{SO}_{4}=0,40 \%$ (EXPERIMENTO 8)

(h) $\mathrm{T}=100^{\circ} \mathrm{C} ; \mathrm{pH}=7,0 ; \mathrm{AE2EO}=1,20 \% ; \mathrm{NaCl}=0,20 \% ; \mathrm{Na}_{2} \mathrm{SO}_{4}=0,80 \%$ (EXPERIMENTO 10)

(i) $\mathrm{T}=90^{\circ} \mathrm{C} ; \mathrm{pH}=5,5 ; \mathrm{AE2EO}=1,00 \% ; \mathrm{NaCl}=0,12 \% ; \mathrm{Na}_{2} \mathrm{SO}_{4}=0,60 \%$ (EXPERIMENTOS 2,9,11)

Observa-se um bom ajuste do modelo aos dados experimentais em todas as condições. 


\subsubsection{Análise de sensibilidade do modelo aos parâmetros $Q$ e $H_{T 0}$}

Após a realização do ajuste do modelo e definição dos parâmetros ótimos destaca-se a importância de verificar o quanto uma variação nesses parâmetros impacta no comportamento da função objetivo. Esta análise, denominada análise da sensibilidade, é uma ferramenta importante na análise de modelos além de proporcionar uma melhor compreensão a respeito do comportamento do sistema.

A análise da sensibilidade foi realizada para o ponto central utilizando-se a seguinte metodologia: inicialmente foi escolhido um dos parâmetros e seu valor alterado sucessivamente mantendo-se o valor dos demais parâmetros constante e analisando o impacto na função objetivo - $E_{I I}$ - definida pela equação (80).

O resultado da análise de sensibilidade realizada para o modelo simplificado é apresentado na Tabela 20 e na Figura 28.

Tabela 20- Resultado do incremento no valor da função objetivo ao variar os parâmetros

\begin{tabular}{|c|c|c|c|c|}
\hline & Q & $\mathrm{H}_{\mathrm{T} 0}$ & Q & $\mathrm{H}_{\mathrm{T} 0}$ \\
\hline & $\begin{array}{l}\text { Parâmetro de } \\
\text { ajuste do modelo } \\
\left(\mathrm{h}^{-1}\right)\end{array}$ & $\begin{array}{c}\text { Concentração total } \\
\text { de íons hidrogênio } \\
\text { ao início da reação } \\
(\mathrm{mol} / \mathrm{kg})\end{array}$ & $\begin{array}{l}\text { Parâmetro de } \\
\text { ajuste do modelo } \\
\left(\mathrm{h}^{-1}\right)\end{array}$ & $\begin{array}{c}\text { Concentração total } \\
\text { de íons hidrogênio } \\
\text { ao início da reação } \\
(\mathrm{mol} / \mathrm{kg})\end{array}$ \\
\hline & \multicolumn{2}{|c|}{$\mathrm{E}_{\mathrm{II}} / \mathrm{E}_{\mathrm{II}} 100 \%$} & \multicolumn{2}{|c|}{$\mathrm{E}_{\mathrm{II}}$} \\
\hline $0 \%$ & 554,7 & 554,7 & $3,61 \mathrm{E}-01$ & $3,61 \mathrm{E}-01$ \\
\hline $10 \%$ & 554,7 & 430,3 & $3,61 \mathrm{E}-01$ & 2,80E-01 \\
\hline $20 \%$ & 554,6 & 326,0 & 3,61E-01 & $2,12 \mathrm{E}-01$ \\
\hline $30 \%$ & 554,1 & 239,8 & $3,61 \mathrm{E}-01$ & $1,56 \mathrm{E}-01$ \\
\hline $40 \%$ & 552,6 & 169,5 & $3,60 \mathrm{E}-01$ & $1,10 \mathrm{E}-01$ \\
\hline $50 \%$ & 547,9 & 113,6 & $3,57 \mathrm{E}-01$ & $7,40 \mathrm{E}-02$ \\
\hline $60 \%$ & 534,0 & 70,6 & $3,47 \mathrm{E}-01$ & 4,59E-02 \\
\hline $70 \%$ & 494,8 & 38,9 & $3,22 \mathrm{E}-01$ & $2,53 \mathrm{E}-02$ \\
\hline $80 \%$ & 394,8 & 17,4 & $2,57 \mathrm{E}-01$ & $1,14 \mathrm{E}-02$ \\
\hline $90 \%$ & 190,3 & 5,1 & $1,24 \mathrm{E}-01$ & $3,34 \mathrm{E}-03$ \\
\hline $100 \%$ & 1,0 & 1,0 & $6,51 \mathrm{E}-04$ & $6,51 \mathrm{E}-04$ \\
\hline $110 \%$ & 566,6 & 4,2 & $3,69 \mathrm{E}-01$ & $2,71 \mathrm{E}-03$ \\
\hline $120 \%$ & $2.756,0$ & 13,9 & $1,79 \mathrm{E}+00$ & $9,02 \mathrm{E}-03$ \\
\hline $130 \%$ & $5.731,6$ & 29,4 & $3,73 \mathrm{E}+00$ & 1,91E-02 \\
\hline $140 \%$ & $8.093,6$ & 50,1 & $5,27 \mathrm{E}+00$ & $3,26 \mathrm{E}-02$ \\
\hline $150 \%$ & $9.548,0$ & 75,5 & $6,21 \mathrm{E}+00$ & 4,91E-02 \\
\hline
\end{tabular}

$\mathrm{E}_{\mathrm{II}} / \mathrm{E}_{\mathrm{II}} 100 \%$ : corresponde ao fator de incremento da função objetivo com a variação nos respectivos parâmetros

$\mathrm{E}_{\mathrm{II}}$ : representa o valor obtido para a função objetivo 

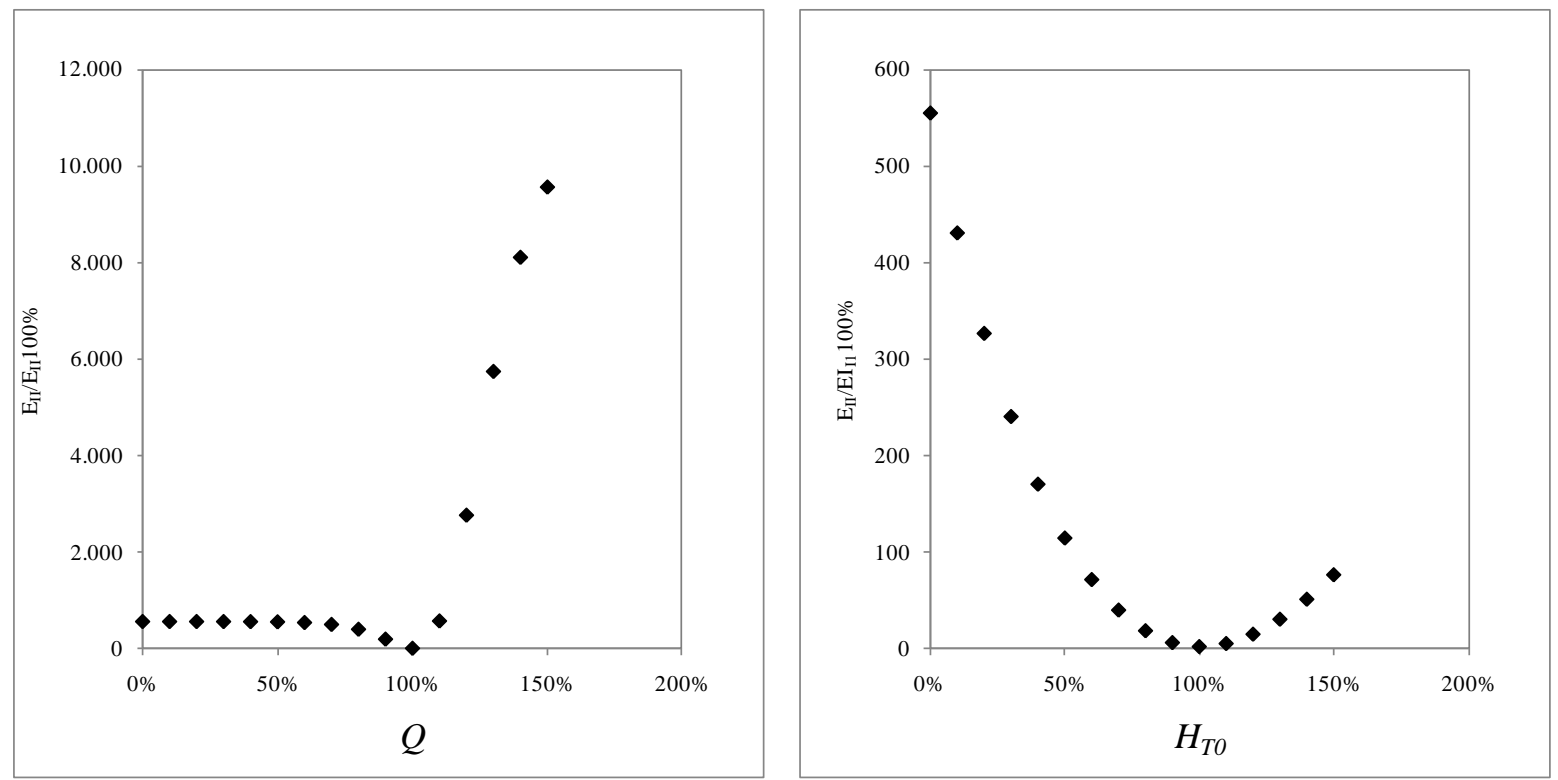

Figura 28- Análise de sensibilidade para os parâmetros do modelo simplificado

Observa-se que o modelo é mais sensível a variações no parâmetro $Q$ do que a variações no parâmetro $H_{T 0}$.

\subsubsection{Análise da estimativa de prazo de validade para o produto}

A partir da estimativa realizada para o parâmetro $Q$ foi possível realizar uma estimativa para o parâmetro $k_{s}$ adotando-se valores para os demais parâmetros $V_{s}, \beta$ e $K_{H / X}$ com base nas informações pesquisadas em literatura.

A hipótese adotada foi a de que os valores dos parâmetros $V_{s}, \beta$ e $K_{H / X}$ são pouco influenciados por alterações nas variáveis $\mathrm{pH}$ inicial, concentração de eletrólitos, teor de insulfatados e temperatura. Essa é uma hipótese comumente adotada nos estudos de cinética das reações micelares.

Os valores adotados para que fosse possível fazer uma estimativa do valor de $k_{s}$ foram os seguintes: $\beta=0,6$ e $V_{s}=0,14$ conforme consta no estudo realizado por Garnett et al. (1983a). O valor do parâmetro $K_{H / N a}$ foi adotado como sendo 1,0 já que esse seria um valor aproximado esperado. 
Dessa forma foi possível calcular o valor de $k_{s}$ para cada condição experimental e, sabendo-se que:

$$
k=A \cdot \exp \left(\frac{-E_{a}}{R \cdot T}\right)
$$

Onde $A$ representa a constante pré-exponencial, $E_{a}$ corresponde à energia de ativaão aparente da reação e que retrata a resposta de variação de $Q, R$ refere-se à constante dos gases e $T$ à temperatura.

A equação (87) pode ser escrita também da seguinte forma:

$$
\ln (k)=\ln (A)-\left(\frac{E_{a}}{R}\right) \cdot \frac{1}{T}
$$

Assim sendo, a partir dos dados encontrados para o parâmetro $k_{s}$ nas diferentes temperaturas testadas $\left(80^{\circ} \mathrm{C}, 90^{\circ} \mathrm{C}\right.$ e $\left.100^{\circ} \mathrm{C}\right)$ - apresentados na Tabela 21 - foi possível estimarmos o valor para os parâmetros $A$ e $E_{a}$ ao traçarmos um gráfico de $\ln (k)$ em função de 1/T com o valor de $T$ expresso em K, conforme se observa na Figura 29. Essa estimativa foi realizada desprezando-se os dois experimentos nos quais não foi observada variação significativa no teor de ativos ao longo do tempo (EXPERIMENTO 6 e EXPERIMENTO 7). Esse cuidado foi tomado pois para esses dois casos acredita-se que pode haver mais de um único valor de $\mathrm{Q}$ com bom resultado de ajuste do modelo.

Tabela 21- Dados para a estimativa de $k_{s}$ em diferentes temperaturas

\begin{tabular}{cc}
\hline & $\mathrm{k}_{\mathrm{s}}$ \\
\cline { 2 - 2 } Temperatura $\left({ }^{\circ} \mathrm{C}\right)$ & $\begin{array}{c}\text { Constante cinética de } \\
\text { reação de hidrólise na } \\
\text { presença de micelas } \\
(\mathrm{L}(\text { mol.h) })\end{array}$ \\
\hline 80 & 0,0505 \\
90 & 0,1010 \\
100 & 0,2021 \\
\hline
\end{tabular}




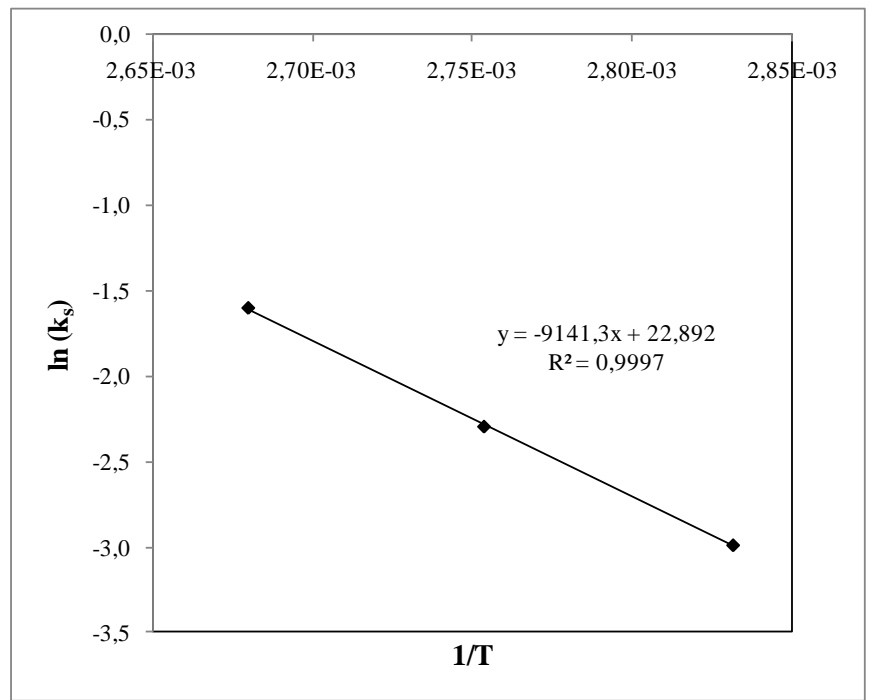

Figura 29- Ajuste linear dos dados ao traçar $\ln (k)$ em função de $1 / T$

Considerando-se o coeficiente angular e o coeficiente linear obtidos pelo ajuste linear dos dados e adotando $R=8,314472 \mathrm{~J} /(\mathrm{mol} . \mathrm{K})$ foi possível estimar os valores dos parâmetros $A$ e $E_{a}$. Os valores encontrados são apresentados na Tabela 22.

Tabela 22- Resultado da estimativa dos parâmetros $A$ e $E_{a}$

\begin{tabular}{cc}
\hline Ea & \\
\hline $\begin{array}{c}\text { Energia de ativação } \\
\text { aparente } \\
(\mathrm{J} / \mathrm{mol})\end{array}$ & $7,60 \mathrm{E}+04$ \\
\hline A & \\
\hline $\begin{array}{c}\text { Constante pré- } \\
\text { exponencial } \\
(\mathrm{L} / \text { mol.h) })\end{array}$ & $8,75 \mathrm{E}+09$ \\
\hline
\end{tabular}

A partir da estimativa desses parâmetros foi possível utilizar o modelo para prever o comportamento e a suscetibilidade à reação de hidrólise do produto em temperaturas mais próximas à temperatura ambiente para estimativa de prazo de validade do produto.

Neste momento foram adotados, para previsão do comportamento do produto à temperatura ambiente $\left(25^{\circ} \mathrm{C}\right)$, os mesmos valores previamente adotados para os parâmetros $V_{s}, K_{H / X}$ e $\beta$ considerando que seriam pouco influenciados pela variação de temperatura e das demais condições. 
Dessa forma foi possível estimar o comportamento do produto e sua susceptibilidade à hidrólise em condições normais em que o produto é exposto.

Assim sendo, utilizando-se as equações (84) a (86) foi possível estimar a variação da concentração total de ativos e a variação da concentração total de íons hidrogênio para estimativa da variação do pH com o tempo - equação (70) - já que conhecendo-se os parâmetros $V_{s}, \beta$ e $K_{H / X}$ é possível calcular o valor de $H_{s}$ utilizando-se a equação (81).

A estimativa do valor de $H_{T 0}$ foi realizada conforme descrito a seguir.

Utilizando a relação descrita na equação (28) e sabendo-se que o valor de $K_{H / X}=1,0$ tem-se que:

$$
H_{s}=\frac{H_{w}}{X_{w}} \cdot X_{s}
$$

No entanto sabe-se que:

$$
\begin{aligned}
& X_{w}=(1-\beta) \cdot C_{T}+X_{a d i c} \\
& H_{T}=H_{w}+H_{s}
\end{aligned}
$$

Onde $X_{\text {adic }}$ corresponde ao total de íons $\mathrm{Na}^{+}$adicionados no meio.

O valor de $H_{w}$ para $t=0-H_{w_{0}}$ - pode ser calculado através do valor de $\mathrm{pH}$ inicial do meio conforme equação (92):

$$
H_{w 0}=10^{-p H_{t=0}^{\exp }}
$$

Para determinar o valor estimado para $H_{T 0}$ partiu-se da equação (91) substituindo-se $H_{s}$ pela expressão da equação (89), assim sendo tem-se: 


$$
H_{T 0}=H_{w 0} \cdot\left(1+\frac{X_{s 0}}{X_{w 0}}\right)
$$

Mas sabe-se também que:

$$
X_{T}=X_{w}+X_{s}
$$

Assim sendo é possível reescrever a equação (93):

$$
H_{T 0}=H_{w 0} \cdot\left(1+\left(\frac{X_{T}-X_{w 0}}{X_{w 0}}\right)\right)
$$

Onde $X_{w 0}$ pode ser calculado pela equação (90) considerando-se a concentração total de ativos - $C_{T}$ - no instante $t=0 . \mathrm{O}$ valor de $H_{w 0}$ pode ser calculado através da equação (92) utilizando-se o pH analisado no instante $t=0$.

$\mathrm{O}$ valor de $k_{s}$ para a temperatura de $25^{\circ} \mathrm{C}$ foi calculado através da equação (87) e em seguida o valor de $Q$ foi determinado utilizando-se a equação (86) e os valores estimados para os parâmetros $V_{s}, \beta$ e $K_{H / X}$ conforme já descrito anteriormente.

Tabela 23- Estimativa para $k_{s}$ e $Q$ à temperatura ambiente

\begin{tabular}{c}
\hline $\mathrm{k}_{\mathrm{s}}\left(25^{\circ} \mathrm{C}\right)$ \\
$\begin{array}{c}\text { Constante cinética de } \\
\text { reação de hidrólise na } \\
\text { presença de micelas } \\
(\mathrm{L} /(\text { mol.h }))\end{array}$ \\
\hline $\mathrm{Q}\left(25^{\circ} \mathrm{C}\right)$ \\
$\begin{array}{c}\text { Parâmetro de ajuste do } \\
\text { modelo } \\
\left(\mathrm{h}^{-1}\right)\end{array}$ \\
\hline
\end{tabular}

A previsão do comportamento para o teor de ativos e $\mathrm{pH}$ do produto foi estimada considerando-se os valores típicos para as variáveis segundo levantamento de análises realizado. O resultado é apresentado na Figuras 30 e 31. 
(a) Teor de ativos: $0,703 \mathrm{~mol} / \mathrm{kg}$

(b) $\mathrm{pH}$ inicial: 7,86

(c) Teor de cloreto de sódio: $0,06 \%$

(d) Teor de sulfato de sódio: 0,34\%

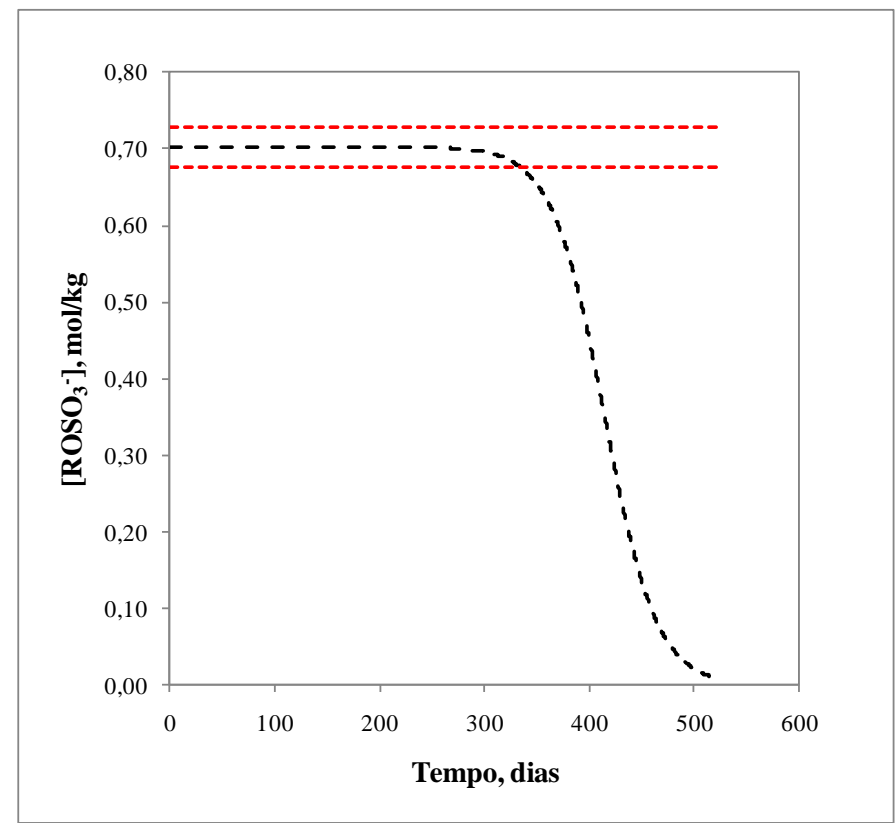

Figura 30- Comportamento estimado para o teor de ativos do produto em suas condições normais de produção segundo modelo

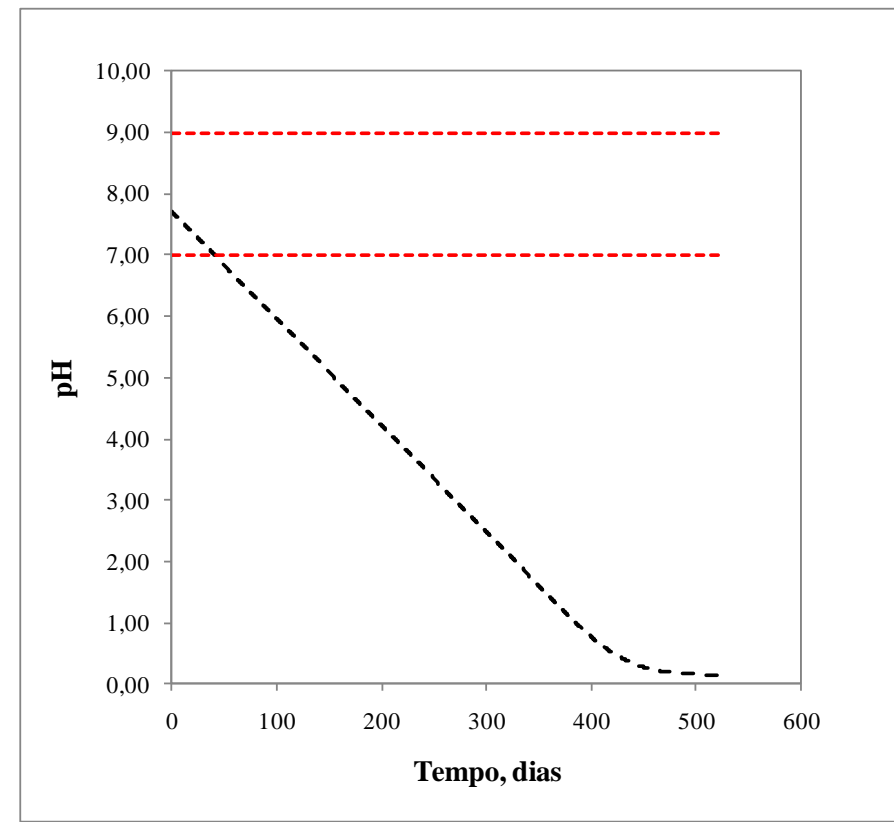

Figura 31- Comportamento estimado para o pH do produto em suas condições normais de produção segundo modelo 
Os limites mínimo e máximo que aparecem nas Figuras 30 e 31 representam as faixas estipuladas pela especificação comercial do produto. Dessa forma é possível estimarmos seu prazo de validade considerando-se qual é o período máximo em que o produto permanece especificado.

Para o teor de ativos a estimativa de prazo de validade do produto, para esse conjunto de condições, seria de cerca de 333 dias. E, no caso do pH, o cenário é ainda pior e o produto seria mantido dentro da especificação por no máximo 40 dias segundo essa estimativa.

No entanto vale ressaltar que neste trabalho não foi estudada a influência da presença de buffers, como é o caso do fosfato de sódio presente na composição do produto. A presença de buffers teria o efeito de retardar a reação de hidrólise e impactaria em um comportamento do $\mathrm{pH}$ mais próximo àquele observado nos experimentos realizados em $\mathrm{pH}$ inicialmente neutro.

O efeito da presença de fosfato de sódio não foi considerado nesse trabalho porque hoje não existe um controle de qual é a quantidade adicionada de ácido fosfórico e, portanto, de quanto seria a concentração de fosfato de sódio formada em cada lote, mas com certeza é uma variável que deverá ser considerada em estudos posteriores.

O modelo ajustado não leva em conta a presença de buffer de forma explícita mas seu efeito está de certa forma embutido nas simulações. Trata-se, portanto, de uma estimativa de prazo de validade que pode ser melhorada através da realização de experimentos adicionais para acompanhamento do produto na temperatura ambiente na presença de uma concentração conhecida e na ausência de buffers.

\subsection{Análise dos dados experimentais utilizando um modelo de redes neurais}

Nesta etapa do trabalho foi realizado um ajuste dos dados experimentais utilizando-se a técnica de redes neurais. Trata-se de um modelo empírico para simular o que acontece no sistema. As variáveis de entrada utilizadas para esse ajuste são apresentadas na Tabela 24. 
Tabela 24- Apresentação das variáveis de entrada e suas respectivas faixas de variação na ordem utilizada para o ajuste do modelo por redes neurais

\begin{tabular}{ll}
\hline Temperatura & $80-100{ }^{\circ} \mathrm{C}$ \\
Teor de insulfatados & $0,80-1,20 \%$ \\
Teor de $\mathrm{NaCl}$ & $0,04-0,20 \%$ \\
Teor de $\mathrm{Na}_{2} \mathrm{SO}_{4}$ & $0,40-0,80 \%$ \\
Tempo & $0-162000 \mathrm{~s}$ \\
pH inicial & $4,0-\mathrm{pH}$ neutro \\
\hline
\end{tabular}

Esses dados foram normalizados para a faixa de $0,1-0,9$ antes de serem utilizados pelo programa. Entende-se esse o conjunto de dados contempla as varáveis mais relevantes para o processo em avaliação.

As variáveis de saída utilizadas foram: teor de ativos e pH. O ajuste foi realizado em separado para cada uma dessas duas variáveis de saída.

O conjunto de dados utilizado para essa simulação foi composto de um total de 203 resultados que correspondem aos dados obtidos a partir dos experimentos realizados em diferentes condições iniciais, alterando as variáveis de entrada de acordo com as faixas especificadas na Tabela 24.

O conjunto do total de 203 resultados experimentais foi dividido em dois grandes grupos: o conjunto de dados de treinamento (learning set) e o conjunto de dados para teste (test set). Os dados para teste da RN, composto de 38 dados, foi elaborado extraindo alguns dados do conjunto total de 203 resultados de forma aleatória. Foram selecionados para serem incluídos no conjunto de teste da RN um total de 2 a 4 resultados por condição experimental dependendo do total de resultados obtidos para cada experimento.

Para o ajuste do modelo, de forma a obter-se o menor erro quadrático, variou-se o número de neurônios da camada oculta e também o valor do parâmetro $\eta$ utilizando-se o programa N14DEZ10.exe de propriedade do LSCP (Laboratório de Simulação e Controle de Processos) do Departamento de Engenharia Química da Escola Politécnica da Universidade de São Paulo. 
Como resposta ao ajuste o programa fornece uma tabela com o cálculo do erro para o conjunto de dados de treinamento, RMST definido pela equação (96), e o erro para o conjunto de teste, RMSTT definido pela equação (97), variando-se o número de apresentações durante o ajuste da $\mathrm{RN}$.

$$
\begin{gathered}
R M S T=\left(\frac{\sqrt{\left(\sum_{m=1}^{r}\left(Y_{\text {calc }}^{(m)}-Y_{\text {exp }}^{(m)}\right)^{2}\right)}}{r}\right) \\
R M S T=\left(\frac{\sqrt{\left(\sum_{m=1}^{r^{\prime}}\left(Y_{\text {calc }}^{(m)}-Y_{\text {exp }}^{(m)}\right)^{2}\right)}}{r^{\prime}}\right)
\end{gathered}
$$

Onde $r^{\prime}$ corresponde ao total de experimentos do conjunto de teste da $\mathrm{RN}$ e $Y_{\text {calc }}^{(m)}$ corresponde ao valor calculado para a variável de saída em avaliação.

\subsubsection{Ajuste do teor de ativos como variável de saída}

Em um primeiro momento foram feitas simulações para o ajuste do teor de ativos como variável de saída e os melhores resultados obtidos são apresentados na Tabela 25.

Na Tabela 25 são apresentados os resultados dos erros - RMST e RMSTT - calculados para os pesos que apresentaram melhor ajuste considerando-se o conjunto de treinamento.

Também são apresentados os dados de $R^{2}, a$ e $b$ para o ajuste linear realizado para o gráfico de $Y_{\text {calc }}^{(m)}$ em função de $Y_{\exp }^{(m)}$ tanto para o conjunto de dados de treinamento (learning test) quanto para o conjunto de testes (test set).

Observando-se os valores de RMST obtidos conclui-se que não foi possível obter um bom ajuste utilizando somente as variáveis de entrada apresentadas na Tabela 24. O melhor ajuste foi obtido quando a variável " $\mathrm{pH}$ ao longo do tempo" foi inserida no pacote de 
variáveis de entrada em substituição à variável "pH inicial", que corresponde à tentativa 5 apresentada na Tabela 25. Esse foi o melhor ajuste obtido por apresentar o menor valor para RMST tendo também apresentado o menor valor para RMSTT assim como bons coeficientes de correlação $-R^{2}$ - tanto para o conjunto de treinamento quando para o conjunto de teste quando comparado com as demais tentativas de ajuste realizadas.

O resultado obtido na tentativa 5 indica que é possível o ajuste de uma RN para a resposta de variação do teor de ativos ao longo do tempo contanto que os dados de variação de $\mathrm{pH}$ ao longo do tempo sejam inseridos no conjunto de variáveis de entrada.

Assim sendo esse modelo não teria muito valor prático pois seria necessário conhecer o comportamento do $\mathrm{pH}$ ao longo do tempo para conseguir prever o comportamento do teor de ativos nesses mesmos instantes.

Na Figura 32 é apresentada a variação no valor de RMST e RMSTT ao longo do ajuste com a variação do número de apresentações para a tentativa 5. 


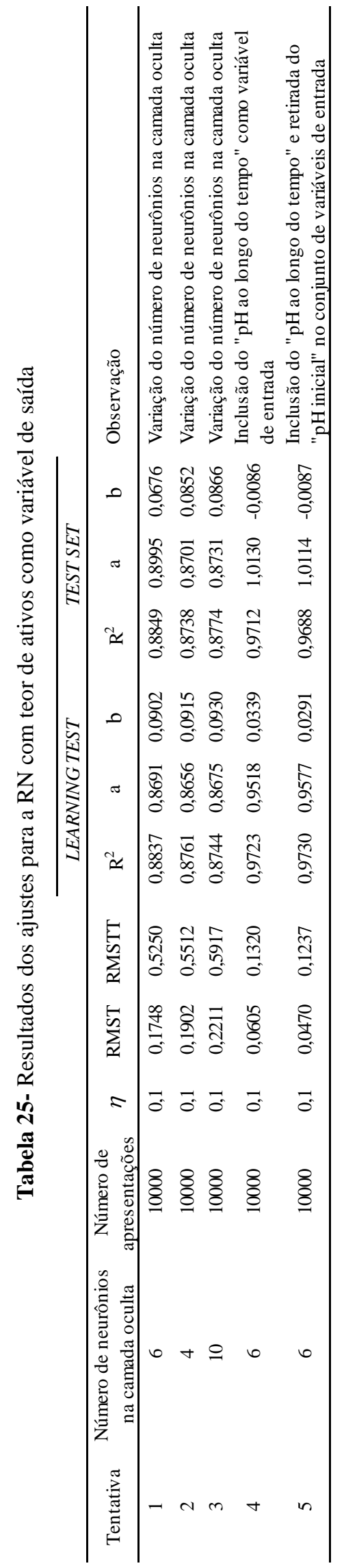




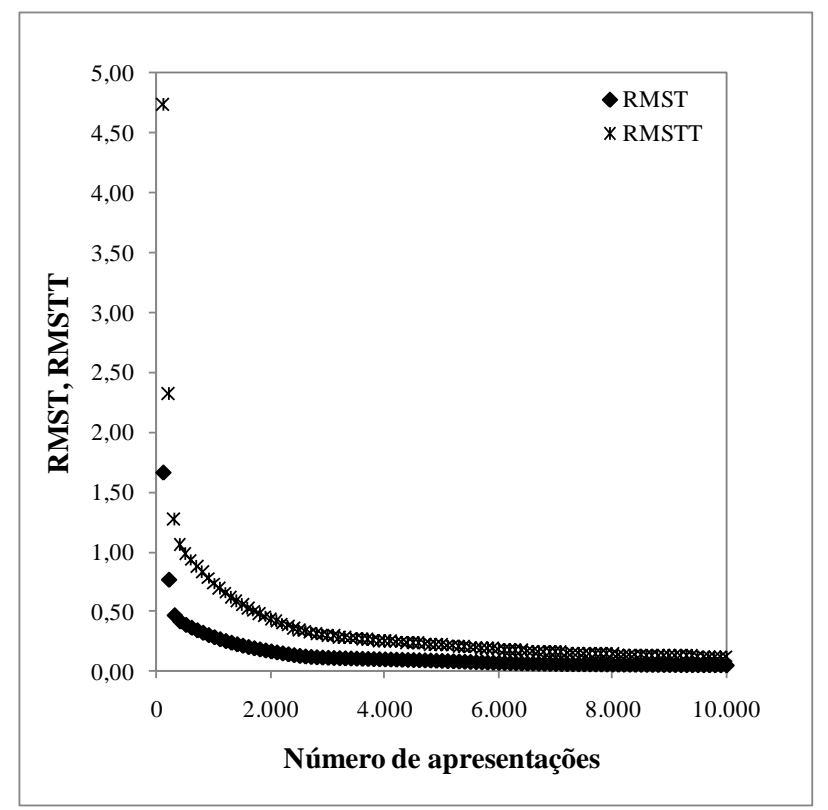

Figura 32- Variação do erro para o conjunto de treinamento ( $R M S T$ ) e para o conjunto de teste ( RMSTT) variando-se o número de apresentações ao longo do ajuste da $\mathrm{RN}$ considerando-se o melhor ajuste obtido para a resposta de teor de ativos

Os valores de erro para o conjunto teste são maiores do que os valores de erro obtidos para o conjunto de treinamento conforme já era esperado.

Na Figura 33 são apresentados os gráficos do teor de ativos calculado pelo modelo em função do teor de ativos obtido experimentalmente. Os dados são apresentados tanto para o conjunto de treinamento quando para o conjunto de teste. 

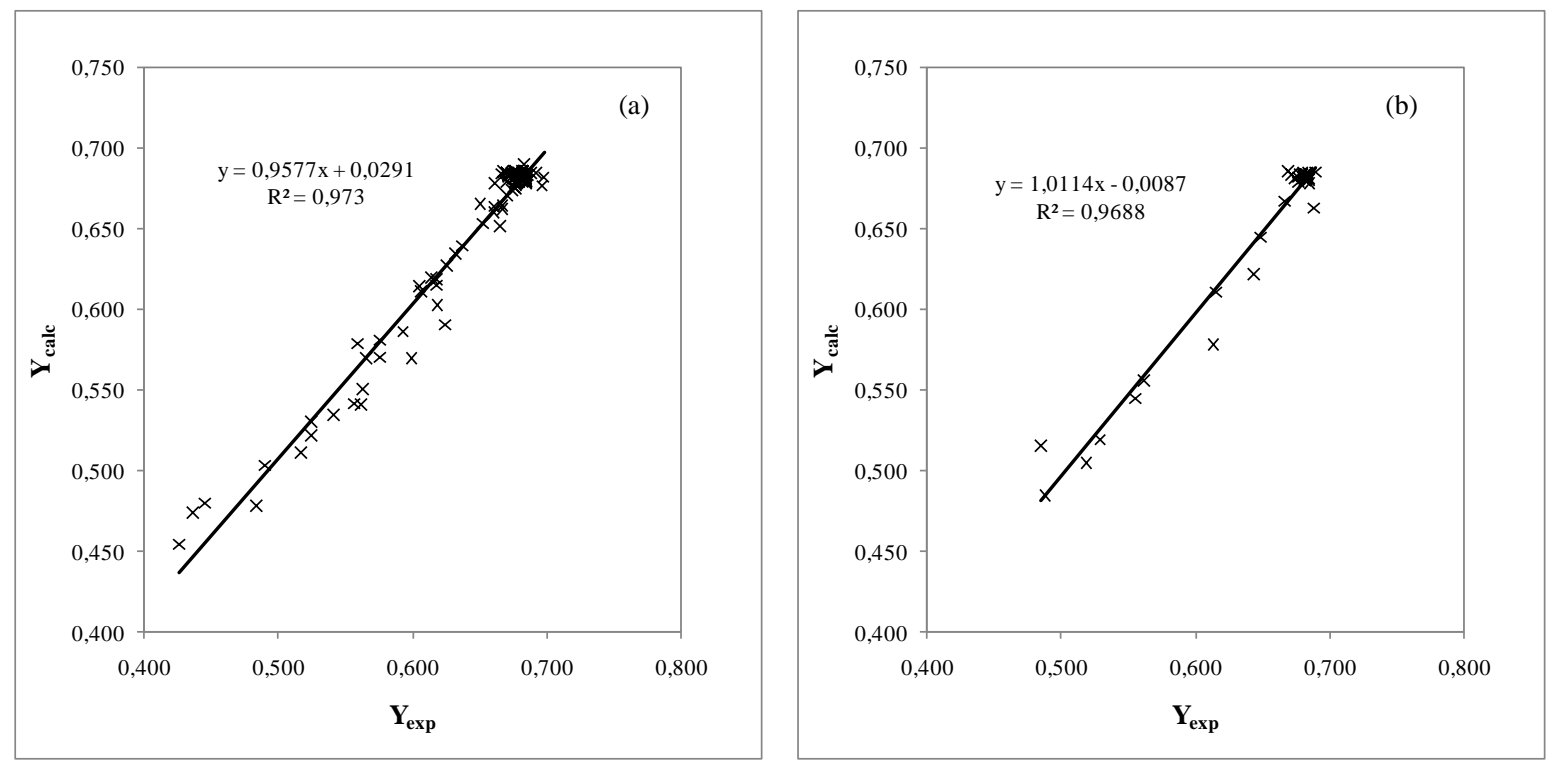

Figura 33- Comparação do resultado de teor de ativo calculado pelo modelo com os dados experimentais para o melhor ajuste obtido (a) considerando-se o conjunto de dados de treinamento (b) considerando-se o conjunto de dados de teste

\subsubsection{Ajuste do pH como variável de saída}

Nesta etapa do trabalho foram feitas simulações para o ajuste do $\mathrm{pH}$ como variável de saída, os resultados obtidos variando-se o número total de neurônios na camada oculta são apresentados na Tabela 26.

Observa-se que o melhor modelo foi obtido utilizando-se 14 neurônios na camada oculta pois esse foi o ajuste que apresentou menor erro - $R M S T=0,0567$ - e ótimos resultados para os outros parâmetros de avaliação do ajuste do modelo ( $R M S T T=0,1333$ e $R^{2}>0,9900$ tanto para o conjunto de treinamento quando para o conjunto de teste).

Na Figura 34 é apresentada a variação observada para RMST e RMSTT ao longo da variação do número de apresentações durante o ajuste do modelo para a condição de número de neurônios na camada oculta igual a 14.

Na Figura 35 são apresentados os gráficos de comparação do $\mathrm{pH}$ calculado pelo modelo com 14 neurônios na camada oculta com os valores de $\mathrm{pH}$ obtidos experimentalmente.

Esse modelo mostra-se adequado para uso em aplicações práticas para prever o comportamento do $\mathrm{pH}$ ao longo do tempo dado um conjunto de condições iniciais. Como se 
trata de um modelo empírico o mesmo só é aplicável para as condições iniciais entro das faixas de variação testadas, conforme apresentado na Tabela 24. 


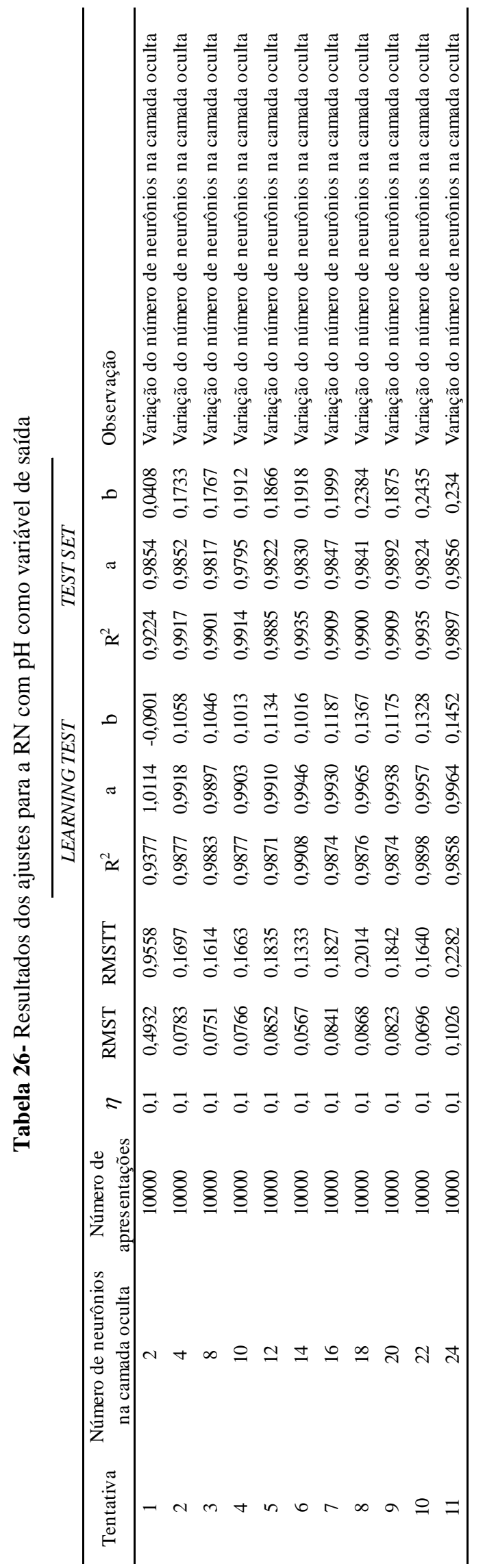




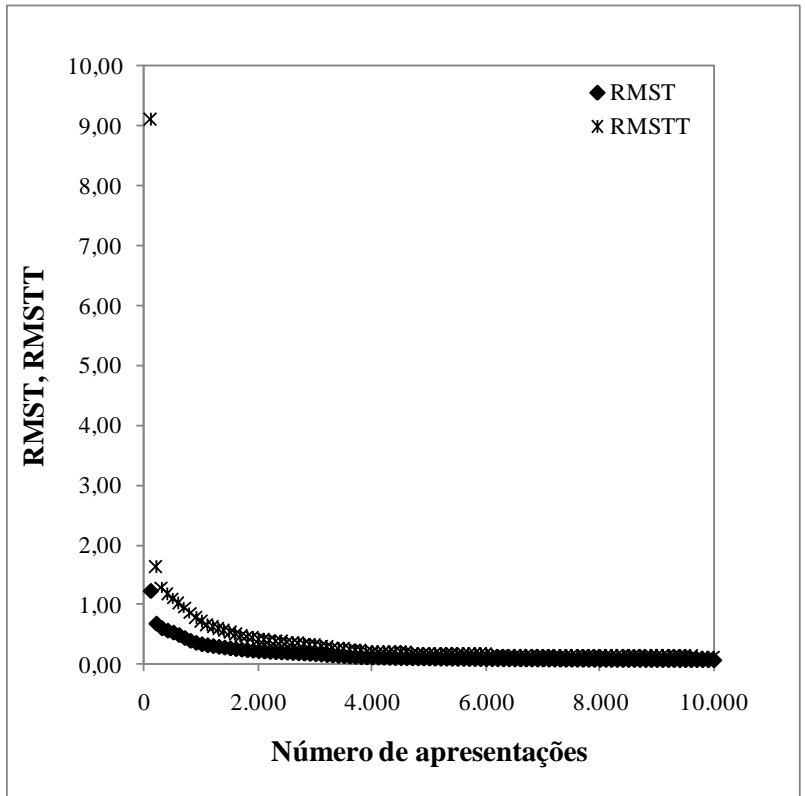

Figura 34- Variação do erro para o conjunto de treinamento ( $R M S T$ ) e para o conjunto de teste ( $R M S T T$ ) variando-se o número de apresentações ao longo do ajuste da RN considerando-se o melhor ajuste obtido para a resposta de $\mathrm{pH}$
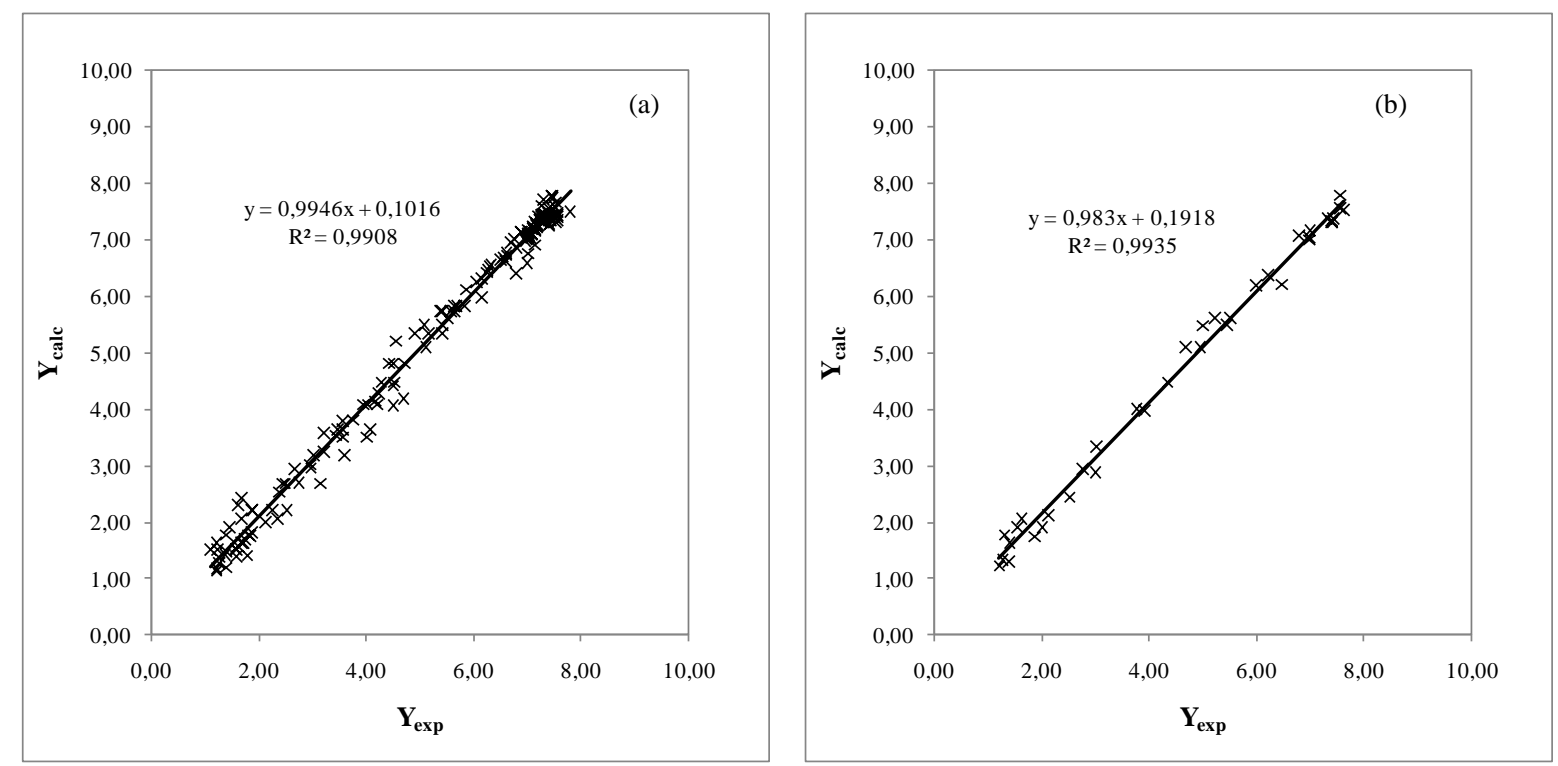

Figura 35- Comparação do resultado de $\mathrm{pH}$ calculado pelo modelo com os dados experimentais para o melhor ajuste obtido (a) considerando-se o conjunto de dados de treinamento (b) considerando-se o conjunto de dados de teste

\subsubsection{Simulação utilizando o modelo ajustado para o pH}

A partir do melhor modelo obtido foi realizada uma simulação utilizando um programa de propriedade do LSCP (Laboratório de Simulação e Controle de Processos) do Departamento de Engenharia Química da Escola Politécnica da Universidade de São Paulo partindo-se dos dados experimentais obtidos na repetição do ponto central para avaliação da resposta do modelo. 
Na Figura 36 é apresentado um gráfico comparativo dos resultados obtidos pela simulação utilizando-se o modelo empírico de RN em comparação com os dados experimentais.

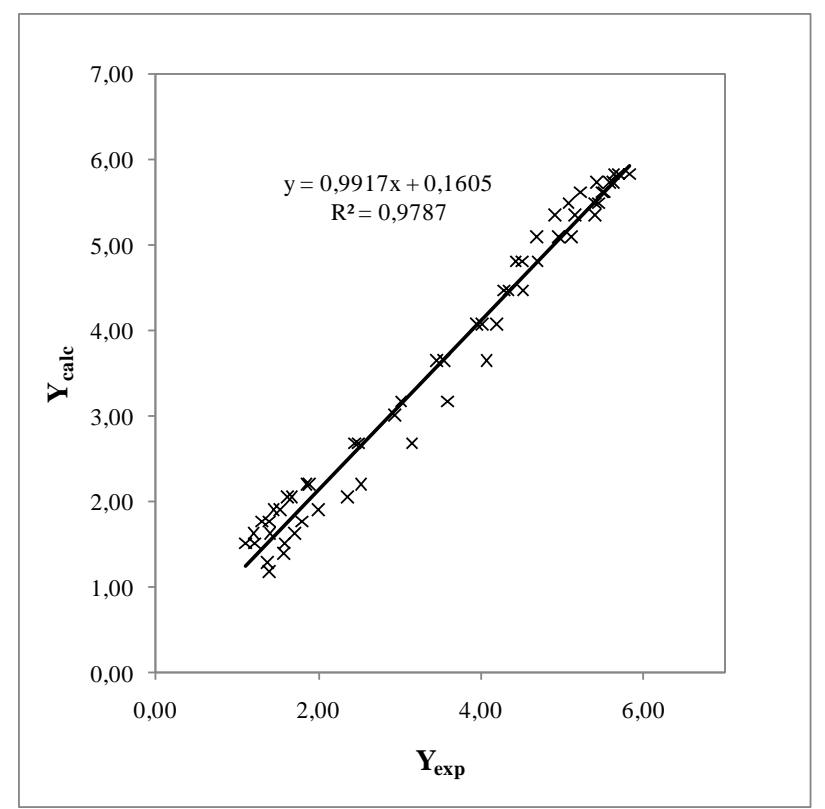

Figura 36- Comparação dos dados de pH obtidos através de uma simulação para as condições do ponto central com os dados obtidos experimentalmente

Observa-se que as respostas obtidas na simulação estão de acordo com esperado atestando a validade do modelo.

Foi realizado, utilizando o mesmo programa, um teste para avaliação da sensibilidade do modelo de RN em relação às variáveis de entrada. Foram realizadas 1000 variações aleatórias de cada variável entre os valores mínimo e máximo avaliando-se o erro quadrático médio em relação aos valores medidos com a rede ajustada para os dados experimentais obtidos no ponto central e a variável que mais afeta o modelo é, de acordo com o esperado, a variável "pH inicial”.

\subsubsection{Estimativa da variação do teor de ativos a partir de dados de variação de pH}

Analisando-se os resultados experimentais obtidos verificou-se uma alta correlação do resultado de $\mathrm{pH}$ com o teor de ativos ao longo do tempo para todas as condições experimentais. 
Na Figura 37 observa-se o comportamento obtidos nos experimentos para o teor de ativos em relação à variação de $\mathrm{pH}$.

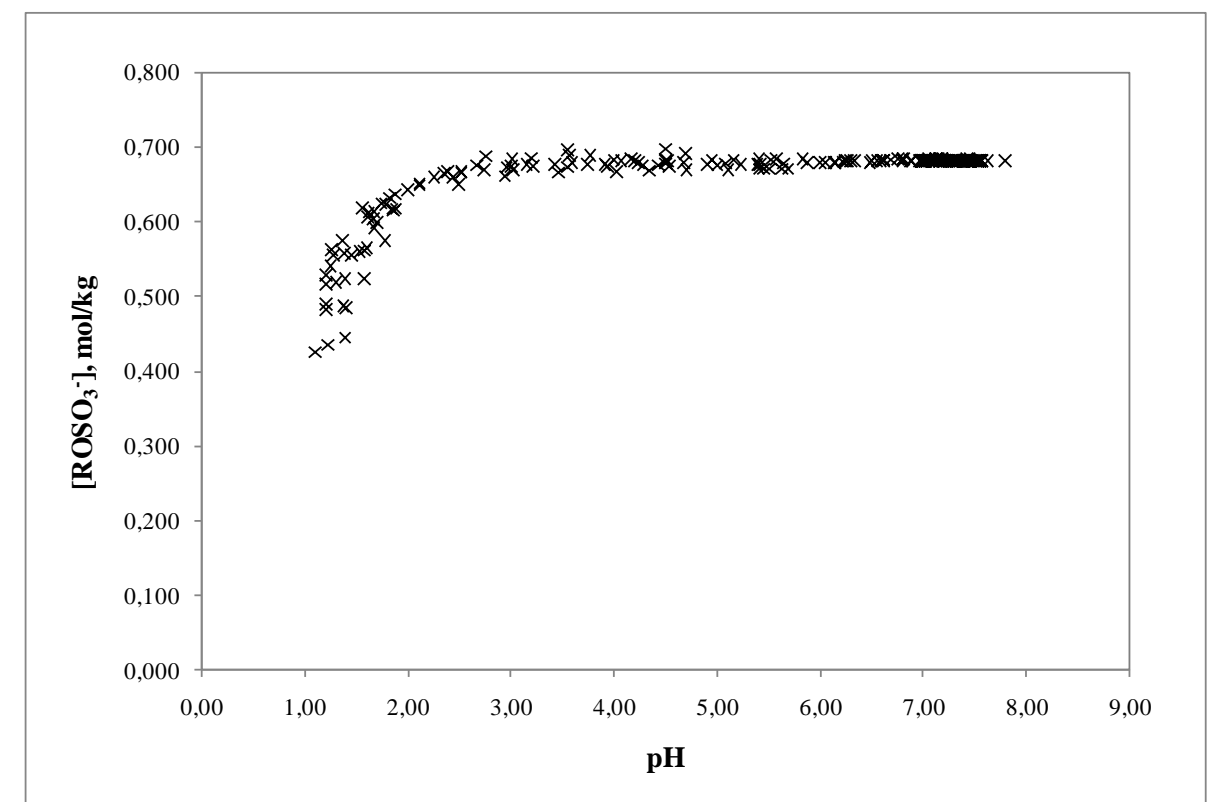

Figura 37: Correlação observada entre os dados de teor de ativos e de variação do pH

Essa correlação é válida para as condições experimentais avaliadas e precisaria ser validada para situações fora do domínio estudado.

O que se observa, no entanto, é que o teor de ativos começa a cair de forma bastante abrupta para valores de $\mathrm{pH}$ na faixa de 2,0 a 3,0. Acima dessa faixa mesmo que tenha sido observada queda no valor de $\mathrm{pH}$ o teor de ativos mantém-se praticamente constante. Essa faixa de $\mathrm{pH}$ de 2,0 a 3,0 indica o início da reação auto-catalítica com conseqüente queda acelerada no teor de ativos.

Assim sendo, a partir da reposta obtida com uma simulação utilizando o modelo de RN obtido para a variável $\mathrm{pH}$ pode-se estimar em que momento seria iniciada a etapa ácidocatalítica de queda acelerada de ativos com o tempo. Essa é uma informação bastante útil e que faz com que seja possível uma melhor previsão para a estimativa mínima de duração dos experimentos em escala de laboratório. 


\section{CONCLUSÕES E RECOMENDAÇÕES}

O estudo envolveu a avaliação do efeito de diversas variáveis na reação de hidrólise por meio da realização de experimentos planejados. Foi possível comprovar o efeito mais significativo das seguintes variáveis: $\mathrm{pH}$ inicial, temperatura e teor de cloreto de sódio. Quanto menor o $\mathrm{pH}$ inicial, menor o teor de cloreto de sódio e maior a temperatura, maior a velocidade de ocorrência da indesejada reação de hidrólise resultando em uma queda no teor de ativos e do $\mathrm{pH}$ do produto. Essas conclusões estão coerentes com o esperado segundo pesquisa realizada na literatura publicada sobre o assunto.

O comportamento da reação de hidrólise ao longo do tempo foi compatível com o esperado. Observou-se, na maioria dos experimentos, um progresso da reação de hidrólise lento no início, com pouca ou quase nenhuma variação no teor de ativos, que corresponderia à etapa não-catalítica, seguido por uma queda mais acentuada no teor de ativos causada pelo decréscimo no valor do $\mathrm{pH}$ e pela presença de íons $H^{+}$em excesso, o que acelera a reação de hidrólise (etapa ácido-catalítica).

Foi utilizado o modelo de troca iônica em pseudo-fase para o tratamento dos resultados experimentais e ajuste dos parâmetros. $\mathrm{O}$ ajuste dos diversos parâmetros contemplados no modelo inicialmente proposto não foi possível para todo o conjunto de condições experimentais, o que era esperado considerando que uma das desvantagens do modelo é a de que o perfil de velocidade calculado pode apresentar mais de uma combinação dos vários parâmetros. Em uma nova abordagem foi utilizada uma simplificação do modelo que permitiu um bom ajuste do modelo teórico aos dados experimentais. Foi novamente possível confirmar, através desse ajuste, a alta correlação da velocidade da reação com as mesmas variáveis mencionadas anteriormente.

Partindo-se do ajuste realizado utilizando o modelo de troca iônica em pseudo-fase foi possível, ao adotar valores para alguns parâmetros com base em informações encontradas na literatura, realizar uma previsão do comportamento da reação em condições ambientes para estimativa do prazo de validade do produto nas condições em que ele é usualmente comercializado. Essa estimativa, no entanto, pode ser melhorada através da realização de 
experimentos adicionais na temperatura ambiente na presença de uma concentração conhecida e na ausência de buffers.

Neste trabalho não foi estudada a influência da presença de buffers, como é o caso do fosfato de sódio presente na composição desse produto. $\mathrm{O}$ modelo ajustado não leva em conta a presença do buffer de forma explícita estando, no entanto, seu efeito de certa forma contemplado nas simulações. Recomenda-se a realização de um estudo complementar para avaliação do uso de buffers para controle da reação de hidrólise. Também se recomenda implementar, como ação de melhoria, um controle das quantidades de ácido fosfórico utilizadas na fabricação do produto para evitar variações em seu comportamento e estabilidade durante a armazenagem.

Em outro momento foi desenvolvido um modelo empírico para previsão da variação do $\mathrm{pH}$ e do teor de ativos ao longo do tempo utilizando-se redes neurais artificiais. O modelo desenvolvido foi capaz de prever com sucesso a variação do $\mathrm{pH}$ ao longo da reação de hidrólise para o domínio de condições estudadas e portanto o modelo é adequado para uso em aplicações práticas para prever o comportamento do pH dado um conjunto de condições iniciais. A partir da alta correlação observada entre os valores de $\mathrm{pH}$ e do teor de ativos é possível estimar em que momento seria iniciada a etapa ácido-catalítica de queda acelerada de ativos com o tempo. 


\section{LISTA DE REFERÊNCIAS}

ABE, M. e OGINO, K. Thermodynamic Studies of 1-Dodecanol and SDS in Aqueous Solutions J. Colloid Interface Sci., v. 80, n. 1, p. 146-152, 1981.

BARROS NETO, B., SCARMINIO, I. S. e BRUNS, R. E. Como fazer experimentos: Pesquisa e desenvolvimento na ciência e na indústria, Campinas, Editora Unicamp, 2003

BARRY, B. W. e WILSON, R. C.M.C., counterion binding and thermodynamics of ethoxylated anionic and cationic surfactants Colloid \& Polimer Science, v.256, n. 3, p. 251-260, 1978

BATTS, B. D. Alkyl Hydrogen Sulphates. Part II The Hydrolysis in Aqueous Acid Solution Journal of Chemical Society, 551-555, 1966

BENKOVIC, S. J. e BENKOVIC, P. A. Studies on sulfate esters .I. Nucleophilic reactions of amines with p-nitrophenyl sulfate Journal of American Chemical Society, v. 88 , p. $5504-5511,1966$

BETHELL, D., FESSEY, R. E., ENGBERTS J. B. F. N. e ROBERTS, D. W. The hydrolysis of $\mathrm{C} 12$ primary alkyl sulfates in concentrated aqueous solutions. Part 2. Influence of alkyl structure on hydrolytic reactivity in concentrated aqueous mixtures of sodium primary alkyl sulfates: 1-benzoyl-3-phenyl-1,2,4-triazole as a probe of water activity Journal of Chemical Society Perkins-Transaction v. 2, p.1496-1502, 2001

BETHELL, D., FESSEY, R. E., NAMWINDWA, E. e ROBERTS, D. W. The hydrolysis of $\mathrm{C} 12$ primary alkyl sulfates in concentrated aqueous solutions. Part 1. General features, kinetic form and mode of catalysis in sodium dodecyl sulfate hydrolysis Journal of Chemical Society Perkins-Transaction v.2, p.1489-1495, 2001

BOX, G. E. P.; HUNTER, W. G. e HUNTER, J. S. Statistics for experimenters: An introduction to design, data analysis and model building, New York, John Wiley \& Sons, 1978

BRAVO, C., LEIS, J. R. e PENA, M. E. Effect of alcohols on catalysis by dodecylsulfate micelles Journal of Physical Chemistry, v.96, p.1957-1961, 1992

BUNTON, C. A.; MHALA, M. M. e MOFFAT, J. R. Nucleophilic reactions in zwitterionic micelles of amine oxide or betaine sulfonate surfactants Journal of Physical Chemistry, v.93, n. 2, p. 854-858, 1989 
BUNTON, C. A.; ROMSTED, L. S. e SMITH, H. J. Quantitative treatment of Micellar Catalysis of Reactions Involving Hydrogen Ions The Journal of Physical Chemistry, v.83, n. 14 , p. $1844-1850,1978$

BUNTON, C. A. e WOLFE, B. The problem of $\mathrm{pH}$ in micellar catalyzed reactions Journal of American Chemical Society, v. 95, n. 11, p. 3742-3749, 1973

BURWELL JUNIOR, R. L. The hydrolysis of optically active secondary butyl hidrogen sulfate Journal of American Chemical Society, v.74, p.1462-1466, 1952

BUURMA, N. J., HERRANZ, A. M. e ENGBERTS, J. B. F. N. The nature of the micellar Stern region as studied by reaction kinetics 2 Journal Organic Chemistry, v.69, n.11, p.3899-3906, 2004

CALHOUN, G. M. e BURWELL JUNIOR, R. L. The Hydrolysis of Sodium Alkyl Sulfates in Basic Aqueous Solution Journal of the American Chemical Society, v.77, p.6441-6447, 1955

CORRIN, M. L. e HARKINS, W. D. The effect of salts on the critical concentration for the formation of micelles in colloidal electrolytes Journal of American Chemical Society, v. 69, p. 683- 688, 1947

CORRIN, M. L. e HARKINS, W. D. Determination of the critical concentration for micelle formation in solutions of colloidal electrolytes by the spectral change of a dye Journal of American Chemical Society, v. 69, p.679-683, 1947

EDGAR, T. F.; HIMMELBLAU, D. M. e LADSON, L. S. Optimization of chemical processes, 2nd. edition, New York, McGraw Hill Chemical Engineering Series, 2001

FENDLER, E. J. e FENDLER, J. H. Hydrolysis of nitrophenyl and dinitrophenyl sulfate esters Journal of Organic Chemistry, v.33. p.3852-3859, 1968

FLOCKHART, B. D. Effect of temperature on critical micelle concentration of some paraffin-chain salts Journal of Colloid Sciences, v.16, n.5, p.484-492, 1961

GARNETT, C. J., LAMBIE, A. J., BECK, W. H. e LILER, M. Kinetics of the acidcatalyzed hydrolysis of dodecyl-sulfate and dodecyldiethoxysulfate surfactants in concentrated micellar solutions. 1. Effects of acid and surfactant concentration and the 
nature and concentration of counterion Journal of the Chemical Society-Faraday Transactions I, v.79, p. 953-964, 1983a

GARNETT, C. J., LAMBIE, A. J., BECK, W. H. e LILER, M. Kinetics of the acidcatalyzed hydrolysis of dodecyl-sulfate and dodecyldiethoxysulfate surfactants in concentrated micellar solutions. 2. Effects of added electrolytes on the hydrolysis of sodium dodecyl-sulfate and sodium dodecyldiethoxysulfate Journal of the Chemical Society-Faraday Transactions I, v.79, p.965-973, 1983b

GROOT, W. H. Sulphonation technology in the detergent industry, The Netherlands, Kluwer Academic Publishers, 1991

HAYKIN, S. Neural networks: A comprehensive foundation, 2nd edition, New Jersey, Prentice Hall, 1999

HOLMBERG, K.; JÖNSSON, B.; KRONBERG, B. e LINDMAN, B. Surfactants and Polymers in Aqueous Solutions, 2nd edition, Chichester, John Wiley and Sons Inc., 2002

KHAN, M. N. A new semi-empiricalkinetic method for the determination of ion exchange constants for the counterions of cationic micelles Advances in Colloid and Interface Science, v. 159, n.2, p. 160-179, 2010

KHAN, M. N. e ISMAIL, E. An empirical approach to study the anion selectivity at aqueous cationic micellar surface: effects of inorganic salts on kinetically determined cationic micellar binding constant of ionized phenyl salicylate Journal of Molecular Líquids, v. 10, n.1-3, p. 277-287, 2003

KICE, J. L. Mechanism of acid hydrolysis of sodium aryl sulfates Journal of American Chemical Society, v.88, p.5242-5245, 1966

KOVÁCS, Z. L. Redes neurais artificiais: Fundamentos e aplicações, 2 ed., São Paulo, Editora Acadêmica, 1996

KURZ, J. L. Effects of micellization on the kinetics of the hydrolysis of monoalkyl sulfates Journal of Physical Chemistry, v.66, p.2239-2246, 1962

LUNKENHEIMER, K., THEIL, F. e LERCHE, K. H. Investigations on the hydrolysis of sodium n-alkyl sulfates in aluminum-oxide suspensions Langmuir, v.8, n. 2, p.403-408, 1992 
MARTINEK, K.; YATSIMIRSKI, A. K.; OSIPOV, A. P. e BEREZIN, I. V. Micellar effects on kinetics and equilibrium of synthesis and hydrolysis on benzylideneaniline. A general kinetic conception of micellar catalysis Tetrahedron, v. 29, n. 7, p. 963-969, 1973

MARTINEK, K.; YATSIMIRSKI, A. K.; OSIPOV, A. P. e BEREZIN, I. V. The kinetic theory and the mechanisms of micellar effects on chemical reactions In: MITTAL, K. L. Micellization, Solubilization and Microemulsions, v. 2, New York, Ed. Plenum Press, p. $489-508,1977$

MODLER, R. F., JANSHEKAR, H. e INOGUCHI, Y. Household detergents and their raw materials, Marketing Research Report on Surfactants, Chemical Economics Handbook-SRI Consulting, 2007

MOTSAVAGE, V. A e KOSTENBAUDER, H. B. Influence of state of aggregation on specific acid-catalyzed hydrolysis of sodium dodecyl sulfate Journal of Colloid Science, v.18, n. 7, p.603-615, 1963

MOYO, L., NHLAPO, N. S. e FOCKE, W. W. A critical assessment of the methods for intercalating anionic surfactants in layered double hydroxides Journal of Materials Science, v.43, p. 6144-6158, 2008

MURAMATSU, M. e INOUE, M. Radiotracer study on slow hydrolysis of sodium dodecylsulfate in aqueous-solutions Journal of Colloid and Interface Science, v.55, n.1, p.80-84, 1976

MYERS, D. Surfaces, Interfaces and Colloids: Principles and Applications, 2nd edition, John Wiley and Sons Inc., 1999

MYSELS, K. J. Surface-tension of solutions of pure sodium dodecyl-sulfate Langmuir, v. 2, n.4, p.423-428, 1986

NAGAKI, M. e YOKOYAMA, S. Acid-Catalyzed Hydrolysis of Sodium Dodecyl Sulfate Journal of Pharmaceutical Sciences, v.74, n.10, p.1047-1052, 1985

NAGAKI, M. e YOKOYAMA, S. Influence of higher alcohols on acid-catalyzed hydrolysis of sodium dodecyl-sulfate-effect of complex formation Bulletin of the Chemical Society of Japan, v.59, n.3, p. 935-936, 1986 
NASCIMENTO, C. e GUARDANI, R. Análise estatística multivariada aplicada a processos químicos, São Paulo, Escola Politécnica, Departamento de Engenharia Química da Universidade de São Paulo, 2007

OGINO, K., ABE, M. e TAKESITA, N. A study of the solubilization of polar oily materials by sodium dodecyl sulfate Bulletin of the Chemical Society of Japan, v.49, n. 12, p.3679-3683, 1976

QUINA, F. H. e CHAIMOVICH, H. Ion Exchange in Micellar Solutions 1. Conceptual Framework for Ion Exchange in Micellar Solutions Journal of Physical Chemistry, v. 83, n.14, p. 1844-1850, 1979

QUINA, F. H. ; POLITI, M. J.; CUCCOVIA, I. M.; BAUMGARTEN, E.; MARTINSFRANCHETTI, S. M. e CHAIMOVICH, H. Ion Exchange in Micellar Solutions 4. "Buffered" Systems Journal of Physical Chemistry, v. 84, n.4, p.361-365, 1980

ROBERTS, D. W e LEJEUNE, S. Chemistry and kinetics of LAS acid thermal decomposition Journal of Surfactants and Detergents, v.5, n. 2, p. 111-115, 2002

RODRÍGUEZ, A.; MÚÑOZ, M.; GRACIANI, M. M.; MOYÁ, M. L. Kinetic micellar effects in tetradecyltrimethylammonium bromide-pentanol micellar solutions Journal of Colloid and Interface Science, v.248, n.2, p. 455-461, 2002

ROMSTED, L. S. A general kinetic theory of rate enhancements for reactions between organic substrates and hydrophilic ions in micellar systems In: MITTAL, K. L. Micellization, Solubilization and Microemulsions, v. 2, New York, Ed. Plenum Press, p. $509-530,1977$

ROSEN, M. J. Purification of surfactants for studies of their fundamental surface properties Journal of Colloid and Interface Science, v. 79, n.2, p.587-588, 1981

ROSEN, M. J. Surfactants and Interfacial Phenomena, 3rd ed, New Jersey, John Wiley and Sons Inc., 2004

SASAKI, T.; HATTORI, M.; SASAKI, J. e NUKINA, K. Studies of aqueous sodium dodecyl sulfate solutions by activity measurements Bulletin of the Chemical Society of Japan, v. 48, n. 5, p. 1397-1403, 1975 
STEPAN COMPANY, Sodium 2-(2-dodecyloxyethoxy)ethyl sulphate (SODIUM LAURETH SULFATE; CAS N. 3088-3 1-1): TEST PLAN, 2006

WEIL, I. Surface concentration and Gibbs adsorption law. The effect of alkali metal cations on surface behavior Journal of Physical Chemistry, v.70, n. 1, p.133-140, 1966 


\section{APÊNDICE A - Ajustes para estimativa do tempo de estabilidade}

Nas Figuras 38 a 43 são apresentadas as curvas e ajustes utilizados para estimativa do tempo de estabilidade.

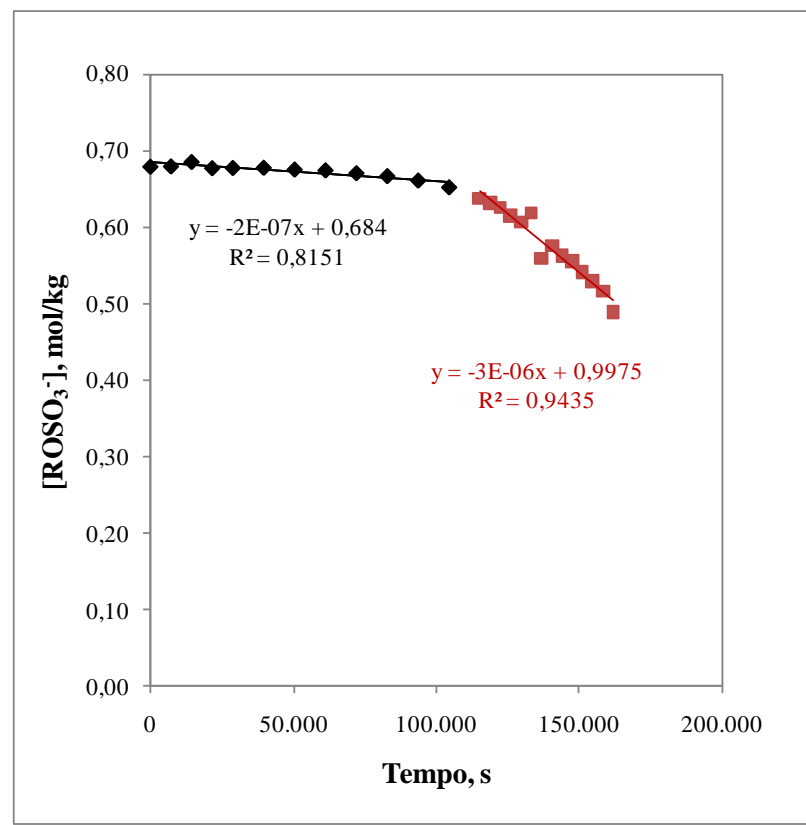

Figura 38- Ajuste realizado para determinação da resposta de tempo de estabilidade para EXPERIMENTO 1

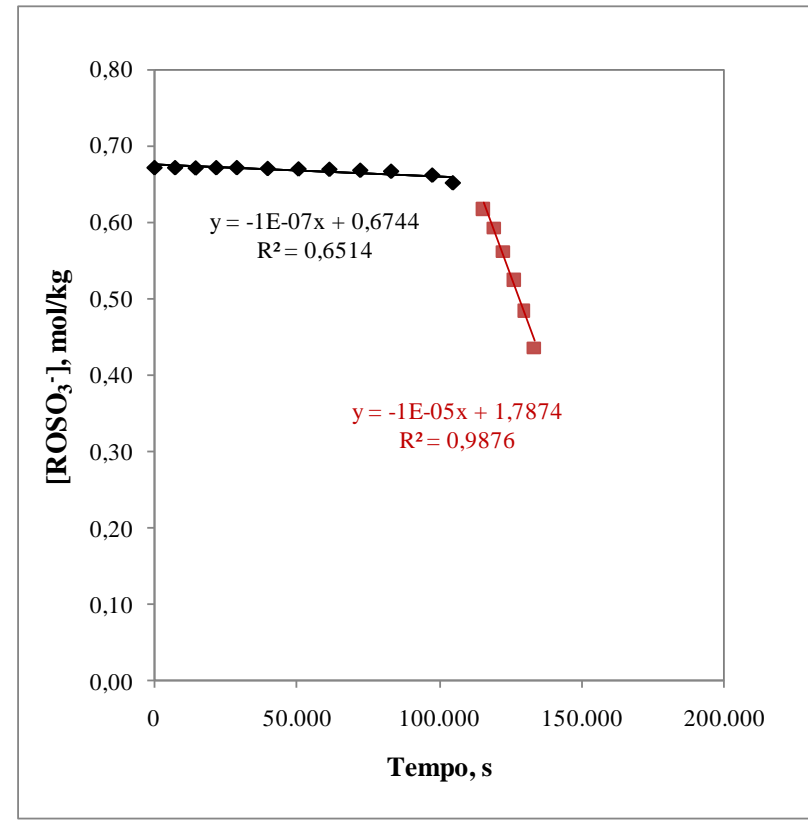

Figura 39- Ajuste realizado para determinação da resposta de tempo de estabilidade para EXPERIMENTO 2 


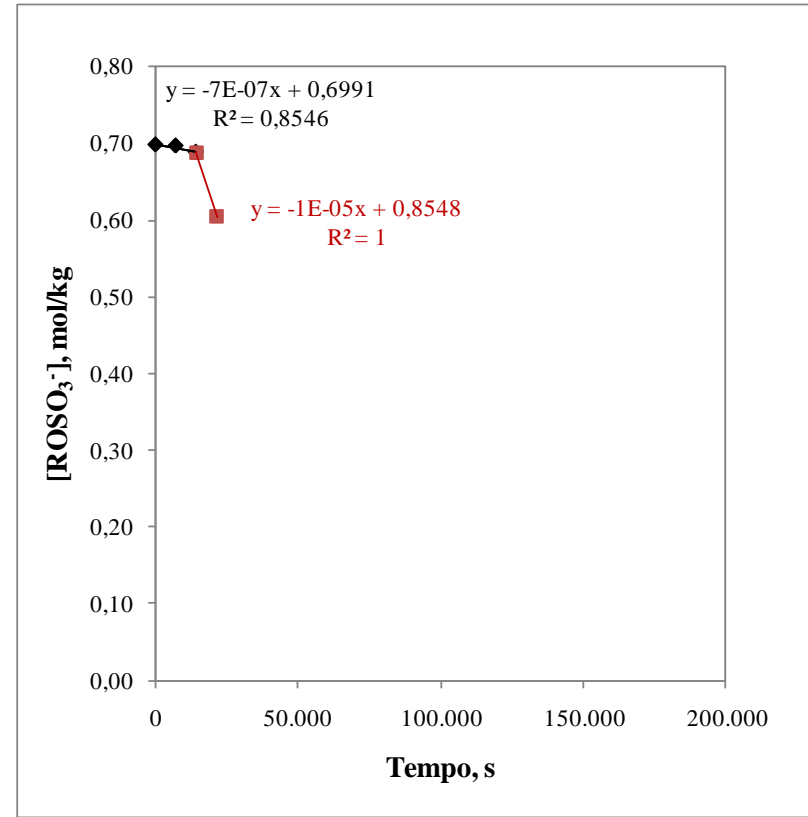

Figura 40- Ajuste realizado para determinação da resposta de tempo de estabilidade para EXPERIMENTO 5

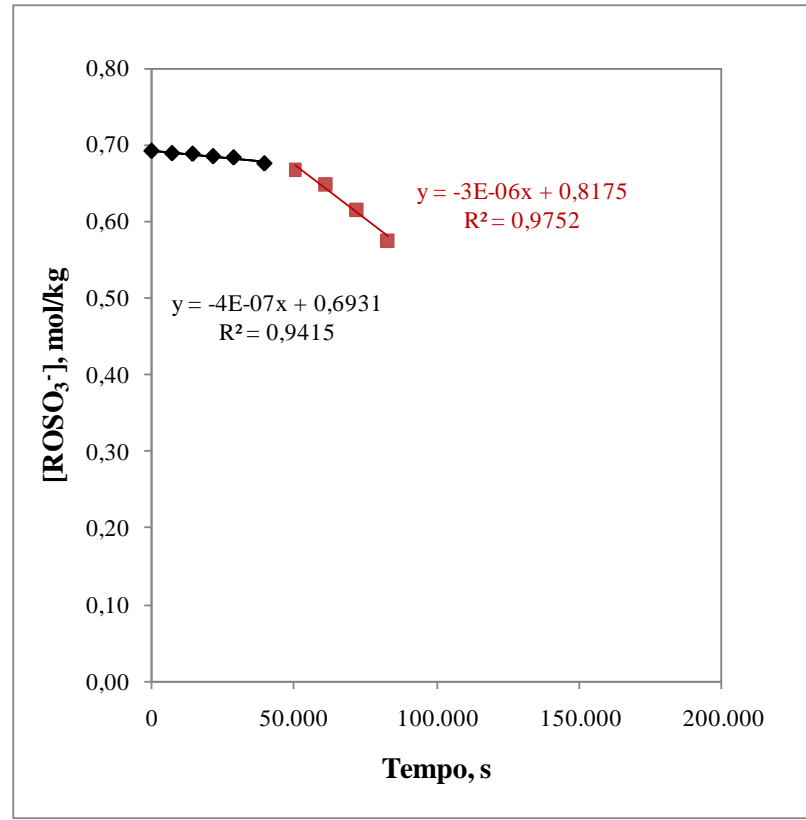

Figura 41- Ajuste realizado para determinação da resposta de tempo de estabilidade para EXPERIMENTO 8 


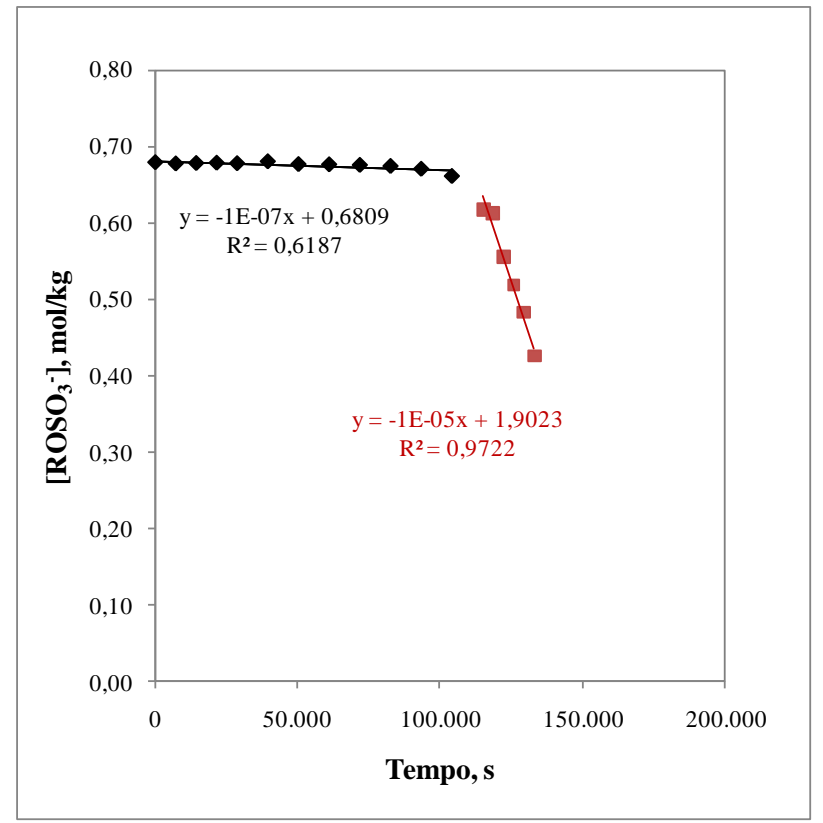

Figura 42- Ajuste realizado para determinação da resposta de tempo de estabilidade para EXPERIMENTO 9

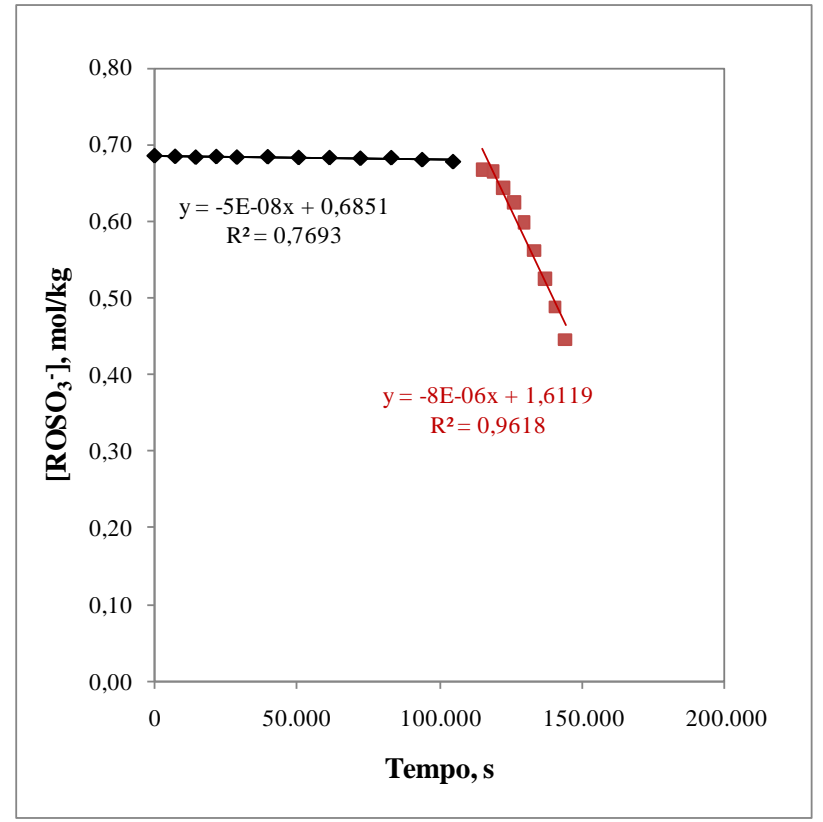

Figura 43- Ajuste realizado para determinação da resposta de tempo de estabilidade para EXPERIMENTO 11 